5

\title{
Characterisation of Pore Structures of
}

Pharmaceutical Tablets: A Review

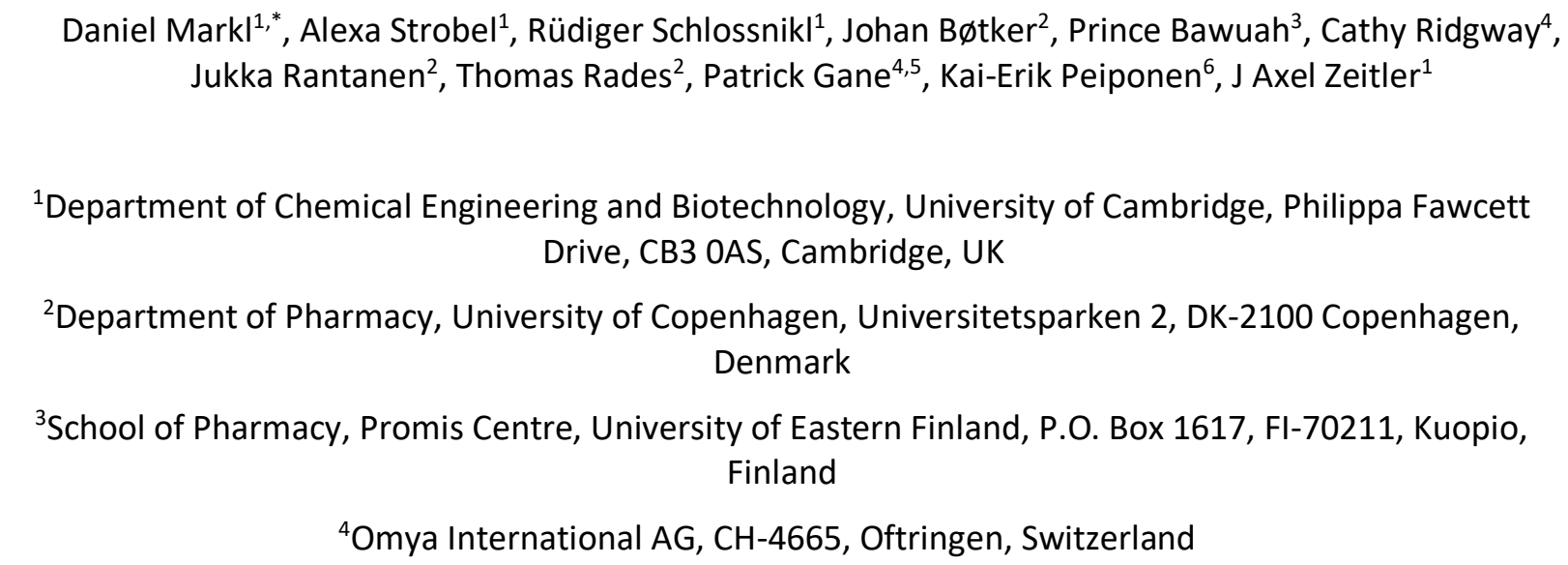
Jukka Rantanen ${ }^{2}$, Thomas Rades², Patrick Gane ${ }^{4,5}$, Kai-Erik Peiponen ${ }^{6}$, J Axel Zeitler ${ }^{1}$

${ }^{1}$ Department of Chemical Engineering and Biotechnology, University of Cambridge, Philippa Fawcett Drive, CB3 OAS, Cambridge, UK

${ }^{2}$ Department of Pharmacy, University of Copenhagen, Universitetsparken 2, DK-2100 Copenhagen, Denmark

${ }^{3}$ School of Pharmacy, Promis Centre, University of Eastern Finland, P.O. Box 1617, FI-70211, Kuopio, Finland

${ }^{4}$ Omya International AG, $\mathrm{CH}-4665$, Oftringen, Switzerland

${ }^{5}$ School of Chemical Technology, Department of Bioproducts and Biosystems, Aalto University, Fl-00076 Aalto, Helsinki, Finland

${ }^{6}$ Institute of Photonics, University of Eastern Finland, P.O. Box 111, FI-80101 Joensuu, Finland

*corresponding author:

Electronic address:dm773@cam.ac.uk

Phone: $\quad+447599822102$

Address: Department of Chemical Engineering and Biotechnology

Philippa Fawcett Drive

CB3 OAS, Cambridge, UK 


\section{ABSTRACT}

Traditionally, the development of a new solid dosage form is formulation-driven and less focus is put on the design of a specific microstructure for the drug delivery system. However, the compaction process particularly impacts the microstructure, or more precisely, the pore architecture in a pharmaceutical tablet. Besides the formulation, the pore structure is a major contributor to the overall performance of oral solid dosage forms as it directly affects the liquid uptake rate, which is the very first step of the dissolution process. In future, additive manufacturing is a potential game changer to design the inner structures and realise a tailor-made pore structure. In pharmaceutical development the pore structure is most commonly only described by the total porosity of the tablet matrix. Yet it is of great importance to consider other parameters to fully resolve the interplay between microstructure and dosage form performance. Specifically, tortuosity, connectivity, as well as pore shape, size and orientation all impact the flow paths and play an important role in describing the fluid flow in a pharmaceutical tablet. This review presents the key properties of the pore structures in solid dosage forms and it discusses how to measure these properties. In particular, the principles, advantages and limitations of helium pycnometry, mercury porosimetry, terahertz time-domain spectroscopy, nuclear magnetic resonance and X-ray computed microtomography are discussed.

Keywords: Pore structure, solid dosage form, terahertz technology, X-ray computed microtomography, mercury porosimetry, helium pycnometry, nuclear magnetic resonance

\section{Introduction}

The most widespread oral solid dosage form is the tablet, which is traditionally manufactured via powder compaction. Ideally, a blend of several excipients and one or more active pharmaceutical ingredients (APIs) is directly compressed to the desired shape, dimension, weight and hardness. However, in the majority of cases either wet or dry granulation has to precede the compaction step to achieve the targeted properties of the finished drug product (Leane et al., 2015). These additional process steps are primarily required due to the often inherently non-ideal API properties (e.g. particle size and morphology). API particles typically have a small particle size relative to excipient particles (Bellamy et al., 2008; Olusanmi et al., 2014) and frequently exhibit a needle-like shape (Tye et al., 2005; Waknis et al., 2013), which can result in poor powder flowability (Carstensen and Chan, 1976, Hart, 2016, Hirschberg, Sun and Rantanen, 2016), segregation (Olusanmi et al., 2014), and unwanted adhesion to surfaces (e.g. tablet punches) (Lam and Newton, 1992, Paul et al., 2017a, Paul et al., 2017b). Granulation (Gabbott et al., 2016; Markl et al., 2017a; van den Ban and Goodwin, 2017; Wikberg and Alderborn, 1990) and compaction (Alderborn et al., 1985; Markl and Zeitler, 2017; Nordström et al., 2013) strongly influence the internal structure of the final tablet. The pores created by the process (interparticle pores) and the intraparticle pores, if present, of each constituent particle result in a complex architecture of void space in the tablet, which impacts the performance of the dosage form. Recent developments are towards engineering particles to improve powder flowability (Trementozzi et al., 2017, Chattoraj and Sun, 2018) and compressibility (Chattoraj and Sun, 2018).

Both interparticle pore space and interparticulate bonds are created during compaction. This process typically consists of several steps: i) granular material is metered into a cavity formed by two punches and a die, ii) rearrangement of particles iii) elastic deformation, iv) plastic deformation and v) fragmentation (Duberg and Nyström, 1986). In addition to these five compaction steps, tabletting also includes the relaxation of the compact resulting in a change of the tablet volume. Every single step has an impact on the final void space, which eventually controls the fluid flow and liquid transport through the solid dosage form. In particular, liquid imbibition is the first, and often the rate-determining, step in the disintegration of immediate-release tablets (Nogami et al., 1967). Although the liquid uptake process does not directly cause the break-up of the dosage form, it is a prerequisite to initiate other disintegration mechanisms, such as swelling, that build up the pressure necessary to rupture the interparticulate bonds (Markl and Zeitler, 2017). Disintegration mechanisms and methods to characterise these phenomena were recently 
reviewed by Desai, Liew and Heng, 2016, Quodbach and Kleindebudde, 2016 as well as by Markl and Zeitler, 2017.

The void space of pharmaceutical solid dosage forms is typically not created by design but rather it is a by-product of the compaction process. Therefore, in the majority of cases it is characterised by a complex and frequently random architecture of pores of different sizes, shapes and orientations (Figure 1). Most of the pores are connected to each other as well as to the surface via small throats (open pores), however some pores are sealed-off (closed pores) from the connected structure. The connected pores form tortuous capillaries through which the physiological fluid flows and enters the dosage form upon ingestion. Moreover, it is well-known that powder compaction yields directionally dependent mechanical properties (hardness and strength) of a tablet (Akseli et al., 2009; Edge et al., 2001; Mullarney and Hancock, 2006; Wu et al., 2008), yet the resulting anisotropic pore structures are studied far less. It is, however, of great importance to investigate the effect of manufacturing route and process parameters on the microstructure of the intermediate and final product to achieve reproducible product quality (Westermarck et al., 1998a; 1998b; 1999). A better understanding of the relationship between material properties, manufacturing process parameters and the evolution of tablet microstructure will eventually lead to design and engineer the tablet microstructure, as recently reviewed by Sun, 2016.

The effect of the pore structure on the performance is not only relevant for tablets manufactured via powder compaction - it is also of critical importance for 3D printed drug delivery systems. Additive manufacturing, or 3D printing, enables the manufacture of highly porous and complex solid dosage forms which were previously considered impossible to create. These porous structures can be designed such that they disintegrate within seconds upon contact with dissolution liquid (Norman et al., 2017). The most common printing technologies in the context of solid dosage form manufacturing are fused deposition modelling (FDM) (Goyanes et al., 2015a; 2015b; Khaled et al., 2015) and the powder based 3D printing method developed at MIT and commercialised (getting a new product or service introduced into the general market) as the ZipDose technology (Aprecia Pharmaceuticals Company; Fina et al., 2017; Katstra et al., 2000; C. W. Rowe et al., 2000). In FDM, a polymer strand is heated, extruded and then deposited layer-by-layer to create a 3D object. It was recently demonstrated that this process generates a strongly anisotropic pore structure (Markl et al., 2017c), which influences the drug release kinetics. In the case of powder based 3D printing, the 3D printed object is built up by adding a binding solution and applying a new layer of powder on top, and repeating these steps. Within powder based 3D printing, Parteli and Pöschel, 2016 have recently highlighted how crucial it is to develop a better understanding of the packing behaviour of the powder bed, as it determines the fusion process between layers.

It has been demonstrated for porous media (Cai and Yu, 2011; Dullien, 1992) in general but also for pharmaceutical tablets (Markl et al., 2018b) that the tortuosity, connectivity, as well as pore shape, size and orientation affect the liquid imbibition process (Figure 1). To advance the understanding of the relationship between the manufacturing process and the performance of the final drug product, it is essential to quantitatively measure, and to routinely report, these characteristic pore parameters in a tablet in addition to the commonly used descriptor of tablets, namely total porosity or solid fraction.

The pore structure of pharmaceutical solid dosage forms can be characterised by a number of different techniques (Figure 2). The methods exploit a range of physical phenomena to determine various macroscopic and microscopic pore parameters. The methods can be divided into two main categories: void space- and matrix-sensitive techniques. Void space-sensitive methods use a fluid (gas or liquid) to directly access the pore volume in the sample. These techniques include helium pycnometry (see section 3), mercury porosimetry (see section 4), nitrogen adsorption (Ferrero and Jiménez-Castellanos, 2002; Westermarck et al., 1999; 1998a) as well as thermoporometry (Faroongsarng and Peck, 2003; Iza et al., 2000; Luukkonen et al., 2001). Cost-effective and simple analysis using an oil absorption method has been reported for the measurement of the porosity of non-uniform ribbons from a roller compaction process (Khorasani et al., 2015a). Since void-space sensitive techniques use a fluid to directly probe the pores, they only provide a measure of the open/connected pores which are accessible from the surface. 
122

123

124

125

126

127

128

129

130

131

132

133

134

135

136

137

138

139

140

141

142

143

144

145

146

147

148

149

150

151

152

153

154

155

156

157

158

159

160

161

162

163

164

165

166

167

168

169

Matrix-sensitive methods typically use electromagnetic radiation to probe the sample. These methods yield a measure of the pore space by either using additional information about the sample (e.g. dimensions or optical properties of the solid material) or applying specifically-developed data processing procedures to separate the solid material from the voids (e.g. thresholding for image-based techniques). 2D imaging methods (surface-sensitive), such as optical microscopy, scanning electron microscopy (SEM) (Andersson et al., 2013; Boissier et al., 2012; Häbel et al., 2016; Wu et al., 2008; 2005; 2007; 2006), transmission electron microscopy (TEM) (Eddleston et al., 2010) and atomic force microscopy (AFM) (Tuntikulwattana et al., 2010) can be applied to determine structural parameters of the sample at the surface or at cross-sections by cutting or breaking the sample. The samples are often frozen using liquid nitrogen before they are cut or broken at a predefined breaking point to avoid smearing and plastic deformation of the sample that may damage the pore structure. However, these measurements may not be representative of the sample as they probe only the surface, and 3D information about the pores can only be estimated by making assumptions about the shape of the pores. The meaning of 2D measurements in 3D volumes can be investigated with the aid of stereological conversions and/or 3D texture models (Jerram and Higgins, 2007; Jerram and Kent, 2006).

There are also several techniques utilising electromagnetic radiation that are sensitive to the volume of the pores. These methods include focused ion beam SEM (FIB-SEM) (Heng et al., 2007; Moghadam et al., 2006; Palmas et al., 2016; Poozesh et al., 2017), confocal laser scanning microscopy (CLSM) (Barman and Bolin, 2017; Häbel et al., 2017; Marucci et al., 2013), nuclear magnetic resonance (NMR, see section 5), Xray computed microtomography $(\mathrm{X} \mu \mathrm{CT}$, see section 6$)$, and terahertz time-domain spectroscopy (THz-TDS, see section 7). NMR is also a void-space sensitive method as it utilises the interaction of the liquid in the pores and solid phase to reveal structural properties of the porous medium. A laser-based method has also been reported to measure the porosity of ribbons by measuring the weight by a precision weighing module as well as the thickness of the sample by two laser displacement sensors (Alles $\varnothing$ et al., 2016).

These and several other techniques are well-known and routinely applied in geology (Anovitz and Cole, 2015), where the pore structure plays an important role. It controls fluid storage in aquifers, oil/gas fields and geothermal systems as well as fluid flow and transport through geological formations. Other matrixsensitive techniques used outside the pharmaceutical field are ultrasmall-angle X-ray (USAXS) (Lee et al. 2014) and ultrasmall-angle neutron scattering (USANS) (Clarkson et al., 2012; Mastalerz et al., 2012).

The destructive nature and the relatively long measurement times of most of these techniques render them incapable of characterising pore structures in an at-line, on-line or in-line setting. There is a need in the pharmaceutical industry for process analysers that can be integrated in a manufacturing line and provide almost real-time measures of the pore structure. This has been demonstrated using near-infrared spectroscopy (NIRS) for roll compaction and tabletting (Khorasani et al., 2015b). However, NIRS does not probe a physical attribute of the material that is directly related to a characteristic property of the pore structure. It measures the surface gloss and it is assumed that this gloss measurement is correlated to the porosity. Another promising technology for in-process control is the novel terahertz-based porosity measurement. This rapid and simple approach has the potential to be applied as a process monitoring tool, as discussed in section 8.

This review begins with discussing the characteristic and performance-determining pore properties based on exemplification. It then presents and critically discusses the state-of-the art and emerging technologies to determine pore parameters of pharmaceutical materials. This includes the discussion of mercury porosimetry and helium pycnometry as well as three methods exploiting the interaction of electromagnetic radiation with porous materials, namely $\mathrm{X} \mu \mathrm{CT}$, NMR and THz-TDS. This review presents their principles and applications on pharmaceutical materials, but we also refer occasionally to applications, methods and processing procedures from other areas to provide a full picture of the capabilities of each technique. The final section of this article discusses the advantages and disadvantages of each technique. 


\section{Pore Analysis}

Quantitative and descriptive pore parameters are needed to capture the sample microstructure. For the purpose of this review, any void space within the tablet boundary is considered a pore.

To illustrate the various pore parameters, an example dataset is used throughout this section. These data were acquired by $\mathrm{X} \mu \mathrm{CT}$ of $3 \mathrm{D}$ printed tablets (the technique and data acquisition are elaborated on in section 5). The printing was performed using a Makerbot Replicator 2 desktop 3D printer (New York, NY, US) and the material used was poly(vinyl alcohol). For the first two layers, the printing nozzle moved in a circular motion, and for subsequent layers it printed a parallel strand pattern, which was rotated by $90^{\circ}$ between layers. Hence, a high degree of anisotropy is expected in the pore formation. The tablet form was a simple disk (height, $H=1.5 \mathrm{~mm}$ and diameter, $D=10 \mathrm{~mm}$ ), as illustrated in Figure 3, that was designed using Comsol Multiphysics (Comsol, Stockholm, Sweden, v5.1). Two samples were printed with the same print resolution $(0.1 \mathrm{~mm})$, however one was printed at a lower temperature $\left(220^{\circ} \mathrm{C}\right.$, referred to as $\mathrm{P} 1)$ compared to the other $\left(230^{\circ} \mathrm{C}\right.$, referred to as $\left.\mathrm{P} 2\right)$.

\subsection{Porosity and Pore Size}

The pore structure is commonly described by one single parameter, the total porosity, which is a measure of all the void space contained within the geometric boundaries of the dosage form and it includes the closed as well as the open pores. Porosity is expressed as $f=V_{\mathrm{p}, \text { total }} / V$, where $V_{\mathrm{p} \text {,total }}$ is the total pore volume, and $V$ is the total sample volume (Rouquerolt et al., 1994).

After identifying and separating individual pores from the dataset (Figure 4) the pore size distribution can be characterised. This gives the spread of pores by volume, surface area, equivalent diameter etc. It is rotation-independent.

\subsection{Tortuosity}

In general, low to high tortuosity describes, respectively, how linear to twisted the pore space structure is (Julbe and Ramsay, 1996). A commonly used definition is $\tau=L_{\mathrm{e}} / L$ where $\tau$ is a dimensionless number relating the average length of the fluid path, $L_{\mathrm{e}}$, and the geometrical length of the sample, $L$ (Figure 1 ). This explains how much farther a liquid must flow through the pores compared to the direct distance with respect to the physical length of the sample. A 3D description is the tortuosity tensor, which describes how the flow of individual streamlines in a pore deviate from the overall macroscopic flow in the pore (Dullien, 1992). In general, tortuosity depends on two key relations. Firstly, $\tau \geq 1$, i.e. a given volume element of fluid must travel further to cover the same distance in a porous medium compared to simple straight pipe flow: passing through a porous material involves covering an additional distance. Secondly, $\lim _{f \rightarrow 1} \tau=1$, i.e. as the medium becomes more porous, the tortuosity approaches 1 , in that the pores are straight and no longer twisted. Using these relations, there are many models relating tortuosity and porosity in the literature, and their use depends on the specific application and material in question (Boudreau, 1996).

For a packed bed, a tortuosity factor can be defined as $\tau=L_{\text {pore }} / H$, where $L_{\text {pore }}$ is the continuous pore void length and $H$ is the bed height. This can be related to the mean pore velocity $U=U_{\mathrm{o}} \tau / f$ (Comiti and Renaud, 1989), where $U_{\mathrm{o}}$ is the overall superficial bed velocity and $f$ is the bed void fraction. The mean velocity of fluid in a pore is faster than the overall superficial bed velocity and it increases with decreasing porosity. The tortuosity factor, however, increases the inside pore speed compared to the overall superficial bed velocity. The tortuosity factor is higher in parallelepiped packings than in spherical packings. The tortuosity and void fraction in a packed bed are also related through the equation $\tau=1-$ $P \ln f$, where $P$ is a fitting parameter that is determined experimentally (Comiti and Renaud, 1989). Tortuosity factors can also be defined in terms of diffusion coefficients, as molecules diffuse under a concentration gradient (Weissberg, 1963), for instance $\tau^{2}=f D_{0} / D_{\text {eff }}$, or as per Maxwell's formula, $\tau=$ $1+\frac{1}{2}(1-f) \cdot D_{0} / D_{\text {eff }}$ is the diffusion coefficient of the diffusing species in a free fluid, $D_{0}$, relative to its 
value in a porous medium, $D_{\text {eff }}$ (Ghanbarian et al., 2013). It has been claimed in the geophysical field that this diffusion-based tortuosity is similar to the electrical tortuosity that is related to the electric conductivity of a material (Ben Clennell, 1997). Boudreau and Meysman, 2006 developed a model, $\tau=$ $1+\frac{32 p}{9 \pi}(1-f)$, based on an assembly of non-penetrating and non-overlapping blocks to predict the tortuosity of muds. These disk-shaped blocks are described by the factor $p$ that represents their radius to thickness ratio. The model was also shown to describe the relationship very well between porosity and tortuosity for functionalised calcium carbonate (FCC) tablets (Markl et al., 2018b). Wu et al., 2006 determined the fastest route through the pore space of sodium chloride compacts by analysing crosssections of the tablets using SEM. The authors measured the relative path length from the SEM images and proposed this as a measure of the tortuosity. This characterisation revealed that the particle size influences the measured relative path length. Furthermore, the results indicated an anisotropic structure with the pores preferentially oriented in the direction of compression. This preferred directional orientation of pores could also be observed for FCC tablets (Markl et al., 2017b,2018a).

\subsection{Connectivity}

Yang et al., 2014 characterised packed ore particle beds by considering pore connectivity, which is especially important to determine the leaching from pores. Analogies can be drawn to that of solubilised drug diffusion through a tablet. Pore connectivity is defined as the summed volume of the individual pore clusters, identified by a suitable image analysis algorithm, divided by the total pore volume of the sample containing the clusters (Yang et al., 2014). A variation on this pore connectivity index is pore interface area divided by total surface area, where interface area is shared by two or more pores. The higher the proportion of interface area, the higher the pore connectivity (Axelsson and Svensson, 2010). Gutiérrez et al., 2014 took a different approach, defining interconnectivity of aluminides in $\mathrm{AlCu}_{7}$ alloys as the volume of the biggest dendritic aluminide divided by the total volume of aluminides. Another parameter to describe the connectivity of pores is percolation, which Fusseis et al., 2012 calculated using a parallelepiped box that moves through the sample volume in a grid-like fashion. This results in a probability function for percolation in different directions. Liu, Pereira, and Regenauer-Lieb, 2014 performed a similar analysis with porous heterogeneous carbonate. More complex and lesser used parameters include Mandelbrot's succolarity and lacunarity (Anovitz and Cole, 2015).

\subsection{Anisotropy}

Pore orientation and anisotropy can be determined from three perpendicular eigenvectors defining the principal axes of a pore $\left(\boldsymbol{v}_{1}, \boldsymbol{v}_{\mathbf{2}}\right.$ and $\left.\boldsymbol{v}_{3}\right)$ describing its orientation in space (Figure 1). $\boldsymbol{v}_{\mathbf{1}}$ corresponds to the longest dimension of the pore and $\boldsymbol{v}_{2}$ corresponds to the second longest dimension that is perpendicular to $\boldsymbol{v}_{\mathbf{1}}$. Finally, $\boldsymbol{v}_{\mathbf{3}}$ is the third longest dimension that is perpendicular to both $\boldsymbol{v}_{\mathbf{2}}$ and $\boldsymbol{v}_{\mathbf{3}}$. Each of these eigenvectors has an eigenvalue, $\lambda_{1}, \lambda_{2}$ or $\lambda_{3}$, respectively. Problems arise when a porosity detection algorithm interprets a cluster of pores as a single large pore, rather than as several small ones - hence, an additional algorithm is needed to separate connected pores before anisotropic analysis can be applied.

Fusseis et al., 2012 investigated dehydrating polycrystalline gypsum pores by using the ratio of the largest eigenvalue divided by the smallest eigenvalue for each pore. They disregarded both very large pores ( $>1$ 200 voxels) and very small pores ( $<50$ voxels), whose shape is not adequately described in this way. Axelsson and Svensson, 2010 plotted anisotropies of pores along different sample planes to characterise the structure of paper. To visualise the angular orientation of irregular pores in carbon-composite materials, Drach et al., 2013 created a spherical probability density function, which is volume weighted to account for the reduced contribution of smaller pores.

A simpler approach was presented by Claes et al., 2016 by plotting $\boldsymbol{v}_{\mathbf{1}}$ for each pore on a 3D unit sphere (Figure 5). The trend for both the samples illustrated is that many larger pores are oriented in the $x y$ plane, demonstrating their alignment along the printing direction. It is therefore possible to infer the $x y$ 
printing orientation, due to two clusters of pores at approximately $90^{\circ}$ to one another. Smaller pores have more random orientations and hence they are dispersed almost evenly around the sphere.

\subsection{Permeability}

The resistance to flow in a porous bed is described by the factor $R=\mu / k$ where $\mu$ is fluid viscosity and $k$ is the permeability. This resistance depends on the pore structure network of the bed, and gives rise to a pressure drop. If the fluid is exposed to an increased internal surface area per unit length of the sample, viscous drag increases, which, in turn, increases resistance to flow (Holdich, 2002). To understand permeability it is important to emphasise that it is determined by the flow behaviour through a saturated porous medium and thus the permeability is related to both its porosity and tortuosity. The equivalent hydraulic radius is a useful metric to describe fluid flow in porous structures, considered to be the radius of a single cylindrical pipe that exhibits the same flow resistance as the overall porous medium. The hydraulic radius itself cannot be defined by observing the overall porous medium physical structure (Costa, 2006), but can be approximated with significant assumptions by modelling, involving 3D minimisation of structure path lengths (Matthews et al., 1993). It is defined as the volume of fluid flowing across a unit cross-sectional area of the sample per unit sample length, divided by the surface area it touches, i.e. it can be described by $r_{\mathrm{h}}=V_{\text {sat }} / A$, where $V_{\text {sat }}$ is the saturated pore volume, and $A$ is the pore surface area (Rouquerolt et al., 1994). It is frequently used to predict permeability properties of the sample, and influences material response to processes such as drying and mechanical loading (Scherer, 1994). To understand flow, the Reynolds number, $R e$, is commonly used, which must be modified for a porous medium. The length dimension is given as the hydraulic radius, which for a porous bed becomes $d=\frac{f}{(1-f) S_{\mathrm{v}}}$ where $S_{\mathrm{v}}$ is the specific surface area per unit volume. Thus, $R e=\frac{\varrho U_{\mathrm{o}}}{(1-f) S_{\mathrm{v}} \mu}$ (Holdich, 2002). At low $R e<2$, the flow is considered laminar and can be described by Darcy's law and the Carman-Kozeny equation. Darcy's law can be used to determine the permeability of the bed experimentally, whereas Carman-Kozeny creates an analytical expression for the permeability, $k=\frac{f^{3}}{K(1-f)^{2} S_{\mathrm{v}}{ }^{2}}$, where $K$ is the Kozeny constant, which is likely dependent on $f$ based on experimental findings (Holdich, 2002). It is derived from Darcy's law in conjunction with Poiseuille's law, by modelling pores as cylindrical tubes (Costa, 2006).

\subsection{Shape}

To gain more insight into the spatial distribution of pores, cumulative porosity plots of the $x y, y z$ and $x z$ planes can be obtained by summing the number of voxels classified as voids along each dimension $z, x$ and $y$, respectively, as done by Reh et al., 2012 and shown in Figure 6 . The colour map depicts the void fraction at each point, i.e. the number of void voxels in a column divided by the total number of voxels in a column. To analyse the spatial distribution of pores further, the void voxels can be averaged in each $x y$ plane and plotted by height $z$.

Pore shape can be classified using particle characterisation techniques, such as Blott and Pye's (Blott and Pye, 2008) elongation ratio $I / L$ and flatness ratio $S / I$, which assign particles to form classes. $L$ is the longest dimension, $I$ is the longest dimension perpendicular to $L$, and $S$ is perpendicular to both $I$ and $L$. Schmitt et al., 2016 used Blott and Pye's approach to analyse pores in German sandstone rocks using Feret calliper diameter measurements to obtain the relevant lengths. Claes et al., 2016 obtained $I, L$ and $S$ with moments of inertia to find the principal axes of an ellipsoid approximating each pore in carbonate reservoir rocks. This concept can be illustrated for the sample tablets: the pore eigenvalues give an indication of the pore size in perpendicular dimensions, allowing the elongation ratio, $I / L=\lambda_{2} / \lambda_{1}$ and flatness ratio, $S / L=\lambda_{3} / \lambda_{2}$ to be calculated. In the example dataset the large pores from P1 (Figure 7a) and P2 (Figure $7 \mathrm{~b}$ ) lie close to the axes and the origin, indicating a blade-like shape of the large pores (Figure 7b).

An extension is to include sphericity (Wadell, 1935) in the $z$ axis, $\pi^{\frac{1}{3}}\left(6 V_{\mathrm{p}}\right)^{\frac{2}{3}} / S_{p}$, where $S_{\mathrm{p}}$ is pore surface area and $V_{\mathrm{p}}$ is pore volume. In general, smaller pores show a higher sphericity (Figure $7 \mathrm{c}$ and d). For the 
larger pores, the more tubular, grid-like pores are expected to have a lower sphericity than round/bubbleshaped pores.

Further shape parameters can be found in the literature, with simple ones including surface area to volume ratios used by Reh et al., 2012 to describe pores in carbon fibre reinforced polymers. More intricate descriptions include pore compactness (Claes et al., 2016) and Gaussian curvature, which Tolnai et al., 2009 used to characterise dendritic solidification of $\mathrm{AlMg}_{4.7} \mathrm{Si}_{8}$.

\section{Helium Pycnometry}

Helium pycnometry is used to obtain a key parameter for porous samples: the true solid density. This can be used in conjunction with the bulk density to calculate the total pore volume and the sample porosity. It does not give information on individual pore sizes, pore shape, pore orientation etc. The measurement apparatus involves two chambers - a sample chamber where the sample is inserted (of volume $V_{\mathrm{c}}$ ), and a reference chamber (of volume $V_{\mathrm{r}}$ ), which are connected by a pressure transducer as shown in Figure 8 . The sample chamber is filled with helium to pressure $P_{c}$. Helium demonstrates close to ideal gas behaviour, and hence is the test gas of choice. Given their small size, helium atoms are able to penetrate into very fine pores. Helium is considered inert and it is assumed that helium is neither adsorbed nor absorbed within the solid material (Lowell et al., 2004). The pressure of the sample chamber is recorded and then the valve to the reference chamber is opened and allowed to equilibrate to $P_{\mathrm{r}}$ (the equilibrated pressure in the reference and sample chambers), which is recorded.

The true density and eventually the porosity of a sample can be derived using the ideal gas law, and applying it to different control volumes (Lowell et al., 2004). The measurement must be performed at constant temperature to be valid. The relationship between the solid, void and reference volumes is given by the following equation (Lowell et al., 2004): $V_{\text {solid }}=V_{c}+\frac{V_{\mathrm{r}}}{1-\frac{P_{\mathrm{c}}}{P_{\mathrm{r}}}}$, where $V_{\text {solid }}$ is the solid volume (not to be confused with $V$, the total sample volume including pores). The true density of the object, which refers to the density of just the solid part, is given by the $\varrho_{\text {true }}=w / V_{\text {solid }}$ where $w$ is the weight of the sample. This can be related to the porosity as $f=1-\varrho_{\text {bulk }} / \varrho_{\text {true }}$, where $\varrho_{\text {bulk }}$ is the bulk density of the sample.

Unless there are closed, non-penetrable voids, helium pycnometry gives an accurate value of the true density of a material. If there are any gaseous particles that could be outgassed from the solid during the pressure changes, the sample must be degassed first. However, certain substances cannot be tested using helium as they release water under these conditions, which distorts the measurement and destroys the sample. For instance, the porosity of microcrystalline cellulose (MCC) is generally overestimated by approximately $3.6-14.2 \%$ due to this phenomenon, and, hence, must be dried adequately beforehand (Sun, 2005). This is particularly important for the characterisation of hygroscopic excipients using helium pycnometry. Many true density values in the literature may thus be erroneous and these materials need to be carefully re-examined.

The helium pycnometer porosity reading is somewhat dependent on the applied pressure: at higher pressures, helium can penetrate into smaller voids, meaning the porosity will be recorded as being higher. This limitation depends on the length scale of the pores in question (Klaja and Przelaskowska, 2015). For some samples, the apparent true density decreases when a powder is compacted to a tablet - this can be explained by an increased frequency of closed pores through which the helium cannot penetrate (Alkhatib et al., 2010).

The measurement using commercial instruments, such as the AccuPyc II 1340, can be made in approximately $3 \mathrm{~min}$. Prior to measuring, the AccuPyc II 1340 completes purging cycles to clean the sample. It then takes several successive measurements until they converge to the same result (Micromeritics Instrument Corp., 2017). Quantachrome Instruments state that their gas pycnometers can analyse data in as little as one minute (Quantachrome Instruments, 2017). 
Table 1: A selection of helium pycnometry applications for porous pharmaceutical materials from recent literature. Information not given is indicated with ' $N / A$ '. ' $T$ ' refers to the temperature of the measurement. Of interest is that few papers note the relative humidity conditions and the maximum pressures used for measurement.

\begin{tabular}{|c|c|c|c|c|c|}
\hline Author & Date & Measuring device & Material & $\begin{array}{c}T \\
\left({ }^{\circ} \mathrm{C}\right)\end{array}$ & Repeat \\
\hline (Alkhatib et al., 2010) & 2010 & $\begin{array}{l}\text { Ultrapycnometer } \\
1000 \\
\text { (Quantachrome) }\end{array}$ & $\begin{array}{l}\text { Polyvinyl acetate-polyvinyl pyrrolidone } \\
\text { matrices with MCC, dibasic calcium } \\
\text { phosphate and D-lactose }\end{array}$ & 25 & Minimum 6 per sample \\
\hline (Schiffter et al., 2010) & 2010 & $\begin{array}{l}\text { Pycnomatic ATR } \\
\text { (ThermoFisher) }\end{array}$ & $\begin{array}{l}\text { Spray freeze dried insulin loaded } \\
\text { microparticles for needle-free ballistic } \\
\text { powder delivery }\end{array}$ & 20 & $\begin{array}{l}20 \text { initial cleansing cycles and then } 6 \\
\text { measurements per sample }\end{array}$ \\
\hline (Schrank et al., 2012) & 2012 & $\begin{array}{l}\text { AccuPyc II } 1340 \\
\text { (Micromeritics) }\end{array}$ & $\begin{array}{l}\text { Ibuprofen-loaded calcium stearate pellets } \\
\text { with different drying conditions }\end{array}$ & 20 & $\begin{array}{l}20 \text { purges to } 1.34 \text { bar and } 5 \text { analytical runs, } \\
\text { with each sample measured } 3 \text { times }\end{array}$ \\
\hline (Khomane and Bansal, 2013) & 2013 & $\begin{array}{l}\text { Pycno } 30 \\
\text { (Smart Instruments) }\end{array}$ & Ranitidine hydrochloride polymorph tablets & 25 & 3 per sample \\
\hline (Pircher et al., 2015) & 2015 & $\begin{array}{l}\text { Accupyc II } 1340 \\
\text { (Micromeritics) }\end{array}$ & $\begin{array}{l}\text { Dual porous biocompatible cellulose } \\
\text { scaffolds }\end{array}$ & 27 & 400 measurements per sample \\
\hline (Yassin et al., 2015b) & 2015 & $\begin{array}{l}\text { Accupyc } 1330 \\
\text { (Micromeritics) }\end{array}$ & $\begin{array}{l}\text { Hydroxypropylmethyl cellulose (HPMC), } \\
\text { Eudragit RSPO and lactose tablets }\end{array}$ & $\mathrm{N} / \mathrm{A}$ & $\begin{array}{l}\text { Chamber is pressurised to } 10 \text { bar } 30 \text { times, } \\
\text { after which measurement is recorded. }\end{array}$ \\
\hline (Yassin et al., 2015a) & 2015 & $\begin{array}{ll}\text { Accupyc } & 1330 \\
\text { (Micrometrics) } & \end{array}$ & $\begin{array}{l}\text { MCC and croscarmellose sodium (CCS) } \\
\text { tablets }\end{array}$ & N/A & $\begin{array}{l}\text { Chamber is pressurised to } 10 \text { bar } 30 \text { times, } \\
\text { after which measurement is recorded. }\end{array}$ \\
\hline (Pircher et al., 2016) & 2016 & $\begin{array}{l}\text { Accupyc II } 1340 \\
\text { (Micromeritics) }\end{array}$ & $\begin{array}{l}\text { Cellulose II aerogels made with different } \\
\text { solvents }\end{array}$ & 27 & 400 measurements per sample \\
\hline
\end{tabular}




\section{Mercury Porosimetry}

Penetration of liquid under pressure can be employed to determine the size and volume of void spaces in a porous medium. This principle works only with liquids that exhibit a contact angle with the solid greater than $90^{\circ}$ as it will then resist wetting the solid and so can be intruded in pores controllably as a function of applied pressure. Mercury has a contact angle $>90^{\circ}$ for very many materials, and it is, therefore, the liquid of choice for such measurements. Mercury is forced under increasing pressure initially into the large pores and then progressively into the finer pores of the porous sample (Figure 9a). The volume of liquid forced into the pores increases as the pressure increases. By assuming a cylindrical pore shape, the YoungLaplace equation, $d_{p}=4 \gamma_{\mathrm{LV}} \cos \theta / P$ is then utilised to determine the pore diameter $d_{p}$ at each pressure, $P$. The liquid-vapour surface tension of mercury $\left(\gamma_{\mathrm{LV}}=0.485 \mathrm{~N} \mathrm{~m}^{-1}\right)$ and the liquid-solid contact angle, $\theta$, for the given sample with mercury need to be known. Thus, in practice, mercury porosimetry measures the intruded volume in relation to the mass of the sample at a range of defined pressures. Increasing the pressure $P$ on a material with a specific pore size distribution yields a unique cumulative pressure-volume curve, which permits the calculation of the pore volume as a function pore size (Figure $9 b$ and $c$ ).

Mercury porosimetry was introduced to the pharmaceutical field by Strickland, Busse, and Higuchi, 1956 to measure the apparent density of granulates and the intragranular porosity. Reich and Gstirner, 1968 developed a mercury porosimeter that made it possible to measure from very low to high pressures continuously, which could thus be used to determine the pore sizes ranging from 0.05 to $500 \mu \mathrm{m}$. This was demonstrated with the example of starch tablets, where the authors showed that an increase in compression force resulted in a decrease in porosity and pore radius, as well as an extended disintegration time of these tablets. These publications and others published before 1981 are summarised in an excellent review article from Dees and Polderman, 1981.

Mercury porosimetry (together with helium pycnometry and nitrogen adsorption) is nowadays one of the most popular methods to measure the pore size distribution and porosity of pharmaceutical powders, granules and tablets (Table 2). Ohno et al., 2007, investigated the effect of changing process parameters of high shear wet granulation on the granule properties and the dissolution behaviour of mefenamic acid tablets. They found that an increase in water amount and kneading time caused an increase in the particle diameter of the granules and a decrease in the mean pore diameter. It was also observed that the larger the mean pore diameter of the granules, the more mefenamic acid API was released after $15 \mathrm{~min}$. This clearly indicates that the initial dissolution behaviour is strongly affected by the pore structure of the granules. Riippi et al., 1998, demonstrated that the pore size distribution correlates with the dissolution behaviour of erythromycin acistrate tablets. However, they also indicated that the dissolution behaviour cannot be explained only by the volume of intruded mercury, as the imbibition of the dissolution medium in the compact also strongly depends on the surface properties, in particular the surface energy (wettability) of the material.

A slightly different application of mercury porosimetry in pharmaceutical technology was demonstrated by Guerin et al., 1999. They proposed that the mercury intrusion of a powder bed causes a rearrangement of the particles, and, therefore, the intruded volume at low pressures can be used to analyse compressibility and flow properties of pharmaceutical powders. Seven different pharmaceutical powders were analysed and the results revealed that the compressible volume determined by mercury porosimetry is in excellent agreement with the compressible volume determined using a powder tester apparatus. The bulk modulus of the skeletal material making up the solid phase of the porous medium (a measure of the ability of the sample solid phase to withstand changes in volume when under compression) of MCC/indomethacin tablets was studied by Ridgway et al., 2017. The authors prepared tablets with varying API concentrations and porosities and measured the bulk modulus of the material making up the pore walls of these different sets of tablets. The measurements revealing the bulk modulus were performed by analysing the change of apparent intruded volume at intrusion and extrusion of mercury at the highest pressures. A typical pore retention hysteresis over the pressure range largely below the maximum pressure region could be observed, which indicated that the skeletal material is partially 
undergoing plastic deformation during the pore volume measurement. At the highest pressures, however, the mercury volume at extrusion could be seen to equal that of intrusion as a function of pressure, such that the skeletal material was considered to have been elastically compressed. Here the gradient of the elastic response to pressure provides a measure of the elastic bulk modulus of the skeletal material, Figure 10. Ridgway et al., 2017, demonstrated that the bulk modulus of the skeletal material increased with porosity associated with increasing API loading.

The determination of elastic bulk modulus of the skeletal material occurring during the porosimetry measurement, as described above, can be undertaken, based on the model proposed by Gane et al., 1996, embedded as part of a pore modelling software program package (PoreXpert software available from the University of Plymouth, Plymouth, UK) that can also simulate the pore structure of the sample measured. The concept of the model is to overcome one of the major limitations to any analysis of mercury intrusion data, i.e. only being able to describe the pore structure as a bundle of parallel capillary tubes corresponding to the range of intruded capillary diameters, which in turn correspond to the pressure range applied. The experimenter must, therefore, resort to such models to advance an understanding of the differences between pore size, connectivity and structure tortuosity. Furthermore, the intrusion method is susceptible to pore shielding, in which access to a large diameter pore is restricted by a narrow entry throat, such that the volume intruded into the large pore is erroneously recorded as intrusion into a pore having the diameter of the narrow throat.

Use of the model, described above, showed the rate of absorption is dependent on many aspects of the geometry of the void structure as well as on the properties of the fluids. The results confirmed that realistic absorption dynamics cannot be modelled using the Lucas-Washburn equilibrium between Poiseuille flow resistance and capillary wetting force alone. Rather, the absorption rate as a function of time depends upon pore size distribution, connectivity and connecting throat length, together with fluid properties including viscosity and density (Ridgway and Gane, 2002). The Bosanquet model can be used, including an inertial acceleration related term complementing the Lucas-Washburn viscous description (Bosanquet, 1923). It could be shown that short timescale acceleration and deceleration of fluid, within the pore structure, leads to plug flow behaviour which deviates from the laminar permeability approximation. The result is that absorption follows two regimes, inertial plug flow where the rate is proportional to time, and viscous where the rate is proportional to the square root of time (Bosanquet, 1923; Schoelkopf et al., 2002).

In specifically designed, discretely separable bimodal (dual) porosity structures, porous particles are compacted together to provide very high absorption rates. In these structures it is possible to separate the permeability, associated with the interparticle pores, and the capillarity, associated with the intraparticle pores, with respect to the inflection point of the bimodal cumulative mercury intrusion curve (Ridgway et al., 2006). Such structures are used across a wide range of industries, but in the context of this review, they constitute the material termed FCC. This material has been demonstrated primarily as a functional excipient for orally dispersible tablets (Stirnimann et al., 2014; 2013; Wagner-Hattler et al., 2017). 


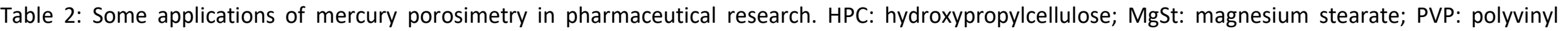
pyrrolidone.

\begin{tabular}{|c|c|c|c|c|}
\hline Author & Date & Measuring apparatus & Material & Application \\
\hline (Strickland et al., 1956) & 1956 & Custom-built & $\begin{array}{l}\text { Glass beads, potassium bromide crystals, } \\
\text { sulfathiazole/starch granules, } \\
\text { phenobarbital/starch granules, sodium } \\
\text { bicarbonate/starch granules, aspirin } \\
\text { granules }\end{array}$ & Intragranular porosity \\
\hline $\begin{array}{l}\text { (Reich, 1967) } \\
\text { (Reich and Gstirner, } \\
\text { 1968) }\end{array}$ & $\begin{array}{l}1967 \\
1968\end{array}$ & Custom-built & Starch tablets & $\begin{array}{l}\text { Pore volume and pore size distribution, } \\
\text { porosity }\end{array}$ \\
\hline $\begin{array}{l}\text { (Selkirk and Ganderton, } \\
\text { 1970a) }\end{array}$ & 1970 & $\begin{array}{l}\text { Micromeritics Porosimeter } \\
\text { Model 905-1 }\end{array}$ & $\begin{array}{l}\text { Tablets containing lactose/sucrose } \\
\text { granules }\end{array}$ & Pore size distribution, porosity \\
\hline $\begin{array}{l}\text { (Selkirk and Ganderton, } \\
\text { 1970b) }\end{array}$ & 1970 & $\begin{array}{l}\text { Micromeritics Porosimeter } \\
\text { Model 905-1 }\end{array}$ & Tablets containing lactose granules & Pore size distribution, porosity \\
\hline $\begin{array}{l}\text { (Ganderton and Hunter, } \\
\text { 1971) }\end{array}$ & 1971 & $\begin{array}{l}\text { Custom-built from } \\
\text { (Strickland et al., 1956) }\end{array}$ & Lactose and calcium phosphate granules & $\begin{array}{l}\text { Intra- and extragranular porosity as well as } \\
\text { total porosity }\end{array}$ \\
\hline (Selkirk, 1974) & 1974 & $\begin{array}{l}\text { Micromeritics Porosimeter } \\
\text { Model 905-1 }\end{array}$ & Tablets containing lactose granules & Pore size distribution, porosity \\
\hline $\begin{array}{l}\text { (Marshall and Sixsmith, } \\
\text { 1974) }\end{array}$ & 1974 & $\begin{array}{l}\text { Micromeritics Porosimeter } \\
\text { Model 905-1 }\end{array}$ & MCC powder & Pore size distribution, porosity \\
\hline $\begin{array}{l}\text { (Palmer and R. C. Rowe, } \\
\text { 1974) }\end{array}$ & 1974 & $\begin{array}{l}\text { Micromeritics Porosimeter } \\
\text { Model } 905-2\end{array}$ & Polyvinylchloride powder, glass beads & $\begin{array}{l}\text { Intra- and interparticle porosities, powder } \\
\text { packing }\end{array}$ \\
\hline (Sixsmith, 1977) & 1976 & $\begin{array}{l}\text { Micromeritics Porosimeter } \\
\text { Model 905-1 }\end{array}$ & MCC tablets & Interparticle pore size distribution, porosity \\
\hline $\begin{array}{l}\text { (Stanley Wood and } \\
\text { Shubair, 1979) }\end{array}$ & 1979 & $\begin{array}{l}\text { Micromeritics Porosimeter } \\
\text { Model 905-1 }\end{array}$ & $\begin{array}{l}\text { Dicalcium phosphate dehydrate/starch } \\
\text { granules }\end{array}$ & $\begin{array}{l}\text { Pore volume and pore size distribution, } \\
\text { porosity }\end{array}$ \\
\hline
\end{tabular}




\begin{tabular}{|c|c|c|c|c|}
\hline (Dees, 1980) & 1980 & Custom-built & Lactose and sulphadimidine tablets & Pore size distribution, porosity \\
\hline (Carli and Motta, 1984) & 1982 & Macropore Unit & $\begin{array}{l}\text { Lactose, MCC, indoprofen, and MgSt } \\
\text { powder }\end{array}$ & $\begin{array}{l}\text { Particle size and surface area distribution, } \\
\text { porosity }\end{array}$ \\
\hline $\begin{array}{l}\text { (Wikberg and Alderborn, } \\
\text { 1990) }\end{array}$ & 1990 & $\begin{array}{l}\text { Custom-built from } \\
\text { (Strickland et al., 1956) }\end{array}$ & Lactose granules & Intragranular porosity \\
\hline $\begin{array}{l}\text { (Wikberg and Alderborn, } \\
\text { 1992) }\end{array}$ & 1992 & $\begin{array}{l}\text { Micromeritics Pore Sizer } \\
9310\end{array}$ & Lactose granule tablets & Pore size distribution, porosity \\
\hline (Johansson et al., 1995) & 1995 & $\begin{array}{l}\text { Micromeritics Pore Sizer } \\
9310\end{array}$ & MCC pellets and MCC/salicylic acid & $\begin{array}{l}\text { Intragranular pore size distribution, } \\
\text { porosity }\end{array}$ \\
\hline (Juppo, 1996) & 1996 & $\begin{array}{l}\text { Quantachrome Autoscan } \\
33 \text { Porosimeter }\end{array}$ & $\begin{array}{l}\text { Lactose, glucose and mannitol granule } \\
\text { tablets }\end{array}$ & Tablet porosity, pore size distribution \\
\hline (Juppo et al., 1997) & 1997 & $\begin{array}{l}\text { Quantachrome Autoscan } \\
33 \text { Porosimeter }\end{array}$ & $\begin{array}{l}\text { Propranolol hydrochloride/MCC extrudates } \\
\text { and pellets (extrusion + spheronisation) }\end{array}$ & $\begin{array}{l}\text { Extrudate and pellet porosity, pore size } \\
\text { distribution }\end{array}$ \\
\hline (Ridgway et al., 1997) & 1997 & Micromeritics AutoPore III & Lactose/anti-inflammatory compound & Pore size distribution, porosity \\
\hline $\begin{array}{l}\text { (Westermarck et al., } \\
\text { 1998a) } \\
\text { (Westermarck et } \\
\begin{array}{l}\text { 1999) } \\
\text { (Westermarck }\end{array} \text { et } \\
\text { 1998b) }\end{array}$ & $\begin{array}{l}1998, \\
1999\end{array}$ & $\begin{array}{l}\text { Quantachrome Autoscan } \\
33 \text { Porosimeter }\end{array}$ & $\begin{array}{l}\text { Mannitol, MCC powder; mannitol, MCC } \\
\text { granules; mannitol powder, MCC powder } \\
\text { tablets; mannitol granule, MCC granule } \\
\text { tablets }\end{array}$ & Pore size distribution, porosity \\
\hline (Riippi et al., 1998) & 1998 & $\begin{array}{l}\text { Quantachrome Autoscan } \\
33 \text { Porosimeter }\end{array}$ & $\begin{array}{l}\text { Erythromycin acistrate granules/MgSt } \\
\text { tablets }\end{array}$ & Pore size distribution \\
\hline (Vertommen et al., 1998) & 1998 & $\begin{array}{l}\text { Quantachrome Autoscan } \\
60 \text { Porosimeter }\end{array}$ & $\begin{array}{l}\text { Pellets of } \alpha \text {-lactose monohydrate, MCC and } \\
\text { riboflabin }\end{array}$ & $\begin{array}{l}\text { Pore size distribution of meso- and } \\
\text { macropores }\end{array}$ \\
\hline (Guerin et al., 1999) & 1999 & $\begin{array}{l}\text { Micromeritics Autopore } \\
9220 \text { Porosimeter }\end{array}$ & $\begin{array}{l}\text { Dicalcium phosphate, Di Tab }{ }^{\circledR} \text {, Lactose Fast } \\
\text { Flo }^{\circledR} \text {, Lactose Extra Fine Kristal }{ }^{\circledR} \text {, Lactose }\end{array}$ & Compressible volume, powder packing \\
\hline
\end{tabular}




\begin{tabular}{|c|c|c|c|c|}
\hline & & & $\begin{array}{l}\text { Fine Kristal }^{\circledR} \text {, } \text { Ketoprofen }^{\circledR}, \text { Acebutolol } \\
\text { Chlorhydrate }^{\circledR}, \text { Celiprolol Chlorhydrate }^{\circledR} \\
\text { powders }\end{array}$ & \\
\hline (Mattsson, 2001) & 2001 & Micromeritics AutoPore III & $\begin{array}{l}\text { Sodium bicarbonate, sodium chloride, PEG } \\
3000, \text { PEG 20000, and pregelatinised starch } \\
\text { (PGS) powders; tablets containing different } \\
\text { mixtures of these constituents }\end{array}$ & $\begin{array}{l}\text { Inter- and interparticulate pore size } \\
\text { distribution }\end{array}$ \\
\hline (Gabaude et al., 2001) & 2001 & Micromeritics AutoPore III & $\begin{array}{l}\text { MCC, starch, Pharmatose, and different } \\
\text { drug powders, }\end{array}$ & Pore size distribution, powder packing, \\
\hline $\begin{array}{l}\text { (Ferrero and Jiménez- } \\
\text { Castellanos, 2002) }\end{array}$ & 2002 & $\begin{array}{l}\text { Quantachrome Autoscan } \\
33\end{array}$ & $\begin{array}{l}\text { Tablets of different copolymers. The } \\
\text { copolymers were synthesised by free } \\
\text { radical copolymerisation of methyl } \\
\text { methacrylate and different carbohydrates } \\
\text { (hydroxypropylstarch, } \\
\text { carboxymethylstarch, } \\
\text { hydroxypropylcellulose) }\end{array}$ & Total porosity and pore size distribution \\
\hline (Freitag et al., 2004) & 2004 & $\begin{array}{l}\text { Micromeritics } \quad \text { Poresizer } \\
9320\end{array}$ & $\begin{array}{l}\text { Magnesium carbonate powder and } \\
\text { granules; magnesium carbonate } \\
\text { granule\MgSt tablets }\end{array}$ & Pore size distribution, tablet porosity \\
\hline (Ohno et al., 2007) & 2007 & $\begin{array}{l}\text { Micromeritics Autopore } \\
9420\end{array}$ & $\begin{array}{l}\text { Mefenamic acid, lactose monohydrate, } \\
\text { low-substituted HPC, MCC, HPC and MgSt } \\
\text { granules }\end{array}$ & $\begin{array}{l}\text { Porosity, intragranular pore size } \\
\text { distribution, effect of average pore } \\
\text { diameter on dissolution. Effect of granule } \\
\text { process parameters on porosity and } \\
\text { average diameters }\end{array}$ \\
\hline (Crean et al., 2010) & 2010 & $\begin{array}{l}\text { Micromeritics AutoPore IV } \\
9500\end{array}$ & $\alpha$-lactose monohydrate granules with PVP & $\begin{array}{l}\text { Intragranular porosity and pore size } \\
\text { distribution }\end{array}$ \\
\hline (Krupa et al., 2012) & 2012 & $\begin{array}{l}\text { Quantachrome } \\
\text { PoreMaster } 60\end{array}$ & $\begin{array}{l}\text { Pure F-Melt tablets; tablets containing of F- } \\
\text { Melt and one of the three APIs: ibuprofen, }\end{array}$ & $\begin{array}{l}\text { Porosity and pore size distribution (related } \\
\text { to disintegration time) }\end{array}$ \\
\hline
\end{tabular}




\begin{tabular}{|c|c|c|c|c|}
\hline & & & $\begin{array}{l}\text { diclofenac sodium or diltiazem } \\
\text { hydrochloride }\end{array}$ & \\
\hline (Schrank et al., 2012) & 2012 & $\begin{array}{l}\text { Quantachrome Poremaster } \\
60-G T\end{array}$ & Calcium stearate/ibuprofen pellets & Porosity and average pore size \\
\hline (Sprunk et al., 2013) & 2013 & Thermo Fisher PASCAL 140 & $\begin{array}{l}\text { Indomethacin/sodium dodecyl } \\
\text { sulfate/maltodextrin dry foams }\end{array}$ & Pore size distribution \\
\hline (Stirnimann et al., 2014) & 2014 & Micromeritics Autopore V & $\begin{array}{l}\text { Compaction structure of functionalised } \\
\text { calcium carbonate }\end{array}$ & Discretely bimodal pore size distribution \\
\hline (Ridgway et al., 2017) & 2017 & Micromeritics Autopore V & Indomethacin/MCC tablets & $\begin{array}{l}\text { Porosity, pore size distribution and bulk } \\
\text { modulus }\end{array}$ \\
\hline (Markl et al., 2017b) & 2017 & Micromeritics Autopore V & Functionalised calcium carbonate & Pore size distribution \\
\hline
\end{tabular}




\section{Nuclear Magnetic Resonance}

NMR is a non-invasive and chemically specific technique that can be applied to study mass transport phenomena quantitatively in the form of molecular diffusion and flow (Mantle, 2013). The complete theory of NMR is beyond the scope of this review article and the reader is referred to several excellent books (Brown et al., 2014; Callaghan, 1993; Levitt, 2008).

Basically, an NMR signal is generated when a nucleus of non-zero spin is subjected to a strong magnetic field and radio-wave irradiation. Since the nucleus has a net magnetic moment, it tends to align with the applied magnetic field. This results in a net magnetisation vector aligned parallel to the direction of the magnetic field, which precesses when disturbed from equilibrium by exposing the system to radiofrequency (RF) radiation. This precession induces a voltage in the surrounding tuned coil, which represents the NMR signal. The frequency of the precession is the so-called Larmor resonance frequency and it is equal to the product of the applied magnetic field and the gyromagnetic ratio. The gyromagnetic ratio is an isotope-specific property that is largest for the hydrogen nucleus. Typically, a pulse of RF radiation at the Larmor resonance frequency of the nucleus of interest is used to disturb the nuclei from equilibrium and to set them into precession. The NMR signal is inherently weak, but it increases in strength with an increasing gyromagnetic ratio and applied magnetic field.

NMR and the closely related magnetic resonance imaging (MRI) technique have been applied to study the fundamental processes involved in the disintegration (Quodbach et al., 2014a; 2014b; Tritt-Goc and Kowalczuk, 2002) and dissolution (C. Chen et al., 2014; Y. Y. Chen et al., 2010; Mantle, 2016; 2013; 2011; Melia et al., 1998; Nott, 2010; Richardson et al., 2005; Tajarobi et al., 2009; Zeitler and Gladden, 2009; Zhang et al., 2011) of solid dosage forms. The characterisation of pore structures using NMR is typically performed by measuring the signal from liquids interacting with the solid material as the relaxation times of the solid phase are too short to be measured by NMR. There are three main approaches in NMR to gather information about the pore structure of porous samples: NMR cryoporometry, diffusometry and relaxometry. Each of these will be discussed in the following.

NMR cryoporometry is a thermoporometry technique, which is suitable for mapping the pore size distribution of a material (Strange et al., 1996). The sample is saturated with a suitable liquid (typically water or cyclohexane) and the porous sample is cooled until all liquid is frozen. The sample is then gradually warmed up causing the melting of the water or cyclohexane crystals that were formed in the pores. In their frozen state the molecules of the liquid used to fill the pores do not result in an NMR signal due to the fast relaxation in solids. The crystals within the small pores will melt before those from larger pores and the volume of the liquid produced yields an NMR signal that is proportional to the volume of pores smaller than a specific size, $x$. The crystals of dimension $x$ melt at a temperature $T$, which is lower than the bulk material melting point $T_{m}$. The Gibbs-Thompson equation, $\Delta T(x)=k / x$, is utilised to relate the melting point change, $\Delta T(x)=T_{m}-T$, for liquids in pores and their respective pore size. The melting point depression constant $k$ depends on the properties of the liquid and the liquid/solid interface. Consequently, $k$ needs to be determined for the probe material using samples with known pore size distribution (Strange et al., 2003). Similar measurements can be performed with differential scanning calorimetry (DSC) or differential scanning microscopy, which results in an experimental graph of heat flow and temperature that can be related to a pore size distribution (Rouquerolt et al., 1994). DSC measures the actual melting manifested by heat transfer, whereas NMR cryoporometry determines the fraction of liquid molten at a range of temperatures. 
493

494

495

496

497

498

499

500

501

502

503

504

505

506

507

508

509

510

511

512

513

514

515

516

517

518

519

520

521

522

523

524

525

526

527

528

529

530

531

532

533

534

535

Diffusometry provides a measure relating to the surface-to-volume ratio and the tortuosity of the pore structure by determining the time-dependent diffusion coefficient, $D(t)$, of a liquid diffusing in the pore space of a material (Collins et al., 2007). The analysis of the $D(t)$ at short observation times provides the surface-to-volume ratio, while the $D(t)$ at long observation time yields the tortuosity of the pore structure.

Another NMR-based approach is relaxometry, which exploits the enhanced relaxation of molecules at a pore surface to determine the pore size. By assuming a rapid exchange between molecules at the surface and in the pores, the inverse spin-lattice and spin-spin relaxation rates are then proportional to the surface-to-volume ratio of the pore structure (Strange et al., 2003). The pore size distribution can be calculated by combining the measured relaxation times with an estimated mean surface relaxivity of the material. This relaxivity is assumed to be constant throughout the sample and it can be calculated by matching the relaxation times with pore size distributions determined by mercury porosimetery or nitrogen adsorption (Collins et al., 2007). Relaxometry was also combined with cryoporometry by measuring the relaxation times throughout the melting of the sample (Valckenborg et al., 2002). The setup of this combined approach is illustrated in Figure 11.

The majority of applications employing NMR methods to characterise pore structures are in fields outside pharmaceutical sciences. NMR cryoporometry was demonstrated for studying the pore structure of silica gels, bones, cements, rocks and many other applications (Allen et al., 1998; Alnaimi et al., 1994; Mitchell et al., 2008; Strange et al., 2003; 1996; 1993). The pharmaceutical applications of NMR are summarised in Table 3.

The pore structure of calcium carbonate was studied using NMR cryoporometry by Gane et al., 2004. A very similar material, namely FCC, has recently found its application in the pharmaceutical field, where it is of particular interest for orally disintegrating tablets (Stirnimann et al., 2014; 2013; Wagner-Hattler et al., 2017) due to its very high intraparticulate porosity. Gane et al., 2004 studied calcium carbonate tablets compacted at different compression pressures leading to different total porosities and pore size distributions as measured by the authors using NMR cryoporometry. Boissier, Feidt and Nordstierna, 2012 applied NMR cryoporometry to measure the pore size distribution of pharmaceutical coatings, which revealed that the amount of solvent in the coating mixture impacted the connectivity of the pore channels in the film. The authors proposed that the lack of interconnected channels prevented the complete removal of the solvent and it therefore affected the permeability of the film. Another pharmaceutical application of NMR cryoporometry was presented by Petrov et al., 2006. The authors studied the pore size distribution of biodegradable polymer microparticles, which can be used for drug delivery in depot formulations (Figure 11b and c). The dry polymer powder was placed in an NMR tube that was filled with water to study the swelling of the microparticles. NMR cryoporometry measurements were performed on samples after 1, 3 and 4 days in the water reservoir to study the evolution of the pore size distribution as the particles swelled and degraded in the aqueous environment. The evolution of the porosity of controlled drug-release pellets was studied by Collins et al., 2007 using diffusometry and relaxometry (Figure 12). The partially soluble pharmaceutical pellets (see Table 3 for their composition) were immersed in water for different lengths of time and the restricted diffusivity of water trapped within the pellets was measured by NMR. This restricted diffusivity was used to calculate the surface-to-volume ratio and tortuosity of the pore structure. Furthermore, the authors also measured the relaxation time of the water trapped within the pellets, which was used to calculate the pore size distribution as a function of immersion time. The pore structure clearly changed as indicated by the decreasing surface-to-volume 
536 ratio and the tortuosity as well as the increasing mean and modal pore sizes with increasing immersion 537 time. NMR relaxometry was also used by Nebgen et al., 1995 to characterise the pore structure of MCC 538 tablets. The pores were filled with silicon oil to overcome the low signal intensity from the solid material 539 and to reveal the inner structure of the tablet. This procedure enabled the analysis of the distribution of 540 open voids that were filled with silicone oil. 
541 Table 3: A selection of applications of NMR in the pharmaceutical field. HPC: hydroxypropylcellulose; EC: ethylcellulose.

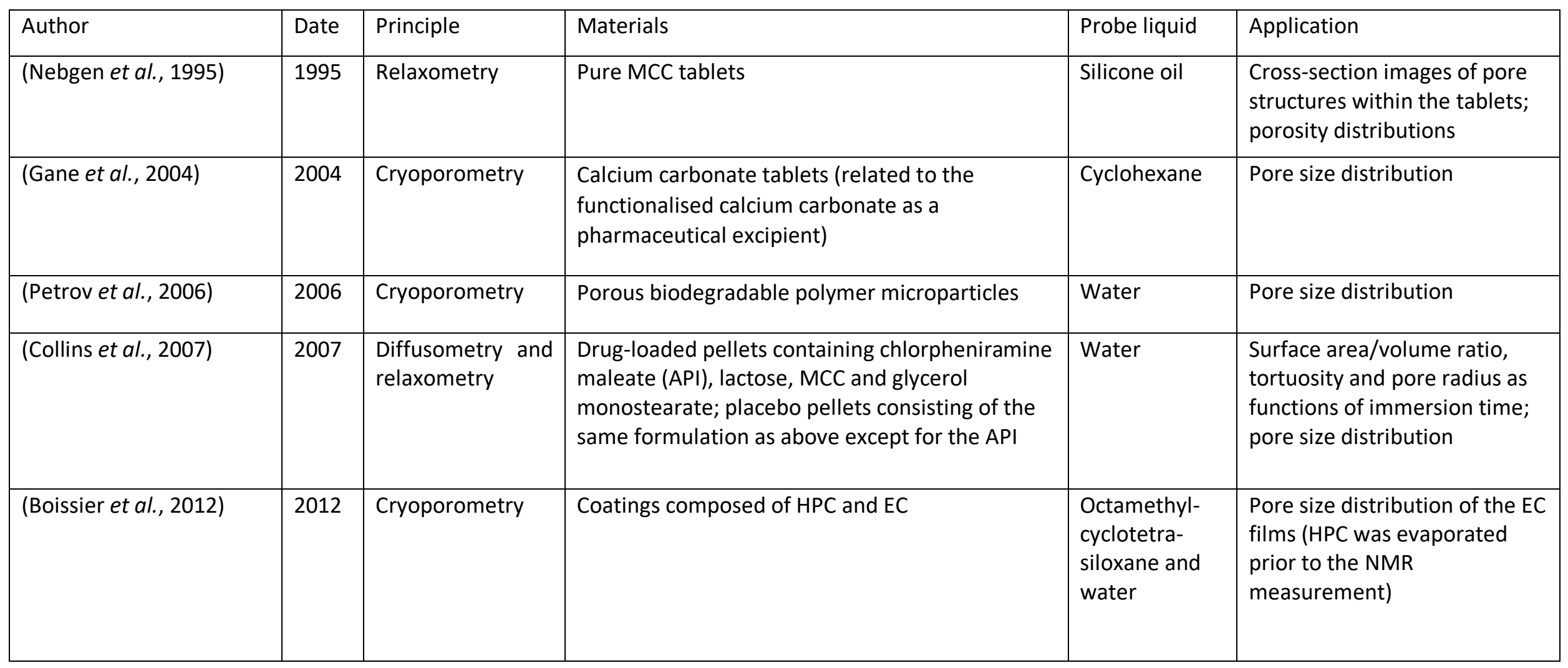




\section{X-ray Computed Microtomography}

544
There are four fundamental steps to capture porosity using X $\mu \mathrm{CT}$ (Figure 13). Firstly, data acquisition in the $\mathrm{X} \mu \mathrm{CT}$ device, which uses polychromatic $\mathrm{X}$-rays to scan an object and obtain vertical projections from different angles around the sample. The attenuation of the X-rays through the object is linked to its absorption coefficient by the Beer-Lambert law and hence its density, which is represented as a grey scale image (Zeitler and Gladden, 2009). There are different possible configurations for the $\mathrm{X} \mu \mathrm{CT}$, notably the cone-beam configuration with a 2D array detector (Figure 14), which is most commonly used. Other setups include the plane-parallel and the first generation single beam configuration (Zeitler and Gladden, 2009).

The second step is data reconstruction: the acquired 2D X $\mu \mathrm{CT}$ vertical images are computationally reconstructed to create 2D horizontal slices using the Feldkamp algorithm, which are stacked to create a $3 \mathrm{D}$ volume. Higher $\mathrm{X} \mu \mathrm{CT}$ resolution results in finer details, but requires additional processing memory and storage space. A key benefit of $\mathrm{X} \mu \mathrm{CT}$ is its non-destructive nature and that it does not require much sample preparation. Drawbacks include both lengthy measurements and image processing. Likewise, a small sample size is needed to avoid beam hardening, which occurs when the sample centre receives more exposure from high energy $\mathrm{X}$-ray beams. Low energy $\mathrm{X}$-ray beams are more easily absorbed and hence $\mathrm{X}$ ray attenuation for the benchtop polychromatic sources is not linear with density across the X-ray spectrum (Ho and Hutmacher, 2006). As with any imaging technique, pores smaller than the $\mathrm{X} \mu \mathrm{CT}$ resolution are not detected. The third step of $\mathrm{X} \mu \mathrm{CT}$ for porosity is image analysis: the 3D images must be segmented to differentiate pores from solid material, such that the pore parameters can be calculated. Finally, in the fourth step the calculated pore parameters need to be analysed, processed and usually presented graphically (see section 2). Depending on the raw data, the image might need to be cropped into a smaller subvolume, to enable the computer to process the data in a reasonable time frame. Since the spatial resolution is typically inversely proportional to the field of view (in particular for a cone-beam configuration), the acquired image size may be restricted to a subvolume of the entire dosage form given the high spatial resolution required to access pharmaceutically relevant pore characteristics. Consequently, the measurement results will depend on the spatial resolution as well as whether or not the selected subvolume is representative of the overall dosage form (Rouquerolt et al., 1994).

There are six main types of image segmentation techniques: histogram shape based, entropy based, spatial, clustering, object attribute and local methods (Sheikhveisi, 2015). lassonov et al., 2009 lament that despite recent advances in computed tomography technology, image segmentation technology lags behind. They criticise that many papers present binarised pore representations without explaining their image processing method. The most common approach is global thresholding: the image intensity histogram is split by a single cut-off value. A substantial review of different publications and their pore image segmentation was undertaken to identify the best processing method, with summarised findings in Table 4.

Specific challenges in image processing include the potentially large errors that are the result of performing the analysis on individual cross-sectional slices in $2 \mathrm{D}$ rather than $3 \mathrm{D}$ analysis, which creates directional bias and ignores geometrical information from planes directly above or below each 2D slice (lassonov et al., 2009; Kaestner et al., 2008). Another image processing artefact is the partial volume effect, where features smaller than one voxel become upscaled to one voxel (Pak et al., 2016). An XuCTspecific image processing problem are real ring artefacts, due to detector drift, and quasi-ring artefacts, due to inconsistent X-ray beam intensity (Antoine et al., 2002). Kaestner et al., 2008, note the importance of removing these before further processing. Additionally, if pore sizes span several orders of magnitude, images at different $\mathrm{X} \mu \mathrm{CT}$ resolutions need to be combined to create accurate, multi-scale pore network models (Pak et al., 2016). 
Table 4: Summary of some X $\mathrm{XCT}$ applications for the characterisation of porous materials. Information not given is indicated with 'N/A'. The references above and below the double line are related to applications across various different fields versus applications on solely pharmaceutical materials, respectively.

\begin{tabular}{|c|c|c|c|c|c|}
\hline Author & Date & $\begin{array}{l}\text { Measuring } \\
\text { technique }\end{array}$ & Material & Processing method & Software \\
\hline (Antoine et al., 2002) & 2002 & $\begin{array}{l}\text { Beamline ID22 of } \\
\text { the European } \\
\text { Synchrotron } \\
\text { Radiation Facility }\end{array}$ & 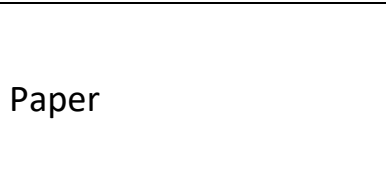 & Low pass filtering and region growing algorithm & N/A \\
\hline (lassonov et al., 2009) & 2009 & $\begin{array}{l}\text { Industrial HYTEC } \\
\text { Flat Panel } \\
\text { Amorphous Silicon } \\
\text { High-Resolution } \\
\text { Computed } \\
\text { Tomography } \\
\text { (FLASHCT }^{\mathrm{TM}} \text { ) } \\
\text { system }\end{array}$ & $\begin{array}{l}\text { Macro- porous soils, } \\
\text { sand-bentonite } \\
\text { mixtures, and precision } \\
\text { glass beads }\end{array}$ & $\begin{array}{l}\text { Compared performance of } 14 \text { algorithms: Otsu } \\
\text { and Ridler clustered global-thresholded best, as } \\
\text { well as locally adaptive thresholded }\end{array}$ & $\begin{array}{l}\text { Custom (MATLAB }{ }^{\text {TM }} \\
\text { and } \mathrm{C}++)\end{array}$ \\
\hline (Tolnai et al., 2009) & 2009 & $\begin{array}{l}\text { Beamline ID19 of } \\
\text { the European } \\
\text { Synchrotron } \\
\text { Radiation Facility }\end{array}$ & Al alloy & $\begin{array}{l}\text { Binary thresholding and region growing algorithm, } \\
\text { identifying volumes of three different phases }\end{array}$ & $\begin{array}{l}\text { Tomo 3D (Eötvös } \\
\text { Loránd University) }\end{array}$ \\
\hline (Yang et al., 2014) & 2010 & $\begin{array}{l}\text { SOMATOM } \\
\text { Sensation } \\
16 \text { (medical CT } \\
\text { scanner) }\end{array}$ & Copper sulphide ores & Otsu thresholding method & Custom (MATLAB ${ }^{\mathrm{TM}}$ ) \\
\hline (Fusseis et al., 2012) & 2012 & $\begin{array}{l}\text { Synchrotron } \\
\text { bending magnet } \\
\text { beam line 2-BM at } \\
\text { the Advanced } \\
\text { Photon Source }\end{array}$ & $\begin{array}{l}\text { Dehydrated } \\
\text { polycrystalline gypsum }\end{array}$ & Binary thresholding & $\begin{array}{l}\text { Commercial (Avizo } \\
\text { Fire) }\end{array}$ \\
\hline
\end{tabular}




\begin{tabular}{|c|c|c|c|c|c|}
\hline (Reh et al., 2012) & 2012 & $\begin{array}{l}\text { X-ray nanotom XCT } \\
\text { system (GE } \\
\text { Phoenix) }\end{array}$ & $\begin{array}{l}\text { Carbon fibre reinforced } \\
\text { polymers }\end{array}$ & $\begin{array}{l}\text { Anisotropic diffusion filter then Otsu's } \\
\text { thresholding algorithm }\end{array}$ & $\begin{array}{l}\text { Custom } \\
\text { (iAnalyse) }\end{array}$ \\
\hline (Korat et al., 2013) & 2013 & Xradia 400 & $\begin{array}{l}\text { Fired silica sludge/fly } \\
\text { ash foams }\end{array}$ & $\begin{array}{l}\text { Hysteresis thresholding, then filling holes function } \\
\text { and watershed algorithm }\end{array}$ & $\begin{array}{l}\text { Commercial (Avizo } \\
\text { Fire) }\end{array}$ \\
\hline (Jie Liu et al., 2014) & 2014 & & $\begin{array}{l}\text { Heterogeneous } \\
\text { carbonates }\end{array}$ & Indicator Kriging segmentation algorithm & N/A \\
\hline $\begin{array}{l}\text { (Suresh and Neethirajan, } \\
\text { 2015) }\end{array}$ & 2015 & $\begin{array}{l}\text { Bruker SkyScan } \\
1172\end{array}$ & Wheat kernels & Multithresholding techniques & $\begin{array}{l}\text { Commercial (Avizo } \\
\text { Fire) }\end{array}$ \\
\hline (Claes et al., 2016) & 2016 & $\begin{array}{l}\text { Siemens Somatom } \\
\text { scanner }\end{array}$ & $\begin{array}{l}\text { Carbonate reservoir } \\
\text { rocks }\end{array}$ & $\begin{array}{l}\text { Dual-thresholding hysteresis algorithm, then } \\
\text { watershed }\end{array}$ & N/A \\
\hline (Pak et al., 2016) & 2016 & $\begin{array}{l}\mu C T \text { instrument } \\
\text { built in-house at } \\
\text { the University of } \\
\text { Edinburgh }\end{array}$ & $\begin{array}{l}\text { Heterogeneous } \\
\text { carbonate rocks }\end{array}$ & $\begin{array}{l}\text { Anisotropic diffusion filter and watershed } \\
\text { algorithm }\end{array}$ & $\begin{array}{l}\text { Commercial (Avizo } \\
\text { Fire, v8) }\end{array}$ \\
\hline (Schmitt et al., 2016) & 2016 & $\begin{array}{l}\text { Nanotom 180S } \\
\text { instrument (GE } \\
\text { Sensing \& Inspec- } \\
\text { tion Technologies) }\end{array}$ & $\begin{array}{l}\text { German sandstone } \\
\text { rocks }\end{array}$ & Watershed algorithm & $\begin{array}{l}\text { Commercial (Avizo } \\
\text { Fire, v9.01) }\end{array}$ \\
\hline (Farber et al., 2003) & 2003 & SkyScan 1072 XRCT & $\begin{array}{l}\text { MCC granules with } \\
\text { either mannitol or } \\
\text { lactose }\end{array}$ & N/A & $\begin{array}{l}\text { Commercial } \\
\text { (Skyscan software } \\
\text { package and Image- } \\
\text { Pro) }\end{array}$ \\
\hline (Sinka et al., 2004) & 2004 & $\begin{array}{l}\text { Tomohawk CT by } \\
\text { AEA Technology }\end{array}$ & $\begin{array}{l}\text { Density distribution in } \\
\text { MCC tablets }\end{array}$ & $\begin{array}{l}\text { No image binarisation needed as X-ray attenuation } \\
\text { is linearly related to density }\end{array}$ & $\begin{array}{l}\text { Commercial } \\
\text { (Tomohawk CT } \\
\text { software) }\end{array}$ \\
\hline
\end{tabular}


(Busignies et al., 2006)

(Ansari and Stepanek, 2006)

(Ansari and Stepanek, 2008)

(Young et al., 2008)

(Rahmanian et al., 2009)

(Crean et al., 2010)

(Akseli et al., 2011)

(Sprunk et al., 2013)
Density profile of MCC compacts with ranging porosities

D-mannitol with polyethylene glycol (PEG$6000)$ granules

Mannitol with

polyethylene glycol

granules and sucrose

with poly-vinyl

pyrrolidone

Inert matrix tablets

(ferrous sulphate,

lactose and Eudragit)

Calcium carbonate and

polyethylene glycol

granules made in a high

shear granulator

$\alpha$-lactose monohydrate

granules with polyvinyl

pyrrolidone

Roller-compacted

ribbons

Indomethacin/sodium

dodecyl

sulfate/maltodextrin

dry foams
Median filter to reduce noise, then greyscale replaced with colour scale and normalisation to increase contrast

Image enhancement by thresholding, despeckling, filling holes, dilating, eroding and again filling holes if necessary

Image filtering and segmentation

Gaussian filter for background noise and then segmentation tool

\section{N/A}

Thresholding, pore and binder domains were measured using a structure thickness distribution

Thresholding used to remove beam-hardening artefacts, then statistical methods to relate average grayscale value to relative density of material

No data processing, only visualisation
N/A

Commercial

(ImageJ)

Commercial

(ImageJ)

Commercial

(Volume Graphics Studio Max)

Commercial (VG

Studio $\max$

software) and

Custom (Fortran)

Commercial

(SkyScan CTAn)

ImageJ and Custom

(MATLAB ${ }^{\text {TM}}$ )

Commercial

(SkyScan CTVox) 
(Wong et al., 2014)

(Robert et al., 2016)

(Dennison et al., 2016)

(Markl et al., 2017b)

(Markl et al., 2017c) 100
1172

Xradia NanoXCT-

Nikon Metrology X-Tek HMXST225

Bruker SkyScan

1172

Bruker SkyScan

1172

compartmental dosage

Bruker SkyScan

1172 raw (2-hydroxypropyl)beta-cyclodextrin, poly (lactic-co-glycolic) acid microparticles, and spray-dried particles that included smooth and nanomatrix bovine serum albumin, lipid-

based carriers, and

mannito

Porous polydimethylsiloxane block for drug delivery

Different droplet sizes of Kollicoat IR coating on model tablet

Functionalised calcium carbonate tablets

3D printed

forms made of

polyvinyl alcohol and

polylactic acid filaments

Phase separation

behaviour of solid

dispersions with

felodipine
Pore volumes, pore size distributions, and porosity of individual mannitol particles and single PLGA particles were obtained using watershed-based segmentation and thresholding limits to differentiate between the material and pores

\section{N/A}

Two methods: Bruker-MicroCT CT-Analyser porosity plugin for 5 farther $z$ slices and ImageJ Huang threshold and binarisation, with a ROI chosen to measure porous area fraction

Watershed algorithm

Watershed algorithm

Commercial (Avizo Fire)

(Volume Graphics Studio Max)

Bruker-MicroCT CTAnalyser and Image J

Commercial (Avizo Fire)

Commercial (Avizo Fire)

Commercial (CTan

Thresholding into binary images 
592

593

594

595

596

597

598

599

600

601

602

603

604

605

606

607

608

609

610

611

612

613

614

615

616

617

618

619

620

621

622

623

624

625

626

627

The final stage is quantifying the image processing error - which is infrequently done in the literature. Chityala et al., 2013 applied different segmentation algorithms to the same dataset and compared their performances. Fusseis et al., 2012 used another approach, dilating and shrinking the pore data set by \pm 1 voxels, their estimated error, and then calculating error bounds of pore parameters. Schmitt et al., 2016 calculated the same parameters with different subvolume sizes to evaluate how representative each subvolume is of the whole sample. Error from noise can be quantified by segmenting the image with and without a denoising filter and calculating the number of voxels whose classification (pore or solid) has changed (lassonov et al., 2009).

$\mathrm{X} \mu \mathrm{CT}$ is helpful in pharmaceutical applications to capture both the open and closed porosity, for both finished tablets and intermediate materials (e.g. granules). The first use of $X \mu C T$ in this field dates back to 1999. Since then improvements in resolution have been achieved. A large challenge is thresholding the acquired images, as contrast in the form of density (greyscale) differences between tablet excipient and pores is not always clear-cut. Impregnation of the porous samples with labelling solutions, such as lead containing solutions, can help to increase contrast. Furthermore, $\mathrm{X} \mu \mathrm{CT}$ has also been used in situ to track the development of voids in a tablet during dissolution (Karakosta et al., 2006). One compromise that needs to be reached is achieving both high resolution and a large field of view with the $\mathrm{X} \mu \mathrm{CT}$, as both are critical to understand tablet microstructure (Takeda and Hamada, 2014). The large benefit of X $\mu C T$ as an imaging method for measuring porosity is the ability to visualise pore networks and calculate pore specific parameters as detailed in section 2. Markl et al., 2017b took advantage of this to create pore distribution plots according to the orientation angle $\theta$ of each pore (relative to eigenvector $\boldsymbol{v}_{1}$ ). Furthermore, results from the X $\mathrm{XCT}$ images can be related to other physical properties, once they are measured with other techniques. Likewise, specific parts of the tablet can be isolated and inspected further, as they might differ with respect to pore properties and other parameters. For example, Takeda and Hamada, 2014 isolated the tablet coating of antihypertensive tablets, with a high resolution nano3DX machine.

The microstructure as elucidated by $\mathrm{X} \mu \mathrm{CT}$ can be linked to both physical characteristics such as density, as well as computer models. This was done by Ansari and Stepanek, 2008 with mannitol-PEG and sucrosePVP granules. Moreno-Atanasio, Williams and Jia, 2010 performed a review of computer simulations coupled to $\mathrm{X} \mu \mathrm{CT}$ measurements. At a basic level, $\mathrm{X} \mu \mathrm{CT}$ can help to validate computer models. Features such as pore surface area, coordination number and particle shape can be used to relate both approaches. One area which presents a challenge is the dynamic state relationship between $\mathrm{X} \mu \mathrm{CT}$ and computer simulations (Moreno-Atanasio et al., 2010). X $\mathrm{CCT}$ can also be used on its own, without excessive image processing and hence more uncertainties. In this application, $\mathrm{X} \mu \mathrm{CT}$ attenuation is related to sample density to create tablet density representations. As long as the reference density points for linear interpolation of the $\mathrm{X} \mu \mathrm{CT}$ greyscale are accurate, and an appropriate noise smoothing filter is used, this method is insightful. Both Busignies et al., 2006 and Sinka et al., 2004, used this approach to understand tablet compaction behaviour.

\section{Terahertz Time-Domain Spectroscopy}

\subsection{Measurement of Total Porosity}

Terahertz radiation generally refers to the electromagnetic radiation in the frequency range of $0.1-4 \mathrm{THz}$. Advancements in femtosecond lasers have enabled the coherent generation and detection of terahertz radiation, which have made it possible to readily perform terahertz spectroscopy in a laboratory setting. Although terahertz imaging and spectroscopy can be performed in a reflection and a transmission setting, the porosity is typically analysed from terahertz transmission measurements.

In contrast to conventional far-infrared spectroscopy, the terahertz measurements involve the generation and detection of pulses of terahertz radiation that are transmitted through a tablet. Given that this is a time-domain technique, both the amplitude and phase changes of the transmitted pulse relative to the incident pulse are measured. The incident pulse is henceforth referred to as the reference waveform, which is acquired when no sample is present in the measurement chamber. The phase information is of 
640

641

642

643

644

645

646

647

648

649

650

651

652

653

654

655

656

657

658

659

660

661

662

663

particular importance for determining the porosity from terahertz measurements: the analysis of the porosity of solid dosage forms is performed by measuring the time delay difference $\Delta t$ between the sample waveform and the reference waveform, i.e. $\Delta t=T_{\mathrm{S}}-T_{\mathrm{R}}$ (Figure 15). In general, $\Delta t$ of a terahertz pulse propagating through a sample depends on the effective refractive index, $n_{\text {eff }}$, as well as the sample thickness, $L$. The value of $n_{\text {eff }}$ can be readily calculated from the pulse delay time by $n_{\text {eff }}=\Delta t \cdot c / L+1$, where $c$ is the speed of light in vacuum. This straight-forward analysis is based on the time-domain data and results in a single effective refractive index value per tablet sample. Since the phase and amplitude of the transmitted terahertz pulse are measured directly, it is furthermore possible to calculate the frequency-dependent refractive index and absorption coefficient of a sample. The frequency-domain analysis of the refractive index may provide additional information about the sample, such as specific phonon vibrations due to a crystalline constituent (e.g. the drug) in the sample (Zeitler, 2016). Such spectral features cause relatively strong dispersion and the refractive index thus undergoes substantial changes at the frequencies of these features. It is of great importance for the accuracy of the porosity calculations that the refractive index is evaluated at the same frequency for measurements of different samples as well as that it is chosen at a frequency which is not affected by the spectral features, i.e. spectral regions where the refractive index remains constant with frequency. Figure 16 depicts examples of effective refractive index values measured for both simple and complex formulations over a range of excipients. The data clearly indicates that the effective refractive indices are linearly dependent on the porosity.

When the formulation of a tablet is kept constant, any variations in $n_{\mathrm{eff}}$ are exclusively due to changes in the porosity or density of the sample. This refractive index-porosity relationship can thus be exploited to calculate the porosity of a solid dosage form from terahertz transmission measurements, either by establishing a simple linear model, namely the zero porosity approximation (ZPA), or by applying effective medium theory (EMT) to relate the measured effective refractive index to the porosity of the sample.

\subsection{Using Terahertz Scattering to Determine Domain Size}

The ZPA and EMT models are defined on the basis of the assumption that scattering of terahertz radiation from a tablet is negligible. This is a sensible assumption for a large number of cases given the relatively long wavelength of terahertz radiation ( $75 \mu \mathrm{m}$ to $3 \mathrm{~mm}$ with maximum intensity at a wavelength of 300 $\mu \mathrm{m})$. If scattering is present, the frequency-dependent effective refractive index of the tablet can be used to study the terahertz response with the aid of Kramers-Kronig relations (Silfsten et al., 2011; Tuononen et al., 2010b). One could, therefore, calculate the porosity based on the effective refractive index of a tablet, and in a separate analysis use the frequency-dependent optical constants together with KramersKronig analysis to check the presence of scattering, and hence the accuracy of the porosity estimate. Moreover, the scattering effect has proven useful to measure additional properties of the sample, such as the 'domain size' of agglomerated granules in a powder compact. Markl et al., 2017a proposed that this 'domain size' is related to the size of the disintegrated particles. It is thus a descriptor for the performance of the dissolution process as it reflects changes in the effective surface area of the disintegrated particles. The authors demonstrated this concept for a complex immediate-release formulation (M04 in Figure 16), where they showed that a 'domain size'-related parameter is strongly correlated to the amount of API dissolved after $20 \mathrm{~min}\left(R^{2}=0.96\right)$. In the specific example, the tablets were all fully disintegrated at $15 \mathrm{~min}$ and the early phase dissolution performance following disintegration is driven by the size of the resulting particles (i.e. by the effective surface area of the disintegrated particles). The authors also showed that the disintegration performance (disintegration time and API

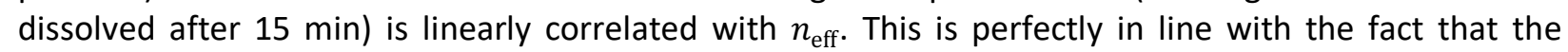
disintegration behaviour of immediate-release tablets is controlled by their porosity/density, which can be directly related to $n_{\text {eff }}$ using the ZPA or EMT models.

\subsection{Pore Shape Analysis}

EMT is a general approach to describe macroscopic properties of composite materials which enables the definition of averages that are representative of the medium in question (Choy, 2016). One of the most 
689

690

691

692

693

694

695

696

697

698

699

700

701

702

703

704

705

706

707

708

709

710

711

712

713

714

715

716

717

718

719

720

721

722

723

724

725

726

727

728

common EMTs are the Maxwell-Garnett and the Bruggeman formula (Choy, 2016). Since the MaxwellGarnett approximation is only valid for samples with a small void space and the Bruggeman theory can be applied to study media with a wide range of void fractions, the latter formalism is mostly used for characterising pharmaceutical samples (Bawuah et al., 2014; Markl et al., 2017b). The basic assumption behind the Bruggeman model is that air voids are embedded in a medium. It is, therefore, possible to consider pores that are embedded in a solid matrix, which consists of a mixture of different excipient and API particles. Such a construct resembles a two-phase system and the concepts developed for a simple formulation (i.e. only one constituent) can be readily applied to multi-component systems. The refractive index of the matrix (dependent on the API and the excipients) can be estimated from terahertz measurements of tablets compacted to different porosities. In general, the refractive indices of the API and the excipients can be determined separately by compressing these into compacts and performing terahertz transmission measurements.

The traditional Bruggeman formalism assumes a spherical shape of the air inclusions in a porous sample and it leads to a systematic error if the actual shape of the pores strongly deviates from a sphere. The interparticle pore space is formed during the compaction and the shape of the pores may depend on the compression force. This was demonstrated for different sets of pure FCC tablets with porosities ranging from $45 \%$ to $65 \%$ (Markl et al., 2017b). The authors showed that the interparticle pores of the FCC compacts are anisotropic in shape and highly aligned. Using an anisotropic Bruggeman model, it was possible to establish that the pores are needle-like in shape and oriented perpendicular to the compaction direction. The porosity determined by applying the anisotropic Bruggeman model yielded a very high correlation coefficient $\left(R^{2}=0.995\right)$ with the porosity calculated from the measured true density (using helium pycnometry) and the bulk density of the tablets (Figure 17).

\subsection{Anisotropy of Pore Structure}

Building on the well-established mathematical formulae of EMTs and optical-mechanical models (Table 4), the Wiener bounds provide an estimate of the upper and lower limits of the effective refractive index if there is no information about the shape of the pores and solid particles. For the special case of spherical pores and solid particles, more stringent limits can be found with the aid of Hashin-Shtrikman bounds, which are, however, only valid for two-phase systems. Both bounds are based on a priori knowledge of the refractive index of the constituents. These can be estimated using the concept of ZPA, which involves the use of a linear extrapolation approach on the obtained effective refractive index from the terahertz measurements.

Based on the Wiener bounds it is possible to quantify the overall degree of anisotropy of a porous structure. Bawuah et al., 2016a introduced the concept of a structural parameter to describe the alignment of pores relative to the solid material in a tablet. This $S$ parameter is capable to reflect differences in the pore structure for samples of the same overall porosity. This concept was developed further in order to characterise structural changes of samples of varying porosities (Markl et al., 2018a). This $S_{a}$ parameter revealed that material attributes, such as particle size or granule density, strongly impact the anisotropy of the pore structure. The degree of anisotropy particularly influences the tortuosity and constrictivity of the structure and eventually the disintegration performance of the tablet (Markl et al., 2018b).

\subsection{Link to Mechanical Properties}

The optical compressibility, which can be obtained with the aid of the effective refractive index, is an example how terahertz measurements can yield characteristic parameters that are related to mechanical properties of the porous tablet. The name "optical compressibility" is adopted to reflect the use of the effective refractive index in the calculation of the compressibility. This is in reference to the use of the relative volume change in response to the applied pressure when calculating the mechanical compressibility (Chakraborty et al., 2017). 
Besides the compressibility, it is also of high interest for the pharmaceutical industry to non-destructively characterise other mechanical properties of a tablet, e.g. the accurate estimation of the effective values of the strain and hence, the Young's modulus. Several methodologies including ultrasonic techniques have been used to obtain the effective elastic moduli of pharmaceutical tablets (Akseli and Cetinkaya, 2008; Akseli et al., 2010; Bassam et al., 1990; Hancock, 2000; Ketolainen et al., 1995; Liu and Cetinkaya, 2010; Liu et al., 2011; Porion et al., 2010; Roberts et al., 1991). Since the Young's modulus has an explicit dependence on the porosity, Mazel et al., 2012, and Palomäki et al., 2015, have devised an experimental technique to measure the porosity dependent Young's modulus of pharmaceutical compacts. In a related study, Peiponen et al., 2015, have estimated the porosity dependent Young's modulus according to Spriggs' and Mooney's relations using the measured terahertz time-domain pulse transmitted through starch acetate tablets. Application of Spriggs law, however, yielded a non-zero Young's modulus at $100 \%$ porosity, which is physically impossible. This inconsistency was addressed by invoking the Mooney's relation. Table 5 presents these "hybrid" optical/mechanical models, i.e. both optical and mechanical parameters are present, where the constants $b$ and $B$ refer to conventional mechanical properties and the porosity $f$ is obtained with the aid of the effective refractive index of the tablet. Now, based on the definition of the optical compressibility, in this review article, we propose a pure optical version of Spriggs' law that can be put into an interesting form as follows: $E(f)=E_{0} e^{-b\left(1-\frac{\beta_{\mathrm{THz}}(0)}{\beta_{\mathrm{THz}}(f)}\right)}$, where the exponent consists of a ratio of optical compressibility at zero-porosity, $\beta_{\mathrm{THz}}(0)$, and at porosity $f, \beta_{\mathrm{THz}}(f)$, of the tablet. A similar expression can be derived for an optical Mooney's relation. Moreover, the terahertz measurements can also be used to non-destructively and non-invasively predict the conventional strain of pharmaceutical tablets (Bawuah et al., 2016c). This optical strain concept is capable of providing fast predictions of the mechanical integrity of tablets.

The properties and models in Table 5 were developed for and applied to terahertz transmission measurements. However, for industrial implementations and imaging applications it could be preferable to perform terahertz measurements in a reflection setting (Zeitler et al., 2007). Besides this spatiallyresolved information, the terahertz reflection signal can also be utilised to extract the effective refractive index (Jepsen et al., 2007), which can in turn be used to predict pore structural and mechanical properties (Table 5) in the same manner as for terahertz transmission measurements. The determination of the refractive index from reflection data is, however, much more prone to errors, which limits the accuracy of these measurements (X. Chen et al., 2017). However, reflection measurements can provide additional information about the surface roughness of a pharmaceutical solid dosage form. The amplitude of the reflected terahertz pulse of a solid sample is correlated to the surface roughness (Dikmelik et al., 2006; Jagannathan et al., 2009; Mou et al., 2017), which has been demonstrated for different pharmaceutical materials (Chakraborty et al., 2016; Markl et al., 2017b). 
Table 5: Summary of various properties of porous pharmaceutical tablets calculated from THz-TDS measurements. More details about most of the materials can be found in the supporting information according to the code in the brackets in the column marked Materials. IM: indomethacin; SA: potato starch acetate; FF: flat-faced tablet; BC: biconvex tablet; $n_{i}$ : intrinsic refractive index of component $i ; x_{i}$ : mass fraction of component $i$ (the mass fraction is $x_{1}=1-f$ in case of the two component models); $\varepsilon_{\text {mech }}$ : mechanical strain; $\lambda$ : depolarisation factor.

\begin{tabular}{|c|c|c|c|c|c|c|}
\hline Property & Model & $\begin{array}{l}\text { Comp- } \\
\text { onents }\end{array}$ & Equation & Materials & Shape & Reference \\
\hline \multirow[t]{2}{*}{ Porosity } & \multirow[t]{2}{*}{$\begin{array}{l}\text { Zero porosity } \\
\text { approximation }\end{array}$} & 2 & $f=\frac{n_{\mathrm{eff}}-n_{1}}{1-n_{1}}$ & $\begin{array}{l}\text { MCC } \\
\text { SA (M02) } \\
\text { MCC } \\
\text { MCC } \\
\text { MCC + IM (M03) } \\
\text { FCC (M01) }\end{array}$ & $\begin{array}{l}\mathrm{FF} \\
\mathrm{FF} \\
\mathrm{BC} \\
\mathrm{FF} \\
\mathrm{FF} \\
\mathrm{FF}\end{array}$ & $\begin{array}{l}\text { (Ervasti et al., 2012) } \\
\text { (Peiponen et al., 2015) } \\
\text { (Bawuah et al., 2016b) } \\
\text { (Ridgway et al., 2017) } \\
\text { (Bawuah et al., 2016c) } \\
\text { (Markl et al., 2017b) }\end{array}$ \\
\hline & & 3 & $f=\frac{n_{1}-\left(n_{1}-n_{2}\right) x_{2}-n_{\mathrm{eff}}}{n_{1}-1}$ & $\begin{array}{l}\mathrm{MCC}+\mathrm{IM}(\mathrm{M} 03) \\
\mathrm{MCC}+\mathrm{IM}(\mathrm{M} 03)\end{array}$ & $\begin{array}{l}\mathrm{FF} \\
\mathrm{FF}\end{array}$ & $\begin{array}{l}\text { (Bawuah et al., 2016c) } \\
\text { (Chakraborty et al., 2017) }\end{array}$ \\
\hline \multirow[t]{2}{*}{ Porosity } & $\begin{array}{l}\text { Bruggeman } \\
\text { model }\end{array}$ & 2 & $\begin{array}{c}\frac{n_{1}^{2}-n_{\mathrm{eff}}^{2}}{n_{\mathrm{eff}}^{2}+2\left(n_{1}^{2}-n_{\mathrm{eff}}^{2}\right)}(1-f)+\frac{1-n_{\mathrm{eff}}^{2}}{n_{\mathrm{eff}}^{2}+2\left(1-n_{\mathrm{eff}}^{2}\right)} f=0 \\
f=\frac{1}{1-\left(\left(1-n_{\mathrm{eff}}^{2}\right) /\left(1+2 n_{\mathrm{eff}}^{2}\right)\right)\left(\left(n_{1}^{2}+2 n_{\mathrm{eff}}^{2}\right) /\left(n_{1}^{2}-n_{\mathrm{eff}}^{2}\right)\right)}\end{array}$ & $\begin{array}{l}\text { MCC } \\
\text { FCC (M01) }\end{array}$ & $\begin{array}{l}\mathrm{FF} \\
\mathrm{FF}\end{array}$ & $\begin{array}{l}\text { (Bawuah et al., 2014) } \\
\text { (Markl et al., 2017b) }\end{array}$ \\
\hline & $\begin{array}{l}\text { Anisotropic } \\
\text { Bruggeman } \\
\text { model }\end{array}$ & 2 & $\begin{array}{c}\frac{n_{1}^{2}-n_{\mathrm{eff}}^{2}}{n_{\mathrm{eff}}^{2}+\lambda\left(n_{1}^{2}-n_{\mathrm{eff}}^{2}\right)}(1-f)+\frac{1-n_{\mathrm{eff}}^{2}}{n_{\mathrm{eff}}^{2}+\lambda\left(1-n_{\mathrm{eff}}^{2}\right)} f=0 \\
f=\frac{1}{1-\left(\left(1-n_{\mathrm{eff}}^{2}\right) /\left(1+\lambda n_{\mathrm{eff}}^{2}\right)\right)\left(\left(n_{1}^{2}+\lambda n_{\mathrm{eff}}^{2}\right) /\left(n_{1}^{2}-n_{\mathrm{eff}}^{2}\right)\right)}\end{array}$ & $\begin{array}{l}\text { FCC (M01) } \\
\text { Complex } \\
\text { formulation } \\
\text { (M04) }\end{array}$ & $\begin{array}{l}\mathrm{FF} \\
\mathrm{BC}\end{array}$ & (Markl et al., 2017b) \\
\hline $\begin{array}{l}\text { Structural } \\
\text { parameter }\end{array}$ & $S$ parameter & $\mathrm{J}$ & $\begin{array}{l}\qquad S=\frac{1}{n_{U}^{2}+n_{L}^{2}}\left[\frac{n_{U}^{2} n_{L}^{2}}{n_{\mathrm{eff}}^{2}}-n_{L}^{2}\right] \\
\text { with } n_{U} \text { and } n_{L} \text { as the upper and lowee Wiener bound. }\end{array}$ & $\begin{array}{l}\text { MCC } \\
M C C+I M(M 03) \\
M C C+I M(M 03)\end{array}$ & $\begin{array}{l}\mathrm{FF} \\
\mathrm{FF} \\
\mathrm{FF}\end{array}$ & $\begin{array}{l}\text { (Bawuah et al., 2016a) } \\
\text { (Bawuah et al., 2016a) } \\
\text { (Chakraborty et al., 2017) }\end{array}$ \\
\hline
\end{tabular}




\begin{tabular}{|c|c|c|c|c|c|c|}
\hline & & & & FCC (M01) & $\mathrm{FF}$ & (Markl et al., 2017b) \\
\hline & $\begin{array}{l}\text { Alternative } \\
\text { S parameter }\end{array}$ & $\mathrm{J}$ & $\begin{array}{l}\qquad S_{a}=\left\{\begin{array}{c}0.5\left(1-\frac{n_{L}^{2}\left(n_{\text {ideal }}^{2}-n_{\text {eff }}^{2}\right)}{n_{\text {eff }}^{2}\left(n_{\text {ideal }}^{2}-n_{\mathrm{L}}^{2}\right)}\right) \\
0.5\left(1-\frac{n_{\text {eff }}^{2}-n_{\text {ideal }}^{2}}{n_{U}^{2}-n_{\text {ideal }}^{2}}\right)\end{array}\right. \\
\text { with } n_{U} \text { and } n_{L} \text { as the upper and lower Wiener bound. } n_{\text {ideal }} \text { is } \\
\text { calculated using either ZPA or an EMT model with a known } \\
\text { porosity. }\end{array}$ & $\begin{array}{l}\text { MCC + IM (M03) } \\
\text { FCC (M01) } \\
\text { Complex } \\
\text { formulation } \\
\text { (M04) }\end{array}$ & $\begin{array}{l}\mathrm{FF} \\
\mathrm{FF} \\
\mathrm{BC}\end{array}$ & (Markl et al., 2018a). \\
\hline \multirow[t]{2}{*}{ Bounds } & $\begin{array}{l}\text { Wiener } \\
\text { bounds }\end{array}$ & J & $\begin{array}{l}n_{U}=\sqrt{f+\sum_{j=1}^{J} x_{j} n_{j}^{2}} \\
n_{L}=\frac{1}{\sqrt{f+\sum_{j=1}^{J} \frac{x_{j}}{n_{j}^{2}}}}\end{array}$ & $\begin{array}{l}\mathrm{MCC}+\mathrm{IM}(\mathrm{M} 03) \\
\mathrm{SA}(\mathrm{M} 02)\end{array}$ & $\begin{array}{l}\mathrm{FF} \\
\mathrm{FF}\end{array}$ & $\begin{array}{l}\text { (Bawuah et al., 2016a) } \\
\text { (Tuononen et al., 2010a) }\end{array}$ \\
\hline & $\begin{array}{l}\text { Hashin- } \\
\text { Shtrikman }\end{array}$ & 2 & $\begin{array}{c}n_{U}=\sqrt{n_{1}^{2}+\frac{f}{\frac{1}{1-n_{1}^{2}}+\frac{1-f}{3 n_{1}^{2}}}} \\
n_{L}=\sqrt{1+\frac{1-f}{\frac{1}{n_{1}^{2}-1}+\frac{f}{3}}}\end{array}$ & $\begin{array}{l}\text { MCC } \\
\text { SA (M02) }\end{array}$ & $\begin{array}{l}\mathrm{FF} \\
\mathrm{FF}\end{array}$ & $\begin{array}{l}\text { (Bawuah and Peiponen, 2016) } \\
\text { (Bawuah and Peiponen, 2016) }\end{array}$ \\
\hline Optical strain & & $\mathrm{J}$ & $\begin{array}{c}\varepsilon_{\mathrm{THz}}=\ln \left(\frac{1-f}{1-f_{0}}\right)+\varepsilon_{\mathrm{mech}} \\
\varepsilon_{\mathrm{THz}}=\ln \left(\frac{\Delta t}{\Delta t_{0}}\right)=\ln \left(\frac{n_{\mathrm{eff}}-1}{n_{\mathrm{eff}, 0}-1}\right)+\epsilon_{\mathrm{mech}}\end{array}$ & $\mathrm{MCC}+\mathrm{IM}(\mathrm{M} 03)$ & $\mathrm{FF}$ & (Bawuah et al., 2016c) \\
\hline $\begin{array}{l}\text { Optical } \\
\text { compressibility }\end{array}$ & & 3 & $\beta_{\mathrm{THz}}=\frac{1}{n_{\mathrm{eff}}-1}$ & $\mathrm{MCC}+\mathrm{IM}(\mathrm{M} 03)$ & $\mathrm{FF}$ & (Chakraborty et al., 2017) \\
\hline
\end{tabular}




\begin{tabular}{|l|l|l|c|l|l|l|}
\hline & & & $\beta_{\mathrm{THz}}=\frac{1}{\left(n_{1}-1\right)(1-f)-\left(n_{1}-n_{2}\right) x_{2}}$ & & \\
\hline $\begin{array}{l}\text { Young's } \\
\text { modulus }\end{array}$ & Spriggs' law & $\mathrm{J}$ & $E_{\mathrm{THz}}=E_{0} e^{-b f}$ & $\mathrm{SA}$ (M02( & FF & (Peiponen et al., 2015) \\
& $\begin{array}{l}\text { Mooney's } \\
\text { relation }\end{array}$ & $\mathrm{J}$ & $E_{\mathrm{THz}}=E_{0} e^{-b\left(1-\frac{\beta_{\mathrm{THz}}(0)}{\beta_{\mathrm{THz}}(f)}\right)}$ & SA (M02) & FF & (Peiponen et al., 2015) \\
\cline { 2 - 6 } & $E_{\mathrm{THz}}=E_{0} e^{-\frac{f}{1-f}}$ & & \\
\hline
\end{tabular}




\section{Discussion}

The five methods presented in this review vary considerably in terms of speed, accessible information as well as sample preparation. An overview of the key characteristics of the five methods is provided in Table 6.

Mercury porosimetry and helium pycnometry are well-established methods to determine bulk properties of a porous sample. The advances in terahertz and X-ray technologies over the last decades provide scientists with new tools to characterise the microstructure of pharmaceutical solid dosage forms. In comparison with the other techniques, one of the main advantages of THz-TDS and X $\mu \mathrm{CT}$ are that they are non-destructive and contactless measurements. This is particularly important when wishing to use different techniques on the same sample or to perform measurements before and after a treatment of a sample. The high acquisition rate of THz-TDS is additionally beneficial for quality control as it facilitates the investigation of several samples within a few seconds. It has, therefore, potential to be applied atline, on-line or even in-line in a production environment to control dosage form porosity in real-time. This would particularly impact the realisation of real-time release testing for immediate-release formulations, where the porosity is one of the most important contributors to the performance of a tablet.

THz-TDS, however, does not yield a pore size distribution and it may be limited by the sample thickness due to strongly absorbing materials. Even though the determination of the porosity by THz-TDS has been demonstrated for biconvex tablets with a thickness of up to $5.3 \mathrm{~mm}$ (M04 in Figure 16), the penetration depth may be shorter for tablets containing materials that exhibit a stronger absorption of terahertz radiation. THz-TDS only provides information on bulk properties and cannot resolve local structural changes, but this is possible with $\mathrm{X} \mu \mathrm{CT}$. Although $\mathrm{X}$-rays can penetrate typical pharmaceutical materials easily, the contrast between voids and solid material can be very low. This can cause issues when processing the images to extract quantitative information as the voids cannot be unambiguously separated from the solid phase, which can result in erroneous structural parameters. Furthermore, the spatial resolution of $\mathrm{X} \mu \mathrm{CT}$ limits the size of detectable pores and voids smaller than the resolution limit will be considered as solid material. For a highly-porous sample, a cluster of fine pores ( $\ll$ resolution limit) may be misclassified as one single large pore. This can result in an overestimation of larger pores by X $\mu \mathrm{CT}$, which helps explaining discrepancies with results obtained from mercury porosimetry where every single pore size is registered separately (Markl et al., 2017b). However, the pore shielding effect in mercury porosimetry may result in an overestimation of fine pores. The nonwetting mercury is forced through fine pores connecting larger pores (see Figure 9), which results in an overestimation of the small pores and at the same time an underestimation of the intrusion volume of the large pores (Gane et al., 2004). This effect impacts the pore size distribution (Farber et al., 2003), but it does not affect the measurement of the overall porosity of the measured sample. However, a small systematic error in the overall porosity can be due to a slight compression of the compact before actual intrusion occurs.

Bulk properties from THz-TDS and $\mathrm{X} \mu \mathrm{CT}$ may also deviate from those obtained using helium pycnometry and mercury porosimetry, since these techniques can only access open pores. In the majority of cases pharmaceutical tablets consist of a highly connected pore structures resulting in a small number of closed pores and therefore, porosity values from the different techniques are typically in good agreement (Figure 17 and Figure 18). A particularly good correlation can be observed between the porosities calculated from THz-TDS and helium pycnometry as shown in Figure $17\left(R^{2}=0.995\right)$ and in Figure $18 \mathrm{~b}\left(R^{2}=1\right)$ for FCC and $\mathrm{MCC} /$ indomethacin tablets, respectively. However, helium pycnometry may overestimate true density values due to the presence of water molecules in the pore space. The calculation of the skeletal volume is then affected by the release of water during the measurement as it assumes a constant number of gas molecules (Sun, 2004). As an example, this phenomenon has to be considered when determining the true density of MCC, as discussed by Sun (Sun, 2005). It has been demonstrated that the walls of the measurement chamber and the surface of the sample may adsorb and absorb small amounts of helium, which causes an overestimation of the true density of the porous material (Keller and Staudt, 2006). 
824 Strange et al., 2003, demonstrated that the pore size distributions from NMR cryoporometry of different silica samples are in very good agreement with those from gas adsorption and DSC thermoporometry. Gane et al., 2004, investigated how mercury intrusion porosimetry, NMR-based cryoporometry, and DSCbased thermoporometry compared in revealing the porous characteristics of ground calcium carbonate structures compacted over a range of pressures. These methods place the samples in nearly the same mutual order with either very similar cumulative pore volume curves (mercury porosimetry and DSC thermoporometry) or similar pore size distribution curves, as determined by the change of pore volume with respect to the change of pore radius by $\mathrm{d} V / \mathrm{d} R$, (mercury porosimetry and NMR). The pore size distribution from NMR cryoporometry may be shifted toward smaller pores in cases where air bubbles are entrapped in larger pores. These air bubbles restrict the liquid from flowing into the larger pores during the imbibition process and NMR cryoporometry then overestimates smaller pore sizes.

Many studies in the literature present data from different techniques that are in excellent agreement. However, this might only be valid for a specific material and range of pore sizes. As an example, thermoand cryoporometric methods may mask some artefacts for smaller pores as they exhibit larger changes in melting points (Gane et al., 2004). Moreover, samples may differ in terms of interconnectivity and pore wall curvature, which particularly influence the results from methods that are based on the imbibition of a liquid. It is therefore of great importance to know the limitations of each technique when interpreting the results, especially for materials that deviate from idealised model systems.

\section{Conclusion}

Developing a better understanding of the relationship between the raw materials, process settings, properties of intermediate products and the performance of the finished product requires highly sophisticated techniques to determine key properties of the material at each stage. This cannot be solved by one single technique, but it requires the use of the most appropriate method to determine critical material and quality attributes. We hope that this review has provided an insight into the basic working principles, the capabilities as well as the limitations and pitfalls of each technique. 
Table 6: Key characteristics of the helium pycnometry, mercury porosimetry, NMR, THz-TDS and X $\mu \mathrm{CT}$.

\begin{tabular}{|c|c|c|c|c|c|}
\hline & Helium pycnometry & Mercury porosimetry & NMR & THz-TDS & $\mathrm{X \mu CT}$ \\
\hline . & $\begin{array}{l}\text { Depending on the number of } \\
\text { purges performed, typically } \\
3 \text { minutes per measurement } \\
\text { for data acquisition and } \\
\text { processing. }\end{array}$ & $\begin{array}{l}\text { Depending on the number } \\
\text { of data points and } \\
\text { equilibration time }-1 \text { to } 3 \\
\text { hours. }\end{array}$ & $\begin{array}{l}\text { Depending on the } \\
\text { spatial resolution }-0.5 \\
\text { to } 1 \text { hour }\end{array}$ & Can be as short as a $100 \mathrm{~ms}$. & $\begin{array}{l}\text { Depending on sample size } \\
\text { and desired resolution, } \\
\text { scanning takes minimum } \\
\sim 30 \text { minutes and up to } \\
\text { several hours. }\end{array}$ \\
\hline 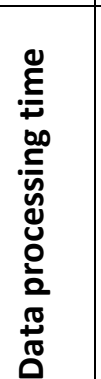 & $\begin{array}{l}\text { Data can be analysed in } \\
\text { under } 1 \text { minute. }\end{array}$ & $\begin{array}{l}\text { Corrections for mercury } \\
\text { compression and } \\
\text { penetrometer expansion are } \\
\text { applied, the elastic response } \\
\text { of the sample skeletal } \\
\text { material can be derived at } \\
\text { highest pressures (Gane et } \\
\text { al., 1996) - } 10 \text { min. }\end{array}$ & $\begin{array}{l}\text { Data can be analysed in } \\
\text { under } 1 \text { minute. }\end{array}$ & $\begin{array}{l}\text { Data analysis takes }<1 \mathrm{~s} \text { per } \\
\text { measurement. }\end{array}$ & $\begin{array}{l}\text { Data reconstruction into a } \\
2 \mathrm{D} \text { image stack takes } 10-15 \\
\text { minutes for a large region of } \\
\text { interest (depending on } \\
\text { computer processing power } \\
\text { and memory), with further } \\
\text { image segmentation steps } \\
\text { taking several hours. }\end{array}$ \\
\hline
\end{tabular}




\begin{tabular}{|c|c|c|c|c|c|}
\hline 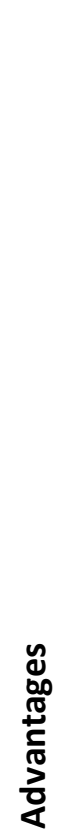 & $\begin{array}{l}\text { - Very accurate technique. } \\
\text { - Fairly short data acquisition } \\
\text { and processing times, } \\
\text { straightforward data } \\
\text { analysis. } \\
\text { - Minimal sample } \\
\text { preparation is needed. }\end{array}$ & $\begin{array}{l}\text { - Wide range of pore size } \\
\text { distribution. } \\
\text { - Total specific pore volume. } \\
\text { - Bulk modulus value (elastic } \\
\text { compression of skeletal } \\
\text { material). } \\
\text { - Bulk density. } \\
\text {-Skeletal density. }\end{array}$ & $\begin{array}{l}\text { - Accesses micropores. } \\
\text { - Information about } \\
\text { surface-to-volume ratio } \\
\text { and tortuosity. }\end{array}$ & $\begin{array}{l}\text { - Very fast, potential for } \\
\text { process analytics (at-line, } \\
\text { on-line or even in-line } \\
\text { application). } \\
\text { - Provides a measure of } \\
\text { open and closed pores. } \\
\text { - Non-invasive, non- } \\
\text { destructive and contactless } \\
\text { measurement. }\end{array}$ & $\begin{array}{l}\text { - Wide range of data is } \\
\text { available, from porosity to } \\
\text { pore size distribution, pore } \\
\text { shape and anisotropy etc. } \\
\text { - Visual representation of } \\
\text { the pore network is } \\
\text { obtained at high resolution } \\
\text { (up to } 1 \mu \mathrm{m} \text { ). Different scale } \\
\text { models can be combined to } \\
\text { create a multiscale network. } \\
\text { - Minimal sample } \\
\text { preparation is needed. } \\
\text { - Provides a measure of } \\
\text { open and closed pores. } \\
\text { - Non-invasive, non- } \\
\text { destructive and contactless. }\end{array}$ \\
\hline
\end{tabular}




\begin{tabular}{|c|c|c|c|c|c|}
\hline & $\begin{array}{l}\text { - Gives limited information } \\
\text { on the nature of the sample, } \\
\text { namely just the true density } \\
\text { and overall porosity. } \\
\text { - Some materials which give } \\
\text { off volatiles might be } \\
\text { unsuitable for the technique, } \\
\text { or require corrections, even } \\
\text { after degassing. } \\
\text { - Must be performed at } \\
\text { constant temperature for } \\
\text { ideal gas law to be valid, and } \\
\text { high enough pressure needs } \\
\text { to be applied for helium to } \\
\text { penetrate all the voids. } \\
\text { - Absorption and/or } \\
\text { adsorption of a small } \\
\text { amount of helium in/on the } \\
\text { solid material may cause a } \\
\text { measurement error. } \\
\text { - Accesses only open pores. }\end{array}$ & $\begin{array}{l}\text { - Destructive measurement. } \\
\text { - Need for special sample } \\
\text { disposal. } \\
\text { - Accesses only open pores. }\end{array}$ & $\begin{array}{l}\text { - Damage of pore } \\
\text { structure by liquid and } \\
\text { freezing. } \\
\text { - Destructive } \\
\text { measurement for } \\
\text { typical pharmaceutical } \\
\text { solid dosage forms. } \\
\text { - Accesses only open } \\
\text { pores. }\end{array}$ & $\begin{array}{l}\text { - A model relating the } \\
\text { measured effective } \\
\text { refractive index to the } \\
\text { porosity has to be } \\
\text { developed. } \\
\text { - Sample needs to be } \\
\text { positioned (in particular for } \\
\text { biconvex tablets) precisely. } \\
\text { - Strong absorption of } \\
\text { terahertz radiation by the } \\
\text { formulation may limit the } \\
\text { tablet thickness. } \\
\text { - Cannot access pore size } \\
\text { distribution. } \\
\text { - Sample volume is limited } \\
\text { by the spot size of the } \\
\text { terahertz beam (typically } \\
\text { between } 1 \text { - } 2 \text { mm in } \\
\text { diameter). }\end{array}$ & $\begin{array}{l}\text { - Lengthy data acquisition } \\
\text { and analysis times. } \\
\text { - Image segmentation can } \\
\text { prove difficult depending on } \\
\text { the sample. Large datasets } \\
\text { may cause computer } \\
\text { software to crash. } \\
\text { Automating the task relieves } \\
\text { time burden. } \\
\text { - Managing the large } \\
\text { amount of data and } \\
\text { selecting the best } \\
\text { parameters for each sample } \\
\text { type can be challenging. } \\
\text { - Sample size is limited by } \\
\text { the X XCT machine size. }\end{array}$ \\
\hline
\end{tabular}




\section{ACKNOWLEDGEMENTS}

J.B. and J.R. would like to acknowledge the Danish Council for Independent Research (DFF), Technology and Production Sciences (FTP), Project 12-126515/0602-02670B (2013-2017). Additional data related to this publication are available at the Cambridge University repository (https://www.repository.cam.ac.uk/handle/xxxx).

\section{REFERENCES}

Akseli, I., Cetinkaya, C., 2008. Air-coupled non-contact mechanical property determination of drug tablets. International Journal of Pharmaceutics 359, 25-34. doi:10.1016/j.ijpharm.2008.03.020

Akseli, I., Dey, D., Cetinkaya, C., 2010. Mechanical Property Characterization of Bilayered Tablets using Nondestructive Air-Coupled Acoustics. AAPS PharmSciTech 11, 90-102. doi:10.1208/s12249-0099352-9

Akseli, I., Hancock, B.C., Cetinkaya, C., 2009. Non-destructive determination of anisotropic mechanical properties of pharmaceutical solid dosage forms. International Journal of Pharmaceutics 377, 3544. doi:10.1016/j.ijpharm.2009.04.040

Akseli, I., Iyer, S., Lee, H.P., Cuitiño, A.M., 2011. A Quantitative Correlation of the Effect of Density Distributions in Roller-Compacted Ribbons on the Mechanical Properties of Tablets Using Ultrasonics and X-ray Tomography. AAPS PharmSciTech 12, 834-853. doi:10.1208/s12249-0119640-z

Alderborn, G., Duberg, M., Nyström, C., 1985. Studies on direct compression of tablets X. Measurement of tablet surface area by permeametry. Powder Technology 41, 49-56. doi:10.1016/00325910(85)85074-9

Alhijjaj, M., Yassin, S., Reading, M., Zeitler, J.A., Belton, P., Qi, S., 2017. Characterization of Heterogeneity and Spatial Distribution of Phases in Complex Solid Dispersions by Thermal Analysis by Structural Characterization and X-ray Micro Computed Tomography. Pharmaceutical Research 34, 971-989. doi:10.1007/s11095-016-1923-3

Alkhatib, H.S., Hamed, S., Mohammad, M.K., Bustanji, Y., Alkhalidi, B., Aiedeh, K.M., Najjar, S., 2010. Effects of Thermal Curing Conditions on Drug Release from Polyvinyl Acetate-Polyvinyl Pyrrolidone Matrices. AAPS PharmSciTech 11, 253-266. doi:10.1208/s12249-010-9378-z

Allen, S.G., Stephenson, P.C.L., Strange, J.H., 1998. Internal surfaces of porous media studied by nuclear magnetic resonance cryoporometry. The Journal of Chemical Physics 108, 8195-8198. doi:10.1063/1.476175

Alles $\varnothing$, M., Holm, R., Holm, P., 2016. Roller compaction scale-up using roll width as scale factor and laser-based determined ribbon porosity as critical material attribute. European Journal of Pharmaceutical Sciences 87, 69-78. doi:10.1016/j.ejps.2015.11.001

Alnaimi, S.M., Strange, J.H., Smith, E.G., 1994. The characterization of porous solids by NMR. Magnetic Resonance Imaging 12, 257-259. doi:10.1016/0730-725x(94)91531-8

Andersson, H., Hjärtstam, J., Stading, M., Corswant, von, C., Larsson, A., 2013. Effects of molecular weight on permeability and microstructure of mixed ethyl-hydroxypropyl-cellulose films. European Journal of Pharmaceutical Sciences 48, 240-248. doi:10.1016/j.ejps.2012.11.003

Anovitz, L.M., Cole, D.R., 2015. Characterization and Analysis of Porosity and Pore Structures. Reviews in Mineralogy and Geochemistry 80, 61-164. doi:10.2138/rmg.2015.80.04

Ansari, M.A., Stepanek, F., 2008. The effect of granule microstructure on dissolution rate. Powder Technology 181, 104-114. doi:10.1016/j.powtec.2006.12.012

Ansari, M.A., Stepanek, F., 2006. Formation of hollow core granules by fluid bed in situ melt granulation: Modelling and experiments. International Journal of Pharmaceutics 321, 108-116. doi:10.1016/j.ijpharm.2006.05.012

Antoine, C., Nygård, P., Gregersen, Ø.W., Holmstad, R., Weitkamp, T., Rau, C., 2002. 3D images of paper obtained by phase-contrast X-ray microtomography: Image quality and binarisation. Nuclear 
Instruments and Methods in Physics Research A 490, 392-402. doi:10.1016/S0168-9002(02)01003-3

Aprecia Pharmaceuticals Company. Making Medicine Using 3D Printing. https://www.spritam.com/\#/patient/zipdose-technology/making-medicine-using-3d-printing (accessed 02/01/2017).

Axelsson, M., Svensson, S., 2010. 3D pore structure characterisation of paper. Pattern Analysis and Applications 13, 159-172. doi:10.1007/s10044-009-0146-1

Barman, S., Bolin, D., 2017. A three-dimensional statistical model for imaged microstructures of porous polymer films. Journal of Microscopy 16, 691. doi:10.1111/jmi.12623

Bassam, F., York, P., Rowe, R.C., Roberts, R.J., 1990. Young's modulus of powders used as pharmaceutical excipients. International Journal of Pharmaceutics 64, 55-60. doi:10.1016/03785173(90)90178-7

Bawuah, P., Chakraborty, M., Ervasti, T., Zeitler, J.A., Ketolainen, J., Gane, P.A.C., Peiponen, K.-E., 2016a. A structure parameter for porous pharmaceutical tablets obtained with the aid of Wiener bounds for effective permittivity and terahertz time-delay measurement. International Journal of Pharmaceutics 506, 87-92. doi:10.1016/j.ijpharm.2016.04.026

Bawuah, P., Ervasti, T., Tan, N., Zeitler, J.A., Ketolainen, J., Peiponen, K.-E., 2016b. Noninvasive porosity measurement of biconvex tablets using terahertz pulses. International Journal of Pharmaceutics 509, 439-443. doi:10.1016/j.ijpharm.2016.06.023

Bawuah, P., Peiponen, K.-E., 2016. A terahertz time-domain study on the estimation of opto-mechanical properties of pharmaceutical tablets using the Hashin-Shtrikman bounds for refractive index: a case study of microcrystalline cellulose and starch acetate compacts. Optical Review 23, 502-509. doi:10.1007/s10043-016-0198-6

Bawuah, P., Pierotic Mendia, A., Silfsten, P., Pääkkönen, P., Ervasti, T., Ketolainen, J., Zeitler, J.A., Peiponen, K.-E., 2014. Detection of porosity of pharmaceutical compacts by terahertz radiation transmission and light reflection measurement techniques. International Journal of Pharmaceutics 465, 70-76. doi:10.1016/j.ijpharm.2014.02.011

Bawuah, P., Tan, N., Tweneboah, S.N.A., Ervasti, T., Zeitler, J.A., Ketolainen, J., Peiponen, K.-E., 2016c. Terahertz study on porosity and mass fraction of active pharmaceutical ingredient of pharmaceutical tablets. European Journal of Pharmaceutics and Biopharmaceutics 105, 122-133. doi:10.1016/j.ejpb.2016.06.007

Bellamy, L.J., Nordon, A., Littlejohn, D., 2008. Effects of particle size and cohesive properties on mixing studied by non-contact NIR. International Journal of Pharmaceutics 361, 87-91. doi:10.1016/j.ijpharm.2008.05.030

Ben Clennell, M., 1997. Tortuosity: a guide through the maze. Geological Society, London, Special Publications 122, 299-344. doi:10.1144/GSL.SP.1997.122.01.18

Blott, S.J., Pye, K., 2008. Particle shape: A review and new methods of characterization and classification. Sedimentology 55, 31-63. doi:10.1111/j.1365-3091.2007.00892.x

Boissier, C., Feidt, F., Nordstierna, L., 2012. Study of Pharmaceutical Coatings by Means of NMR Cryoporometry and Sem Image Analysis. Journal of Pharmaceutical Sciences 101, 2512-2522. doi:10.1002/jps.23160

Bosanquet, C.H., 1923. LV. On the flow of liquids into capillary tubes. Philosophical Magazine Series 645 , 525-531. doi:10.1080/14786442308634144

Boudreau, B.P., 1996. The diffusive tortuosity of fine-grained unlithified sediments. Geochimica et Cosmochimica Acta 60, 3139-3142. doi:10.1016/0016-7037(96)00158-5

Boudreau, B.P., Meysman, F.J.R., 2006. Predicted tortuosity of muds. Geology 34, 693-696. doi:10.1130/G22771.1

Brown, R.W., Cheng, Y.C.N., Haacke, E.M., Thompson, M.R., Venkatesan, R., 2014. Magnetic Resonance Imaging, Second Edition. ed. John Wiley \& Sons. doi:10.1002/9781118633953

Busignies, V., Leclerc, B., Porion, P., Evesque, P., 2006. Quantitative measurements of localized density variations in cylindrical tablets using $\mathrm{X}$-ray microtomography. European Journal of Pharmaceutics and Biopharmaceutics 64, 38-50. doi:10.1016/j.ejpb.2006.02.007 
Cai, J., Yu, B., 2011. A Discussion of the Effect of Tortuosity on the Capillary Imbibition in Porous Media. Transport in Porous Media 89, 251-263. doi:10.1007/s11242-011-9767-0

Callaghan, P.T., 1993. Principles of Nuclear Magnetic Resonance Microscopy. Oxford University Press.

Carli, F., Motta, A., 1984. Particle size and surface area distributions of pharmaceutical powders by microcomputerized mercury porosimetry. Journal of Pharmaceutical Sciences 73, 197-203. doi:10.1002/jps.2600730213

Carstensen, J.T., Chan, P.-C., 1976. Relation between particle size and repose angles of powders. Powder Technology 15, 129-131. doi:10.1016/0032-5910(76)80037-X

Chakraborty, M., Bawuah, P., Tan, N., Ervasti, T., Pääkkönen, P., Zeitler, J.A., Ketolainen, J., Peiponen, K.E., 2016. On the Correlation of Effective Terahertz Refractive Index and Average Surface Roughness of Pharmaceutical Tablets. Journal of Infrared, Millimiter and Terahertz Waves 37, 776-785. doi:10.1007/s10762-016-0262-0

Chakraborty, M., Ridgway, C., Bawuah, P., Markl, D., Gane, P.A.C., Ketolainen, J., Zeitler, J.A., Peiponen, K.-E., 2017. Optics-based compressibility parameter for pharmaceutical tablets obtained with the aid of the terahertz refractive index. International Journal of Pharmaceutics 525, 85-91. doi:10.1016/j.ijpharm.2017.03.093

Chattoraj, S., Sun, C.C., 2018. Crystal and particle engineering strategies for improving powder compression and flow properties to enable continuous tablet manufacturing by direct compression. Journal of Pharmaceutical Sciences. doi:10.1016/j.xphs.2017.11.023

Chen, C., Gladden, L.F., Mantle, M.D., 2014. Direct Visualization of in VitroDrug Mobilization from Lescol XL Tablets Using Two-Dimensional $19 \mathrm{~F}$ and $1 \mathrm{H}$ Magnetic Resonance Imaging. Molecular Pharmaceutics 11, 630-637. doi:10.1021/mp400407c

Chen, X., Parrott, E.P.J., Ung, B.S.Y., Pickwell-MacPherson, E., 2017. A Robust Baseline and Reference Modification and Acquisition Algorithm for Accurate THz Imaging. IEEE Transactions on Terahertz Science and Technology 7, 493-501. doi:10.1109/tthz.2017.2722981

Chen, Y.Y., Hughes, L.P., Gladden, L.F., Mantle, M.D., 2010. Quantitative Ultra-Fast MRI of HPMC Swelling and Dissolution. Journal of Pharmaceutical Sciences 99, 3462-3472. doi:10.1002/jps.22110

Chityala, R., Pudipeddi, S., Arensten, L., Hui, S., 2013. Segmentation and visualization of a large, highresolution micro-ct data of mice. Journal of Digital Imaging 26, 302-308. doi:10.1007/s10278-0129498-y

Choy, T.C., 2016. Effective Medium Theory. Oxford University Press.

Claes, S., Soete, J., Cnudde, V., Swennen, R., 2016. A three-dimensional classification for mathematical pore shape description in complex carbonate reservoir rocks. Mathematical Geosciences 48, 619639. doi:10.1007/s11004-016-9636-z

Clarkson, C.R., Freeman, M., He, L., Agamalian, M., Melnichenko, Y.B., Mastalerz, M., Bustin, R.M., Radliński, A.P., Blach, T.P., 2012. Characterization of tight gas reservoir pore structure using USANS/SANS and gas adsorption analysis. Fuel 95, 371-385. doi:10.1016/j.fuel.2011.12.010

Collins, J.H.P., Gladden, L.F., Hardy, I.J., Mantle, M.D., 2007. Characterizing the Evolution of Porosity during Controlled Drug Release. Appl Magn Reson 32, 185-204. doi:10.1007/s00723-007-0008-1

Comiti, J., Renaud, M., 1989. A new model for determining mean structure parameters of fixed beds from pressure drop measurements: application to beds packed with parallelepipedal particles. Chemical Engineering Science 44, 1539-1545. doi:10.1016/0009-2509(89)80031-4

Costa, A., 2006. Permeability-porosity relationship: A reexamination of the Kozeny-Carman equation based on a fractal pore-space geometry assumption. Geophysical Research Letters 33, 261. doi:10.1029/2005GL025134

Crean, B., Parker, A., Le Roux, D., Perkins, M., Luk, S.Y., Banks, S.R., Melia, C.D., Roberts, C.J., 2010. Elucidation of the internal physical and chemical microstructure of pharmaceutical granules using $X-$ ray micro-computed tomography, Raman microscopy and infrared spectroscopy. European Journal of Pharmaceutics and Biopharmaceutics 76, 498-506. doi:10.1016/j.ejpb.2010.08.006

Dees, P.J., 1980. The Mechanism of Tablet Disintegration. State University of Leiden, Leiden.

Dees, P.J., Polderman, J., 1981. Mercury porosimetry in pharmaceutical technology. Powder Technology 
29, 187-197. doi:10.1016/0032-5910(81)85016-4

Desai, P.M., Liew, C.V., Heng, P.W.S., 2016. Review of Disintegrants and the Disintegration Phenomena. Journal of Pharmaceutical Sciences 105, 2545-2555. doi:10.1016/j.xphs.2015.12.019

Dennison, T.J., Smith, J., Hofmann, M.P., Bland, C.E., Badhan, R.K., Al-Khattawi, A., Mohammed, A.R., 2016. Design of experiments to study the impact of process parameters on droplet size and development of non-invasive imaging techniques in tablet coating. PLoS ONE 11, 1-17. doi:10.1371/journal.pone.0157267

Dikmelik, Y., Spicer, J.B., Fitch, M.J., Osiander, R., 2006. Effects of surface roughness on reflection spectra obtained by terahertz time-domain spectroscopy. Optical Letter 31, 3653-3655. doi:10.1364/OL.31.003653

Drach, B., Drach, A., Tsukrov, I., 2013. Characterization and statistical modeling of irregular porosity in carbon/carbon composites based on X-ray microtomography data. ZAMM Zeitschrift fur Angewandte Mathematik und Mechanik 93, 346-366. doi:10.1002/zamm.201100190

Duberg, M., Nyström, C., 1986. Studies on direct compression of tablets XVII. Porosity-pressure curves for the characterization of volume reduction mechanisms in powder compression. Powder Technology 46, 67-75. doi: 10.1016/0032-5910(86)80100-0

Dullien, F.A.L., 1992. Porous Media, Second. ed. Academic Press Inc.

Eddleston, M.D., Bithell, E.G., Jones, W., 2010. Transmission Electron Microscopy of Pharmaceutical Materials. Journal of Pharmaceutical Sciences 99, 4072-4083. doi:10.1002/jps.22220

Edge, S., Steele, D.F., Tobyn, M.J., Staniforth, J.N., Chen, A., 2001. Directional Bonding in Compacted Microcrystalline Cellulose. Drug Development and Industrial Pharmacy 27, 613-621. doi:10.1081/DDC-100107317

Ervasti, T., Silfsten, P., Ketolainen, J., Peiponen, K.-E., 2012. A Study on the Resolution of a Terahertz Spectrometer for the Assessment of the Porosity of Pharmaceutical Tablets 66, 319-323. doi:10.1366/11-06315

Farber, L., Tardos, G., Michaels, J.N., 2003. Use of X-ray tomography to study the porosity and morphology of granules. Powder Technology 132, 57-63. doi:10.1016/S0032-5910(03)00043-3

Faroongsarng, D., Peck, G.E., 2003. Thermal porosity analysis of croscarmellose sodium and sodium starch glycolate by differential scanning calorimetry. AAPS PharmSciTech 4, 531-538. doi:10.1208/pt040467

Ferrero, C., Jiménez-Castellanos, M.R., 2002. The influence of carbohydrate nature and drying methods on the compaction properties and pore structure of new methyl methacrylate copolymers. International Journal of Pharmaceutics 248, 157-171. doi:10.1016/s0378-5173(02)00432-5

Fina, F., Goyanes, A., Gaisford, S., Basit, A.W., 2017. Selective laser sintering (SLS) 3D printing of medicines. International Journal of Pharmaceutics 529, 285-293. doi:10.1016/j.ijpharm.2017.06.082

Freitag, F., Reincke, K., Runge, J., Grellmann, W., Kleinebudde, P., 2004. How do roll compaction/dry granulation affect the tableting behaviour of inorganic materials? European Journal of Pharmaceutical Sciences 22, 325-333. doi:10.1016/j.ejps.2004.04.001

Fusseis, F., Schrank, C., Liu, J., Karrech, A., Llana-Funez, S., Xiao, X., Regenauer-Lieb, K., 2012. Pore formation during dehydration of a polycrystalline gypsum sample observed and quantified in a time-series synchrotron X-ray micro-tomography experiment. Solid Earth 3, 71-86. doi:10.5194/se3-71-2012

Gabaude, C.M.D., Gautier, J.C., Saudemon, P., Chulia, D., 2001. Validation of a new pertinent packing coefficient to estimate flow properties of pharmaceutical powders at a very early development stage, by comparison with mercury intrusion and classical flowability methods. Journal of Materials Science 36, 1763-1773. doi:10.1023/A:1017528809955

Gabbott, I.P., Husban, Al, F., Reynolds, G.K., 2016. The combined effect of wet granulation process parameters and dried granule moisture content on tablet quality attributes. European Journal of Pharmaceutics and Biopharmaceutics 106, 70-78. doi:10.1016/j.ejpb.2016.03.022

Ganderton, D., Hunter, B.M., 1971. A comparison of granules prepared by pan granulation and by 
massing and screening. Journal of Pharmacy and Pharmacology 23, 1S-10S. doi:10.1111/j.20427158.1971.tb08762.x

Gane, P.A.C., Kettle, J.P., Matthews, G.P., Ridgway, C.J., 1996. Void Space Structure of Compressible Polymer Spheres and Consolidated Calcium Carbonate Paper-Coating Formulations. Industrial \& Engineering Chemistry Research, 35 (5), 1753-1764.

Gane, P.A.C., Ridgway, C.J., Lehtinen, E., Valiullin, R., Furó, I., Schoelkopf, J., Paulapuro, H., Daicic, J., 2004. Comparison of NMR Cryoporometry, Mercury Intrusion Porosimetry, and DSC Thermoporosimetry in Characterizing Pore Size Distributions of Compressed Finely Ground Calcium Carbonate Structures. Industrial \& Engineering Chemistry Research 43, 7920-7927. doi:10.1021/ie049448p

Ghanbarian, B., Hunt, A.G., Ewing, R.P., Sahimi, M., 2013. Tortuosity in Porous Media: A Critical Review. Soil Science Society of America Journal 77, 1461-1477. doi:10.2136/sssaj2012.0435

Goyanes, A., Martinez, P.R., Buanz, A., Basit, A.W., Gaisford, S., 2015a. Effect of geometry on drug release from 3D printed tablets. International Journal of Pharmaceutics 494, 657-663. doi:10.1016/j.ijpharm.2015.04.069

Goyanes, A., Wang, J., Buanz, A., Martínez-Pacheco, R., Telford, R., Gaisford, S., Basit, A.W., 2015b. 3D Printing of Medicines: Engineering Novel Oral Devices with Unique Design and Drug Release Characteristics. Molecular Pharmaceutics 12, 4077-4084. doi:10.1021/acs.molpharmaceut.5b00510

Guerin, E., Tchoreloff, P., Leclerc, B., Tanguy, D., Deleuil, M., Couarraze, G., 1999. Rheological characterization of pharmaceutical powders using tap testing, shear cell and mercury porosimeter. International Journal of Pharmaceutics 189, 91-103. doi:10.1016/S0378-5173(99)00243-4

Gutierrez, R.F., Requena, G., Stauder, B., 2014. 3D-Characterization of AlCu5Mg0.3Mn0.3 and AlCu7Mn0.4 Alloys, in:. Presented at the iCT Conference, pp. 141-147.

Hancock, B., 2000. Micro-scale measurement of the mechanical properties of compressed pharmaceutical powders. 1: The elasticity and fracture behavior of microcrystalline cellulose. International Journal of Pharmaceutics 209, 27-35. doi:10.1016/s0378-5173(00)00541-x

Hart, A., 2015. Effect of Particle Size on Detergent Powders Flowability and Tabletability. Journal of Chemical Engineering \& Process Technology 6. doi:10.4172/2157-7048.1000215

Häbel, H., Andersson, H., Olsson, A., Olsson, E., Larsson, A., Särkkä, A., 2016. Characterization of pore structure of polymer blended films used for controlled drug release. Journal of Controlled Release 222, 151-158. doi:10.1016/j.jconrel.2015.12.011

Häbel, H., Rajala, T., Marucci, M., Boissier, C., Schladitz, K., Redenbach, C., Särkkä, A., 2017. A threedimensional anisotropic point process characterization for pharmaceutical coatings. Spatial Statistics. doi:10.1016/j.spasta.2017.05.003

Heng, D., Tang, P., Cairney, J.M., Chan, H.-K., Cutler, D.J., Salama, R., Yun, J., 2007. Focused-ion-beam milling: A movel approach to probing the interior of particles used for inhalation aerosols. Pharmaceutical Research 24, 1608-1617. doi:10.1007/s11095-007-9276-6

Hirschberg, C., Sun, C.C., Rantanen, J., 2016. Analytical method development for powder characterization: Visualization of the critical drug loading affecting the processability of a formulation for direct compression. Journal of Pharmaceutical and Biomedical Analysis 128, 462468. doi:10.1016/j.jpba.2016.06.014

Ho, S.T., Hutmacher, D.W., 2006. A comparison of micro CT with other techniques used in the characterization of scaffolds. Biomaterials 27, 1362-1376. doi:10.1016/j.biomaterials.2005.08.035

Holdich, R., 2002. Fundamentals of Particle Technology, Natural Science. Midland Information Technology and Publishing, Loughborough. ISBN: 0954388100

lassonov, P., Gebrenegus, T., Tuller, M., 2009. Segmentation of X-ray computed tomography images of porous materials: A crucial step for characterization and quantitative analysis of pore structures. Water Resources Research 45, 1-12. doi:10.1029/2009WR008087

Iza, M., Woerly, S., Danumah, C., Kaliaguine, S., Bousmina, M., 2000. Determination of pore size distribution for mesoporous materials and polymeric gels by means of DSC measurements: thermoporometry. Polymer 41, 5885-5893. doi:10.1016/S0032-3861(99)00776-4 
1104

1105

1106

1107

1108

1109

1110

1111

1112

1113

1114

1115

1116

1117

1118

1119

1120

1121

1122

1123

1124

1125

1126

1127

1128

1129

1130

1131

1132

1133

1134

1135

1136

1137

1138

1139

1140

1141

1142

1143

1144

1145

1146

1147

1148

1149

1150

1151

1152

1153

1154

Jagannathan, A., Gatesman, A.J., Giles, R.H., 2009. Characterization of roughness parameters of metallic surfaces using terahertz reflection spectra. Optical Letter 34, 1927-. doi:10.1364/OL.34.001927

Jepsen, P.U., Møller, U., Merbold, H., 2007. Investigation of aqueous alcohol and sugar solutions with reflection terahertz time-domain spectroscopy. Optical Express 15, 14717. doi:10.1364/oe.15.014717

Jerram, D.A., Higgins, M.D., 2007. 3D Analysis of Rock Textures: Quantifying igneous microstructures. Elements 3, 239-245. doi:10.2113/gselements.3.4.239

Jerram, D.A., Kent, A.J.R., 2006. An overview of modern trends in petrography: Textural and microanalysis of igneous rocks. Journal of Volcanology and Geothermal Research 154, vii-ix. doi:10.1016/j.jvolgeores.2005.09.026

Johansson, B., Wikberg, M., Ek, R., Alderborn, G., 1995. Compression behaviour and compactability of microcrystalline cellulose pellets in relationship to their pore structure and mechanical properties. International Journal of Pharmaceutics 117, 57-73. doi:10.1016/0378-5173(94)00295-G

Julbe, A., Ramsay, J.D.F., 1996. Methods for the characterisation of porous structure in membrane materials, in: Burggraaf, A.J., Cot, L. (Eds.), Fundamentals of Inorganic Membrane Science and Technology. Elsevier Science, pp. 67-118.

Juppo, A.M., 1996. Porosity parameters of lactose, glucose and mannitol tablets obtained by mercury porosimetry. International Journal of Pharmaceutics 129, 1-12. doi:10.1016/0378-5173(95)04201-6

Juppo, A.M., Hellén, L., Pullinen-Strander, V., Kalsta, K., Yliruusi, J., Kristoffersson, E., 1997. Application of mercury porosimetry in evaluation of extrusion-spheronisation process. European Journal of Pharmaceutics and Biopharmaceutics 44, 205-214. doi:10.1016/S0939-6411(97)00090-8

Kaestner, A., Lehmann, E., Stampanoni, M., 2008. Imaging and image processing in porous media research. Advances in Water Resources 31, 1174-1187. doi:10.1016/j.advwatres.2008.01.022

Karakosta, E., Jenneson, P.M., Sear, R.P., McDonald, P.J., 2006. Observations of coarsening of air voids in a polymer-highly-soluble crystalline matrix during dissolution. Physical Review E 74, 1479. doi:10.1103/physreve.74.011504

Katstra, W.E., Palazzolo, R.D., Rowe, R.C., Giritlioglu, B., Teung, P., Cima, M.J., 2000. Oral dosage forms fabricated by Three Dimensional Printing. Journal of Controlled Release 66, 1-9. doi:10.1016/S0168-3659(99)00225-4

Keller, J.U., Staudt, R., 2006. Gas Adsorption Equilibria. Springer Science \& Business Media.

Ketolainen, J., Oksanen, M., Rantala, J., Stor-Pellinen, J., Luukkala, M., Paronen, P., 1995. Photoacoustic evaluation of elasticity and integrity of pharmaceutical tablets. International Journal of Pharmaceutics 125, 45-53. doi:10.1016/0378-5173(95)00110-5

Khaled, S.A., Burley, J.C., Alexander, M.R., Yang, J., Roberts, C.J., 2015. 3D printing of five-in-one dose combination polypill with defined immediate and sustained release profiles. Journal of Controlled Release 217, 308-314. doi:10.1016/j.jconrel.2015.09.028

Khomane, K.S., Bansal, A.K., 2013. Effect of particle size on in-die and out-of-die compaction behavior of ranitidine hydrochloride polymorphs. AAPS PharmSciTech 14, 1169-1177. doi:10.1208/s12249-0130008-4

Khorasani, M., Amigo, J.M., Sonnergaard, J., Olsen, P., Bertelsen, P., Rantanen, J., 2015a. Visualization and prediction of porosity in roller compacted ribbons with near-infrared chemical imaging (NIR-Cl). Journal of Pharmaceutical and Biomedical Analysis 109, 11-17. doi:10.1016/j.jpba.2015.02.008

Khorasani, M., Amigo, J.M., Sun, C.C., Bertelsen, P., Rantanen, J., 2015b. Near-infrared chemical imaging (NIR-Cl) as a process monitoring solution for a production line of roll compaction and tableting. European Journal of Pharmaceutics and Biopharmaceutics 93, 293-302. doi:10.1016/j.ejpb.2015.04.008

Klaja, J., Przelaskowska, A., 2015. Helium porosity measurements for rocks from unconventional reservoirs performed on crushed samples. Nafta-Gaz 71, 856-863. doi:10.18668/NG2015.11.07

Korat, L., Ducman, V., Legat, A., Mirtič, B., 2013. Characterisation of the pore-forming process in lightweight aggregate based on silica sludge by means of $\mathrm{X}$-ray micro-tomography (micro-CT) and mercury intrusion porosimetry (MIP). Ceramics International 39, 6997-7005. 
doi:10.1016/j.ceramint.2013.02.037

Krupa, A., Jachowicz, R., Pędzich, Z., Wodnicka, K., 2012. The influence of the API properties on the ODTs manufacturing from co-processed excipient systems. AAPS PharmSciTech 13, 1120-1129. doi:10.1208/s12249-012-9831-2

Lam, K.K., Newton, J.M., 1992. Influence of particle size on the adhesion behaviour of powders, after application of an initial press-on force. Powder Technology 73, 117-125. doi:10.1016/00325910(92)80072-5

Leane, M., Pitt, K., Reynolds, G., The Manufacturing Classification System (MCS) Working Group, 2015. A proposal for a drug product Manufacturing Classification System (MCS) for oral solid dosage forms. Pharmaceutical Development and Technology 20, 12-21. doi:10.3109/10837450.2014.954728

Levitt, M.H., 2008. Spin Dynamics, Second Edition. ed. John Wiley \& Sons.

Liu, Jie, Pereira, G.G., Regenauer-Lieb, K., 2014. From characterisation of pore-structures to simulations of pore-scale fluid flow and the upscaling of permeability using microtomography: A case study of heterogeneous carbonates. Journal of Geochemical Exploration 144, 84-96. doi:10.1016/j.gexplo.2014.01.021

Liu, Cetinkaya, C., 2010. Mechanical and geometric property characterization of dry-coated tablets with contact ultrasonic techniques. International Journal of Pharmaceutics 392, 148-155. doi:10.1016/j.ijpharm.2010.03.060

Liu, Stephens, J.D., Kowalczyk, B.R., Cetinkaya, C., 2011. Real-time in-die compaction monitoring of drycoated tablets. International Journal of Pharmaceutics 414, 171-178. doi:10.1016/j.ijpharm.2011.05.029

Lowell, S., Shields, J.E., Thomas, M.A., Thommes, M., 2004. Density Measurement, in: Characterization of porous solids and powders: Surface area, Pore size and density, Particle Technology Series. Springer Netherlands, Dordrecht, pp. 326-338. doi:10.1007/978-1-4020-2303-3

Luukkonen, P., Maloney, T., Rantanen, J., Paulapuro, H., Yliruusi, J., 2001. Microcrystalline cellulosewater interaction-A novel approach using thermoporosimetry. Pharmaceutical Research 18, 15621569. doi:10.1023/A:1013030414555

Mantle, M.D., 2016. Magnetic resonance imaging and its applications to solid pharmaceutical dosage forms, in: Müllertz, A., Perrie, Y., Rades, T. (Eds.), Analytical Techniques in the Pharmaceutical Sciences, Advances in Delivery Science and Technology. Springer New York, New York, NY, pp. 591628. doi:10.1007/978-1-4939-4029-5_18

Mantle, M.D., 2013. NMR and MRI studies of drug delivery systems. Current Opinion in Colloid \& Interface Science 18, 214-227. doi:10.1016/j.cocis.2013.03.006

Mantle, M.D., 2011. Quantitative magnetic resonance micro-imaging methods for pharmaceutical research. International Journal of Pharmaceutics 417, 173-195. doi:10.1016/j.ijpharm.2010.11.035

Markl, D., Bawuah, P., Ridgway, C., van den Ban, S., Goodwin, D.J., Ketolainen, J., Gane, P., Peiponen, K.E., Zeitler, J.A., Zeitler, J.A., 2018a. Fast and Non-destructive Pore Structure Analysis using Terahertz Time-Domain Spectroscopy. International Journal of Pharmaceutics 537, 102-110. doi: 10.1016/j.ijpharm.2017.12.029

Markl, D., Sauerwein, J., Goodwin, D.J., van den Ban, S., Zeitler, J.A., 2017a. Non-destructive determination of disintegration time and dissolution in immediate release tablets by terahertz transmission measurements. Pharmaceutical Research 34, 1012-1022. doi:10.1007/s11095-0172108-4

Markl, D., Wang, P., Ridgway, C., Karttunen, A.-P., Chakraborty, M., Bawuah, P., Pääkkönen, P., Gane, P., Ketolainen, J., Peiponen, K.-E., Zeitler, J.A., 2017b. Characterization of the pore structure of functionalized calcium carbonate tablets by terahertz time-domain spectroscopy and X-ray computed microtomography. Journal of Pharmaceutical Sciences 106, 1586-1595. doi:10.1016/j.xphs.2017.02.028

Markl, D., Zeitler, J.A., 2017. A review of disintegration mechanisms and measurement techniques. Pharmaceutical Research 34, 890-917. doi:10.1007/s11095-017-2129-z

Markl, D., Zeitler, J.A., Rasch, C., Michaelsen, M.H., Müllertz, A., Rantanen, J., Rades, T., Bøtker, J., 
2017c. Analysis of 3D prints by X-ray computed microtomography and terahertz pulsed imaging. Pharmaceutical Research 34, 1037-1052. doi:10.1007/s11095-016-2083-1

Markl, D., Wang, P., Ridgway, C., Karttunen, A.-P., Bawuah, P., Ketolainen, J., Gane, P., Peiponen, K.-E., Zeitler, J.A., 2018b. Resolving the rapid water absorption of mesoporous functionalised calcium carbonate powder compacts by terahertz pulsed imaging. Chemical Engineering Research and Design.

Marshall, K., Sixsmith, D., 1974. Some physical characteristics of microcrystalline cellulose 1. Powders for pharmaceutical use. Drug Development Communications 1, 51-71. doi:10.3109/03639047409088168

Marucci, M., Arnehed, J., Jarke, A., Matic, H., Nicholas, M., Boissier, C., Corswant, von, C., 2013. Effect of the manufacturing conditions on the structure and permeability of polymer films intended for coating undergoing phase separation. European Journal of Pharmaceutics and Biopharmaceutics 83, 301-306. doi:10.1016/j.ejpb.2012.09.020

Mastalerz, M., He, L., Melnichenko, Y.B., Rupp, J.A., 2012. Porosity of Coal and Shale: Insights from Gas Adsorption and SANS/USANS Techniques. Energy \& Fuels 26, 5109-5120. doi:10.1021/ef300735t

Matthews, G.P., Moss, A.K., Spearing, M.C., Voland, F., 1993. Network calculation of mercury intrusion and absolute permeability in sandstone and other porous media. Powder Technology 76, 95-107. doi:10.1016/0032-5910(93)80045-C

Mattsson, S., 2001. The use of mercury porosimetry in assessing the effect of different binders on the pore structure and bonding properties of tablets. European Journal of Pharmaceutics and Biopharmaceutics 52, 237-247. doi:10.1016/s0939-6411(01)00163-1

Mazel, V., Busignies, V., Diarra, H., Tchoreloff, P., 2012. Measurements of Elastic Moduli of Pharmaceutical Compacts: A New Methodology Using Double Compaction on a Compaction Simulator. Journal of Pharmaceutical Sciences 101, 2220-2228. doi:10.1002/jps.23122

Melia, C.D., Rajabi-Siahboomi, A.R., Bowtell, R.W., 1998. Magnetic resonance imaging of controlled release pharmaceutical dosage forms. Pharmaceutical Science \& Technology Today 1, 32-39. doi:10.1016/S1461-5347(98)00008-X

Micromeritics Instrument Corp., 2017. AccuPyc II 1340.

Mitchell, J., Webber, J.B.W., Strange, J.H., 2008. Nuclear magnetic resonance cryoporometry. Physics Reports 461, 1-36. doi:10.1016/j.physrep.2008.02.001

Moghadam, S.H., Dinarvand, R., Cartilier, L.H., 2006. The focused ion beam technique: A useful tool for pharmaceutical characterization. International Journal of Pharmaceutics 321, 50-55. doi:10.1016/j.ijpharm.2006.05.006

Moreno-Atanasio, R., Williams, R.A., Jia, X., 2010. Combining X-ray microtomography with computer simulation for analysis of granular and porous materials. Particuology 8, 81-99. doi:10.1016/j.partic.2010.01.001

Mou, Y., Wu, Z.-S., Yang, Z.-Q., Gao, Y.-Q., Zhang, G., Yang, Q.-J., 2017. Retrieval Method for Complex Refractivity From Reflection Measurements of Rough Surfaces. IEEE Antennas and Wireless Propagation Letters 16, 1581-1584. doi:10.1109/LAWP.2017.2651885

Mullarney, M.P., Hancock, B.C., 2006. Mechanical property anisotropy of pharmaceutical excipient compacts. International Journal of Pharmaceutics 314, 9-14. doi:10.1016/j.ijpharm.2005.12.052

Nebgen, G., Gross, D., Lehmann, V., Müller, F., 1995. 1H-NMR Microscopy of Tablets *. Journal of Pharmaceutical Sciences 84, 283-291. doi:10.1002/jps.2600840304

Nogami, H., Hasegawa, J., Miyamoto, M., 1967. Studies on Powdered Preparations. XX. Disintegration of the Aspirin Tablets containing Starches as Disintegrating Agent. Chemical and Pharmaceutical Bulletin 15, 279-289. doi:10.1248/cpb.15.279

Nordström, J., Persson, A.-S., Lazorova, L., Frenning, G., Alderborn, G., 2013. The degree of compression of spherical granular solids controls the evolution of microstructure and bond probability during compaction 442, 3-12. doi:10.1016/j.ijpharm.2012.08.011

Norman, J., Madurawe, R.D., Moore, C.M.V., Khan, M.A., Khairuzzaman, A., 2017. A new chapter in pharmaceutical manufacturing: 3D-printed drug products. Advanced Drug Delivery Reviews 108, 
39-50. doi:10.1016/j.addr.2016.03.001

Nott, K.P., 2010. Magnetic resonance imaging of tablet dissolution. European Journal of Pharmaceutics and Biopharmaceutics 74, 78-83. doi:10.1016/j.ejpb.2009.07.003

Ohno, I., Hasegawa, S., Yada, S., Kusai, A., Moribe, K., Yamamoto, K., 2007. Importance of evaluating the consolidation of granules manufactured by high shear mixer. International Journal of Pharmaceutics 338, 79-86. doi:10.1016/j.ijpharm.2007.01.030

Olusanmi, D., Jayawickrama, D., Bu, D., McGeorge, G., Sailes, H., Kelleher, J., Gamble, J.F., Shah, U.V., Tobyn, M., 2014. A control strategy for bioavailability enhancement by size reduction: Effect of micronization conditions on the bulk, surface and blending characteristics of an active pharmaceutical ingredient. Powder Technology 258, 222-233. doi:10.1016/j.powtec.2014.03.032

Pak, T., Butler, I.B., Geiger, S., Van Dijke, M.I.J., Jiang, Z., Surmas, R., 2016. Multiscale pore-network representation of heterogeneouscarbonate rocks. Water Resources Research 52, 5433-5441. doi:10.1029/2008WR006912.M

Palmas, P., Botzanowski, T., Guerain, M., Forzy, A., Bruneton, E., Delrio, G., 2016. Size Determination of Porosity Inclusions in an Organic Solid Material by1H NMR Diffusion and SEM-FIB Experiments: The TATB Case. The Journal of Physical Chemistry B 120, 4152-4159. doi:10.1021/acs.jpcb.6b02176

Palmer, H.K., Rowe, R.C., 1974. The application of mercury porosimetry to porous polymer powders. Powder Technology 9, 181-186. doi:10.1016/0032-5910(74)80030-6

Palomäki, E., Ehlers, H., Antikainen, O., Sandler, N., Yliruusi, J., 2015. Non-destructive assessment of mechanical properties of microcrystalline cellulose compacts. International Journal of Pharmaceutics 495, 633-641. doi:10.1016/j.ijpharm.2015.09.051

Parteli, E.J.R., Pöschel, T., 2016. Particle-based simulation of powder application in additive manufacturing. Powder Technology 288, 96-102. doi:10.1016/j.powtec.2015.10.035

Paul, S., Wang, K., Taylor, L.J., Murphy, B., Krzyzaniak, J., Dawson, N., Mullarney, M.P., Meenan, P., Sun, C.C., 2017a. Dependence of punch sticking on compaction pressure-Roles of particle deformability and tablet tensile strength. Journal of Pharmaceutical Sciences 106, 2060-2067. doi:10.1016/j.xphs.2017.04.059

Paul, S., Taylor, L.J., Murphy, B., Krzyzaniak, J.F., Dawson, N., Mullarney, M.P., Meenan, P., Sun, C.C., 2017b. Powder properties and compaction parameters that influence punch sticking propensity of pharmaceuticals. International Journal of Pharmaceutics 521, 374-383. doi:10.1016/j.ijpharm.2017.02.053

Peiponen, K.-E., Bawuah, P., Chakraborty, M., Juuti, M., Zeitler, J.A., Ketolainen, J., 2015. Estimation of Young's modulus of pharmaceutical tablet obtained by terahertz time-delay measurement. International Journal of Pharmaceutics 489, 100-105. doi:10.1016/j.ijpharm.2015.04.068

Petrov, O., Furó, I., Schuleit, M., Domanig, R., Plunkett, M., Daicic, J., 2006. Pore size distributions of biodegradable polymer microparticles in aqueous environments measured by NMR cryoporometry. International Journal of Pharmaceutics 309, 157-162. doi:10.1016/j.ijpharm.2005.11.027

Pircher, N., Carbajal, L., Schimper, C., Bacher, M., Rennhofer, H., Helga, J.-M.N., Rosenau, T., Liebner, F., 2016. Impact of selected solvent systems on the pore and solid structure of cellulose aerogels. Cellulose 23, 1949-1966. doi:10.1007/s10570-016-0896-z

Pircher, N., Fischhuber, D., Carbajal, L., Strau, C., Nedelec, J.-M., Kasper, C., Rosenau, T., Liebner, F., 2015. Preparation and Reinforcement of Dual-Porous Biocompatible Cellulose Scaffolds for Tissue Engineering. Macromolecular Materials and Engineering 300, 911-924. doi:10.1002/mame.201500048

Poozesh, S., Setiawan, N., Arce, F., Sundararajan, P., Rocca, Della, J., Rumondor, A., Wei, D., Wenslow, R., Xi, H., Zhang, S., Stellabott, J., Su, Y., Moser, J., Marsac, P.J., 2017. Understanding the processproduct-performance interplay of spray dried drug-polymer systems through complete structural and chemical characterization of single spray dried particles. Powder Technology 320, 685-695. doi:10.1016/j.powtec.2017.07.042

Porion, P., Busignies, V., Mazel, V., Leclerc, B., Evesque, P., Tchoreloff, P., 2010. Anisotropic Porous Structure of Pharmaceutical Compacts Evaluated by PGSTE-NMR in Relation to Mechanical Property 
Anisotropy. Pharmaceutical Research 27, 2221-2233. doi:10.1007/s11095-010-0228-1

Preisig, D., Haid, D., Varum, F.J.O., Bravo, R., Alles, R., Huwyler, J., Puchkov, M., 2014. Drug loading into porous calcium carbonate microparticles by solvent evaporation. European Journal of Pharmaceutics and Biopharmaceutics 87, 548-558. doi:10.1016/j.ejpb.2014.02.009

Quantachrome Instruments, 2017. Gas Pycnometers.

Quodbach, J., Moussavi, A., Tammer, R., Frahm, J., Kleinebudde, P., 2014a. Tablet Disintegration Studied by High-Resolution Real-Time Magnetic Resonance Imaging. Journal of Pharmaceutical Sciences 103, 249-255. doi:10.1002/jps.23789

Quodbach, J., Moussavi, A., Tammer, R., Frahm, J., Kleinebudde, P., 2014b. Assessment of disintegrant efficacy with fractal dimensions from real-time MRI. International Journal of Pharmaceutics 475, 605-612. doi:10.1016/j.ijpharm.2014.09.021

Quodbach, J., Kleinebudde, P., 2016. A critical review on tablet disintegration. Pharmaceutical Development and Technology 47, 1-12. doi:10.3109/10837450.2015.1045618

Rahmanian, N., Ghadiri, M., Jia, X., Stepanek, F., 2009. Characterisation of granule structure and strength made in a high shear granulator. Powder Technology 192, 184-194. doi:10.1016/j.powtec.2008.12.016

Reh, A., Plank, B., Kastner, J., Gröller, E., Heinzl, C., 2012. Porosity Maps - Interactive Exploration and Visual Analysis of Porosity in Carbon Fiber Reinforced Polymers. Computer Graphics Forum 31, 1185-1194. doi:10.1111/j.1467-8659.2012.03111.x

Reich, B., 1967. Die Bestimmung der Porengrößen-Verteilung in grobporösen Körpern mit Hilfe der Quecksilber-Porosimetrie. Chemie Ingenieur Technik 39, 1275-1279. doi:10.1002/cite.330392204

Reich, B., Gstirner, F., 1968. Über die Textur von Stärketabletten. Archiv der Pharmazie 301, 830-839. doi:10.1002/ardp.19683011106

Richardson, J., Bowtell, R., Mader, K., Melia, C., 2005. Pharmaceutical applications of magnetic resonance imaging (MRI). Advanced Drug Delivery Reviews 57, 1191-1209. doi:10.1016/j.addr.2005.01.024

Ridgway, C., Bawuah, P., Markl, D., Zeitler, J.A., Ketolainen, J., Peiponen, K.-E., Gane, P., 2017. On the role of API in determining porosity, pore structure and bulk modulus of the skeletal material in pharmaceutical tablets formed with MCC as sole excipient. International Journal of Pharmaceutics 526, 321-331. doi:10.1016/j.ijpharm.2017.04.038

Ridgway, C.J., Gane, P.A.C., 2002. Dynamic absorption into simulated porous structures. Colloids and Surfaces A: Physicochemical and Engineering Aspects 206, 217-239. doi:10.1016/S09277757(02)00078-X

Ridgway, C.J., Gane, P.A.C., Schoelkopf, J., 2006. Achieving Rapid Absorption and Extensive Liquid Uptake Capacity in Porous Structures by Decoupling Capillarity and Permeability: Nanoporous Modified Calcium Carbonate. Transport in Porous Media 63, 239-259. doi:10.1007/s11242-0055391-1

Ridgway, C.J., RIdgway, K., Matthews, G.P., 1997. Modelling of the Void Space of Tablets Compacted Over a Range of Pressures. j pharm pharmacol 49, 377-383. doi:10.1111/j.20427158.1997.tb06810.x

Riippi, M., Yliruusi, J., Niskanen, T., Kiesvaara, J., 1998. Dependence between dissolution rate and porosity of compressed erythromycin acistrate tablets. European Journal of Pharmaceutics and Biopharmaceutics 46, 169-175. doi:10.1016/S0939-6411(98)00003-4

Robert, M.C., Frenette, M., Zhou, C., Yan, Y., Chodosh, J., Jakobiec, F.A., Stagner, A.M., Vavvas, D., Dohlman, C.H., Paschalis, E.I., 2016. A Drug Delivery System for Administration of Anti-TNF-alpha Antibody. Transl Vis Sci Technol 5, 11. doi:10.1167/tvst.5.2.11\#: TVST-15-0252 [pii]

Roberts, R.J., Rowe, R.C., York, P., 1991. The relationship between Young's modulus of elasticity of organic solids and their molecular structure. Powder Technology 65, 139-146. doi:10.1016/00325910(91)80176-j

Rouquerolt, J., Avnir, D., Fairbridge, C.W., Everett, D.H., Haynes, J.H., Pernicone, N., Ramsay, J.D.F., Sing, K.S.W., Unger, K.K., 1994. Recommendations for the characterization of porous solids. Pure \& Appl. 
Chem. 66, 1739-1758. doi:doi:10.1351/pac199466081739

Rowe, C.W., Katstra, W.E., Palazzolo, R.D., Giritlioglu, B., Teung, P., Cima, M.J., 2000. Multimechanism oral dosage forms fabricated by three dimensional printing ${ }^{\mathrm{TM}}$. Journal of Controlled Release 66, 1117. doi:10.1016/S0168-3659(99)00224-2

Scherer, G.W., 1994. Hydraulic Radius and Mesh Size of Gels. Journal of Sol-Gel Science and Technology 291, 285-286.

Schiffter, H., Condliffe, J., Vonhoff, S., 2010. Spray-freeze-drying of nanosuspensions : the manufacture of insulin particles for needle-free ballistic powder delivery. J.R. Soc. Interface 7, 483-500.

Schmitt, M., Halisch, M., Muller, C., Peres Fernandes, C., 2016. Classification and quantification of pore shapes in sandstone reservoir rocks with 3-D X-ray micro-computed tomography. Solid Earth 7, 285-300. doi:10.5194/se-7-285-2016

Schoelkopf, J., Gane, P.A.C., Ridgway, C.J., Matthews, G.P., 2002. Practical observation of deviation from Lucas-Washburn scaling in porous media. Colloids and Surfaces A: Physicochemical and Engineering Aspects 206, 445-454. doi:10.1016/S0927-7757(02)00066-3

Schrank, S., Hodzic, A., Zimmer, A., Glasser, B.J., Khinast, J., Roblegg, E., 2012. Ibuprofen-Loaded Calcium Stearate Pellets: Drying-Induced Variations in Dosage Form Properties. AAPS PharmSciTech 13, 686698. doi:10.1208/s12249-012-9791-6

Selkirk, A.B., 1974. The pore structure of tablets prepared by direct compression of freely flowing lactose powders. Powder Technology 10, 37-42. doi:10.1016/0032-5910(74)85029-1

Selkirk, A.B., Ganderton, D., 1970a. An investigation of the pore structure of tablets of sucrose and lactose by mercury porosimetry. j pharm pharmacol 22, 79S-85S. doi:10.1111/j.20427158.1970.tb08584.x

Selkirk, A.B., Ganderton, D., 1970b. The influence of wet and dry granulation methods on the pore structure of lactose tablets. j pharm pharmacol 22, 86S-94S. doi:10.1111/j.20427158.1970.tb08585.x

Sheikhveisi, H., 2015. A Function-Based Image Binarization based on Histogram. International Research Journal of Applied and Basic Sciences 9, 418-426.

Silfsten, P., Kontturi, V., Ervasti, T., Ketolainen, J., Peiponen, K.-E., 2011. Kramers-Kronig analysis on the real refractive index of porous media in the terahertz spectral range. Optical Letter $36,778-780$. doi:10.1364/OL.36.000778

Sinka, I.C., Burch, S.F., Tweed, J.H., Cunningham, J.C., 2004. Measurement of density variations in tablets using X-ray computed tomography. International Journal of Pharmaceutics 271, 215-224. doi:10.1016/j.ijpharm.2003.11.022

Sixsmith, D., 1977. The effect of compression on some physical properties of microcrystalline cellulose powders. j pharm pharmacol 29, 33-36. doi:10.1111/j.2042-7158.1977.tb11233.x

Sprunk, A., Page, S., Kleinebudde, P., 2013. Influence of process parameters and equipment on dry foam formulation properties using indomethacin as model drug. International Journal of Pharmaceutics 455, 189-196. doi:10.1016/j.ijpharm.2013.07.039

Stanley Wood, N.G., Shubair, M.S., 1979. The influence of binder concentration on the bond formation of pharmaceutical granules. j pharm pharmacol 31, 429-433. doi:10.1111/j.20427158.1979.tb13547.x

Stirnimann, T., Atria, S., Schoelkopf, J., Gane, P.A.C., Alles, R., Huwyler, J., Puchkov, M., 2014. Compaction of functionalized calcium carbonate, a porous and crystalline microparticulate material with a lamellar surface. International Journal of Pharmaceutics 466, 266-275. doi:10.1016/j.ijpharm.2014.03.027

Stirnimann, T., Di Maiuta, N., Gerard, D.E., Alles, R., Huwyler, J., Puchkov, M., 2013. Functionalized Calcium Carbonate as a Novel Pharmaceutical Excipient for the Preparation of Orally Dispersible Tablets. Pharmaceutical Research 30, 1915-1925. doi:10.1007/s11095-013-1034-3

Strange, J.H., Mitchell, J., Webber, J.B.W., 2003. Pore surface exploration by NMR. Magnetic Resonance Imaging 21, 221-226. doi:10.1016/S0730-725X(03)00128-0

Strange, J.H., Rahman, M., Smith, E.G., 1993. Characterization of porous solids by NMR. Physical Review 
Letters, 71, 3589-3591. doi:10.1103/PhysRevLett.71.3589

Strange, J.H., Webber, J.B.W., Schmidt, S.D., 1996. Pore size distribution mapping. Magnetic Resonance Imaging 14, 803-805. doi:10.1016/S0730-725X(96)00167-1

Strickland, W.A., Busse, L.W., Higuchi, T., 1956. The Physics of Tablet Compression XI.:Determination of Porosity of Tablet Granulations. Journal of the American Pharmaceutical Association (Scientific ed.) 45, 482-486. doi:10.1002/jps.3030450716

Sun, C.C., 2005. True Density of Microcrystalline Cellulose. Journal of Pharmaceutical Sciences 94, 21322134. doi:10.1002/jps.20459

Sun, C.C., 2004. A Novel Method for Deriving True Density of Pharmaceutical Solids Including Hydrates and Water-Containing Powders. Journal of Pharmaceutical Sciences 93, 646-653. doi:10.1002/jps.10595

Sun, C.C., 2016. Microstructure of Tablet-Pharmaceutical Significance, Assessment, and Engineering. Pharmaceutical Research 34, 918-928. doi:10.1007/s11095-016-1989-y

Suresh, A., Neethirajan, S., 2015. Real-time 3D visualization and quantitative analysis of internal structure of wheat kernels. Journal of Cereal Science 63, 81-87. doi:10.1016/j.jcs.2015.03.006

Tajarobi, F., Abrahmsén-Alami, S., Carlsson, A.S., Larsson, A., 2009. Simultaneous probing of swelling, erosion and dissolution by NMR-microimaging-Effect of solubility of additives on HPMC matrix tablets. European Journal of Pharmaceutical Sciences 37, 89-97. doi:10.1016/j.ejps.2009.01.008

Takeda, Y., Hamada, K., 2014. Visualization and analysis of pharmaceutical solids by X-ray microscopy 30, 17-22.

Tolnai, D., Degischer, H.P., Lendvai, J., 2009. Characterization of phases in an Al casting alloy by synchrotron tomography. Physica Status Solidi (A) Applications and Materials Science 206, 18501854. doi:10.1002/pssa.200881597

Trementozzi, A.N., Leung, C.-Y., Osei-Yeboah, F., Irdam, E., Lin, Y., MacPhee, J.M., Boulas, P., Karki, S.B., Zawaneh, P.N., 2017. Engineered particles demonstrate improved flow properties at elevated drug loadings for direct compression manufacturing. Int J Pharm 523, 133-141. doi:10.1016/j.ijpharm.2017.03.011

Tritt-Goc, J., Kowalczuk, J., 2002. In situ, real time observation of the disintegration of paracetamol tablets in aqueous solution by magnetic resonance imaging. European Journal of Pharmaceutical Sciences 15, 341-346. doi:10.1016/S0928-0987(02)00016-7

Tuntikulwattana, S., Mitrevej, A., Kerdcharoen, T., Williams, D.B., Sinchaipanid, N., 2010. Development and Optimization of Micro/Nanoporous Osmotic Pump Tablets. AAPS PharmSciTech 11, 924-935. doi:10.1208/s12249-010-9446-4

Tuononen, H., Fukunaga, K., Kuosmanen, M., Ketolainen, J., Peiponen, K.-E., 2010a. Wiener Bounds for Complex Permittivity in Terahertz Spectroscopy: Case Study of Two-Phase Pharmaceutical Tablets. Applied Spectroscopy 64, 127-131. doi:10.1366/000370210792966170

Tuononen, H., Gornov, E., Zeitler, J.A., Aaltonen, J., Peiponen, K.-E., 2010b. Using modified KramersKronig relations to test transmission spectra of porous media in THz-TDS. Optical Letter 35, 631. doi:10.1364/OL.35.000631

Tye, C.K., Sun, C.C., Amidon, G.E., 2005. Evaluation of the effects of tableting speed on the relationships between compaction pressure, tablet tensile strength, and tablet solid fraction. Journal of Pharmaceutical Sciences 94, 465-472. doi:10.1002/jps.20262

Valckenborg, R.M.E., Pel, L., Kopinga, K., 2002. Combined NMR cryoporometry and relaxometry. J. Phys. D: Appl. Phys. 35, 249-256. doi:10.1088/0022-3727/35/3/314

van den Ban, S., Goodwin, D.J., 2017. The Impact of Granule Density on Tabletting and Pharmaceutical Product Performance. Pharmaceutical Research 34, 1002-1011. doi:10.1007/s11095-017-2115-5

Vertommen, J., Rombaut, P., Kinget, R., 1998. Internal and external structure of pellets made in a rotary processor. International Journal of Pharmaceutics 161, 225-236. doi:10.1016/s03785173(97)00357-8

Wadell, H., 1935. Volume, Shape, and Roundness of Quartz Particles. The Journal of Geology 43, 250280. 
1461

1462

1463

1464

1465

1466

1467

1468

1469

1470

1471

1472

1473

1474

1475

1476

1477

1478

1479

1480

1481

1482

1483

1484

1485

1486

1487

1488

1489

1490

1491

1492

1493

1494

1495

1496

1497

1498

1499

1500

1501

1502

1503

1504

1505

1506

1507

1508

1509

1510

1511

Wagner-Hattler, L., Wyss, K., Schoelkopf, J., Huwyler, J., Puchkov, M., 2017. In vitro Characterization and Mouthfeel Study of Functionalized Calcium Carbonate in Orally Disintegrating Tablets. International Journal of Pharmaceutics. doi:10.1016/j.ijpharm.2017.10.009

Waknis, V., Chu, E., Schlam, R., Sidorenko, A., Badawy, S., Yin, S., Narang, A.S., 2013. Molecular Basis of Crystal Morphology-Dependent Adhesion Behavior of Mefenamic Acid During Tableting. Pharmaceutical Research 31, 160-172. doi:10.1007/s11095-013-1149-6

Weissberg, H.L., 1963. Effective Diffusion Coefficient in Porous Media. Journal of Applied Physics 34, 2636-2639. doi:10.1063/1.1729783

Westermarck, S., Juppo, A.M., Kervinen, L., Yliruusi, J., 1999. Microcrystalline cellulose and its microstructure in pharmaceutical processing. European Journal of Pharmaceutics and Biopharmaceutics 48, 199-206. doi:10.1016/s0939-6411(99)00051-x

Westermarck, S., Juppo, A.M., Kervinen, L., Yliruusi, J., 1998a. Pore structure and surface area of mannitol powder, granules and tablets determined with mercury porosimetry and nitrogen adsorption. European Journal of Pharmaceutics and Biopharmaceutics 46, 61-68. doi:10.1016/s0939-6411(97)00169-0

Westermarck, S., Juppo, A.M., Koiranen, K., Yliruusi, J., 1998b. Mercury Porosimetry of Pharmaceutical Powders and Granules. Journal of Porous Materials 5, 77-86. doi:10.1023/A:1009630015598

Wikberg, M., Alderborn, G., 1992. Compression characteristics of granulated materials: VI. Pore size distributions, assessed by mercury penetration, of compacts of two lactose granulations with different fragmentation propensities. International Journal of Pharmaceutics 84, 191-195. doi:10.1016/0378-5173(92)90059-b

Wikberg, M., Alderborn, G., 1990. Compression characteristics of granulated materials II. Evaluation of granule fragmentation during compression by tablet permeability and porosity measurements. International Journal of Pharmaceutics 62, 229-241. doi:10.1016/0378-5173(90)90236-w

Wong, J., D'Sa, D., Foley, M., Chan, J.G.Y., Chan, H.-K., 2014. NanoXCT: A Novel Technique to Probe the Internal Architecture of Pharmaceutical Particles. Pharmaceutical Research 31, 3085-3094. doi:10.1007/s11095-014-1401-8

Wu, Y.S., Frijlink, H.W., van Vliet, L.J., Stokroos, I., van der Voort Maarschalk, K., 2005. LocationDependent Analysis of Porosity and Pore Direction in Tablets. Pharmaceutical Research 22, 13991405. doi:10.1007/s11095-005-5280-x

Wu, Y.S., van Vliet, L.J., Frijlink, H.W., Stokroos, I., van der Voort Maarschalk, K., 2008. Pore Direction in Relation to Anisotropy of Mechanical Strength in a Cubic Starch Compact. AAPS PharmSciTech 9, 528-535. doi:10.1208/s12249-008-9074-4

Wu, Y.S., van Vliet, L.J., Frijlink, H.W., van der Voort Maarschalk, K., 2007. Pore size distribution in tablets measured with a morphological sieve. International Journal of Pharmaceutics 342, 176-183. doi:10.1016/j.ijpharm.2007.05.011

Wu, Y.S., van Vliet, L.J., Frijlink, H.W., van der Voort Maarschalk, K., 2006. The determination of relative path length as a measure for tortuosity in compacts using image analysis. European Journal of Pharmaceutical Sciences 28, 433-440. doi:10.1016/j.ejps.2006.05.006

Yang, B.-H., Wu, A.-X., Miao, X.-X., Liu, J.-Z., 2014. 3D characterization and analysis of pore structure of packed ore particle beds based on computed tomography images. Transactions of Nonferrous Metals Society of China 24, 833-838. doi:10.1016/s1003-6326(14)63131-9

Yassin, S., Goodwin, D.J., Anderson, A., Sibik, J., Wilson, D.I., Gladden, L.F., Zeitler, J.A., 2015a. The Disintegration Process in Microcrystalline Cellulose Based Tablets, Part 1: Influence of Temperature, Porosity and Superdisintegrants. Journal of Pharmaceutical Sciences 104, 3440-3450. doi:10.1002/jps.24544

Yassin, S., Su, K., Lin, H., Gladden, L.F., Zeitler, J.A., 2015b. Diffusion and Swelling Measurements in Pharmaceutical Powder Compacts Using Terahertz Pulsed Imaging. Journal of Pharmaceutical Sciences 104, 1658-1667. doi:10.1002/jps.24376

Young, P.M., Nguyen, K., Jones, A.S., Traini, D., 2008. Microstructural Analysis of Porous Composite Materials: Dynamic Imaging of Drug Dissolution and Diffusion Through Porous Matrices. AAPS J 10, 

560-564. doi:10.1208/s12248-008-9063-2

Zeitler, J., Gladden, L., 2009. In-vitro tomography and non-destructive imaging at depth of pharmaceutical solid dosage forms. European Journal of Pharmaceutics and Biopharmaceutics 71, 2-22. doi:10.1016/j.ejpb.2008.08.012

Zeitler, J.A., Shen, Y., Baker, C., Taday, P.F., Pepper, M., Rades, T., 2007. Analysis of Coating Structures and Interfaces in Solid Oral Dosage Forms by Three Dimensional Terahertz Pulsed Imaging 96, 330340. doi:10.1002/jps.20789

Zeitler, J. A., 2016. Pharmaceutical Terahertz Spectroscopy and Imaging, in: Analytical Techniques in the Pharmaceutical Sciences. Springer New York, pp. 171-222. Doi: 10.1007/978-1-4939-4029-5_5

Zhang, Q., Gladden, L., Avalle, P., Mantle, M., 2011. In vitro quantitative $1 \mathrm{H}$ and $19 \mathrm{~F}$ nuclear magnetic resonance spectroscopy and imaging studies of fluvastatin ${ }^{\text {TM }}$ in Lescol ${ }^{\circledR}$ XL tablets in a USP-IV dissolution cell. Journal of Controlled Release 156, 345-354. doi:10.1016/j.jconrel.2011.08.039

\section{Figure Captions}

Figure 1: Schematic of different pore structures. The porous materials in both columns have the same porosities $\left(f_{1}=f_{2}, f_{3}=f_{4}\right)$, but vary in their structures and thus differ in their tortuosities $\left(L_{e, 1}>L_{e, 2}\right)$. $L$ is the sample thickness and $L_{e}$ is the effective streamline length. The single pore representation illustrates the description of the pore orientation using eigenvectors.

Figure 2: Overview of different techniques used to characterise pore structures of pharmaceutical materials. AFM: atomic force microscopy; SEM: scanning electron microscopy; TEM: transmission electron microscopy; CLSM: confocal laser scanning microscopy; FIB-SEM: focused ion beam SEM; THz-TDS: terahertz time-domain spectroscopy; $\mathrm{X} \mu \mathrm{CT}$ : $\mathrm{X}$-ray computed microtomography; NMR: nuclear magnetic resonance.

Figure 3: Schematic of the 3D printed disks. A model of the printed disk is depicted in (a), which also highlights the volume investigated by $\mathrm{X} \mu \mathrm{CT}$ as shown in (b). The dimensions of the subvolume in (b) are $3.16 \times 3.16 \times 0.89 \mathrm{~mm}^{3}$ (1064 x $1064 \times 301$ voxels).

Figure 4: Pore network visualisations classified by pore equivalent diameter for (a) P1 and (b) P2 as well as (c) pore size distribution for both samples.

Figure 5: Orientation of pores, plotted by the largest eigenvector $\boldsymbol{v}_{\mathbf{1}}$ and classified by size. Shown for (a, b) P1 and (c, d) P2 for two different view angles. The same colour bar applies to all subfigures. Pores larger than 1500 voxels are neglected from the anisotropy analysis, as the simple eigenvalue ratio description becomes meaningless. Small pores are largely randomly oriented while the larger pores are oriented at an angle of approximately $90^{\circ}$ to one another in the $x y$-plane.

Figure 6: Cumulative porosity plots $(a, b)$ and porosity by height for $(a, c) P 1$ and $(b, d) P 2$. The pore alignment of the large pores as well as the layer structure in the printed object are clearly resolved.

Figure 7: Blott and Pye charts classified by pore volume for (a, c) P1 and (b, d) P2. (c) and (d) are an extension of the Blott and Pye chart to analyse the sphericity of the pores. The same colour bar applies to all subfigures.

Figure 8: Experimental set-up for the helium pycnometry measurement.

Figure 9: Overview of mercury porosimetry: (a) schematic of the setup, (b) cumulative pore intrusion volume, $V$, as a function of the pore diameter, $d_{p}$, and (c) pore volume size distributions of one tablet per batch. The samples analysed were pure FCC tablets. More details about the samples can be found in the supporting information.

Figure 10: Schematic of mercury porosimetry, showing the impact of pore wall material compression at the highest intrusion pressures (Gane et al., 1996; Ridgway et al., 2017). 
Figure 11: NMR cryoporometry: (a) schematic of a setup as used by Valckenborg, Pel and Kopinga, 2002, to measure the surface-to-volume ratio by cryoporometry and relaxometry of silica gels. Example data of porous biodegradable polymer microparticles after swelling for 1 day from Petrov et al., 2006 are illustrated in (b) and (c). The data shown here correspond to the sample F in Petrov et al., 2006: (b) normalised intensity of non-frozen water in the porous particles as a function of temperature, and (c) pore size distribution in the microparticle after swelling for 1 day.

Figure 12: Data from NMR diffusometry and relaxometry from Collins et al., 2007: (a) signal attenuation plot for drug-loaded pellets, (b) surface-to-volume (S/V) ratio and tortuosity as a function of immersion time from NMR diffusometry measurements, (c) distribution of the $T_{2}$ (spin-spin) relaxation time, and (c) pore size distribution calculated from the $T_{2}$ relaxation time measurements.

Figure 13: Workflow for $\mathrm{X} \mu \mathrm{CT}$ porosity analysis, with examples of machines and software in brackets. The first section is experimental, and the next three are computational steps.

Figure 14: Measurement setup of $\mathrm{X} \mu \mathrm{CT}$ using a cone-beam configuration.

Figure 15: Schematic of the measurement principle of THz-TDS. The time delay of the terahertz pulse is $T_{\mathrm{S}}$ and $T_{\mathrm{R}}$ for the sample and the reference waveform, respectively.

Figure 16: Effective refractive index, $n_{\text {eff }}$, as a function of the porosity, $f_{\mathrm{THz}}$, from THz-TDS measurements. The different samples are composed of porous FCC (M01), potato starch acetate (SA, M02), MCC with $10 \%$ indomethacin (IM), MCC compacts prepared by varying the IM concentration, tablet thickness and porosity simultaneously (M03). The complex formulation M04 consisted of a BCS class II drug and four excipients. More details about the samples are provided in the supporting information.

Figure 17: Correlation between the porosity calculated from THz-TDS $\left(f_{\mathrm{THz}}\right)$ measurements and from helium pycnometry $\left(f_{\mathrm{He}-\mathrm{Pyc}}\right)$ for FCC tablets (set M01). $f_{\mathrm{THz}}$ was calculated using the anisotropic Bruggeman model and an intrinsic refractive index of 2.97. Helium pycnometry was used to determine the true density $\left(\varrho_{\text {true,FCC }}=2.958 \mathrm{~g} \mathrm{~cm}^{-3}\right)$ of FCC. More details about the samples are provided in the supporting information.

Figure 18: Porosity calculated from mercury porosimetry $\left(f_{\mathrm{MP}}\right)$, helium pycnometry $\left(f_{\mathrm{He}-\mathrm{Pyc}}\right)$, and THz-TDS measurements $\left(f_{\mathrm{THz}}\right)$ of $\mathrm{MCC} /$ indomethacin tablets. More details about the samples are provided in the supporting information. 


\section{Figure 2}

Pore size

$1 \mathrm{~nm} 10 \mathrm{~nm} \quad 100 \mathrm{~nm} \quad 1 \mu \mathrm{m} \quad 10 \mu \mathrm{m} 100 \mu \mathrm{m} \quad 1 \mathrm{~mm}$

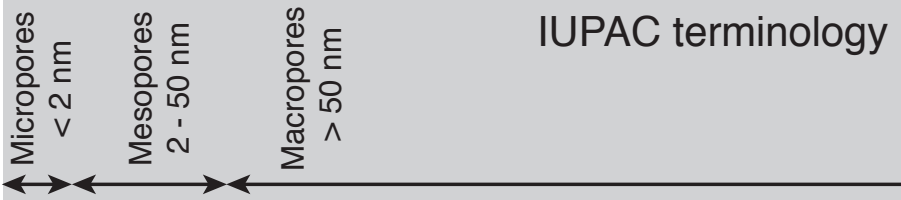

Optical microscopy

SEM

AFM

TEM

CLSM

FIB-SEM

THZ-TDS
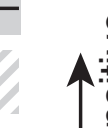

(1)

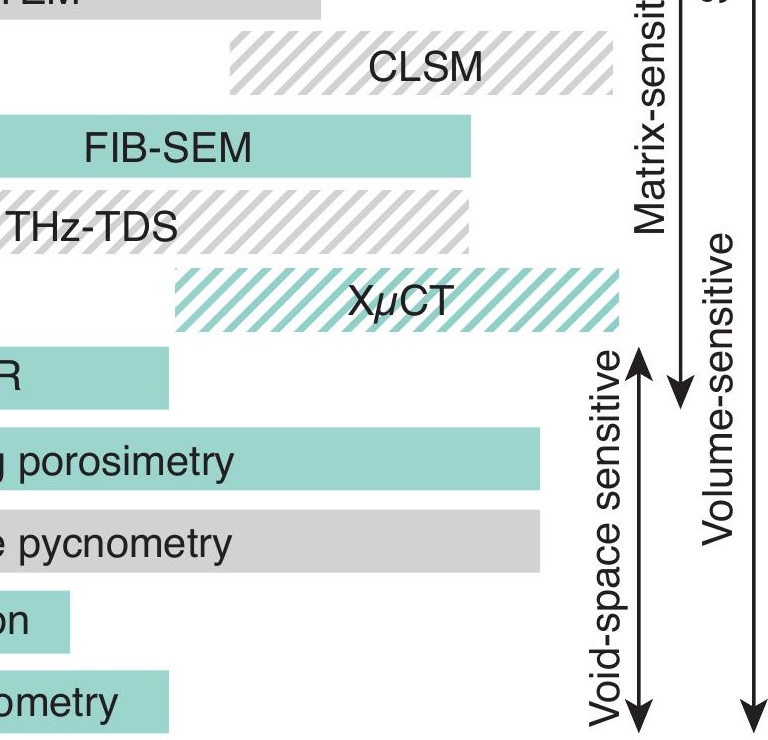

NMR

Hg porosimetry

He pycnometry

$\mathrm{N}_{2}$ adsorption

Thermoporometry

Information about individual pores (e.g. pore size distribution)

Non-destructive technique 
a

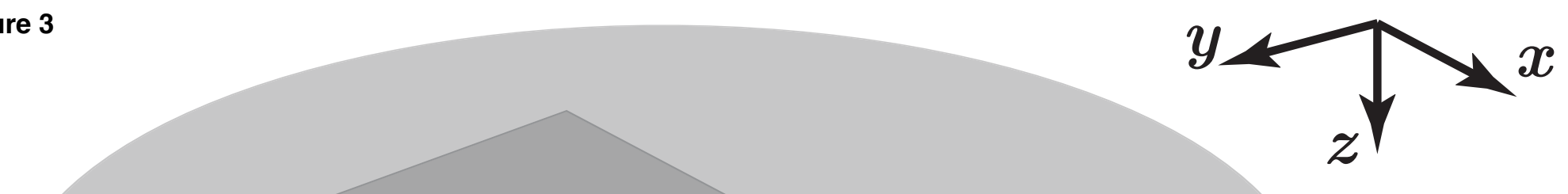

\section{D}

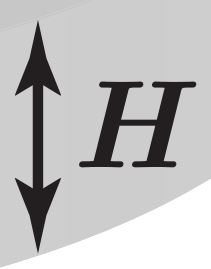

b

Printed strand

Pores

$d$

$\checkmark$

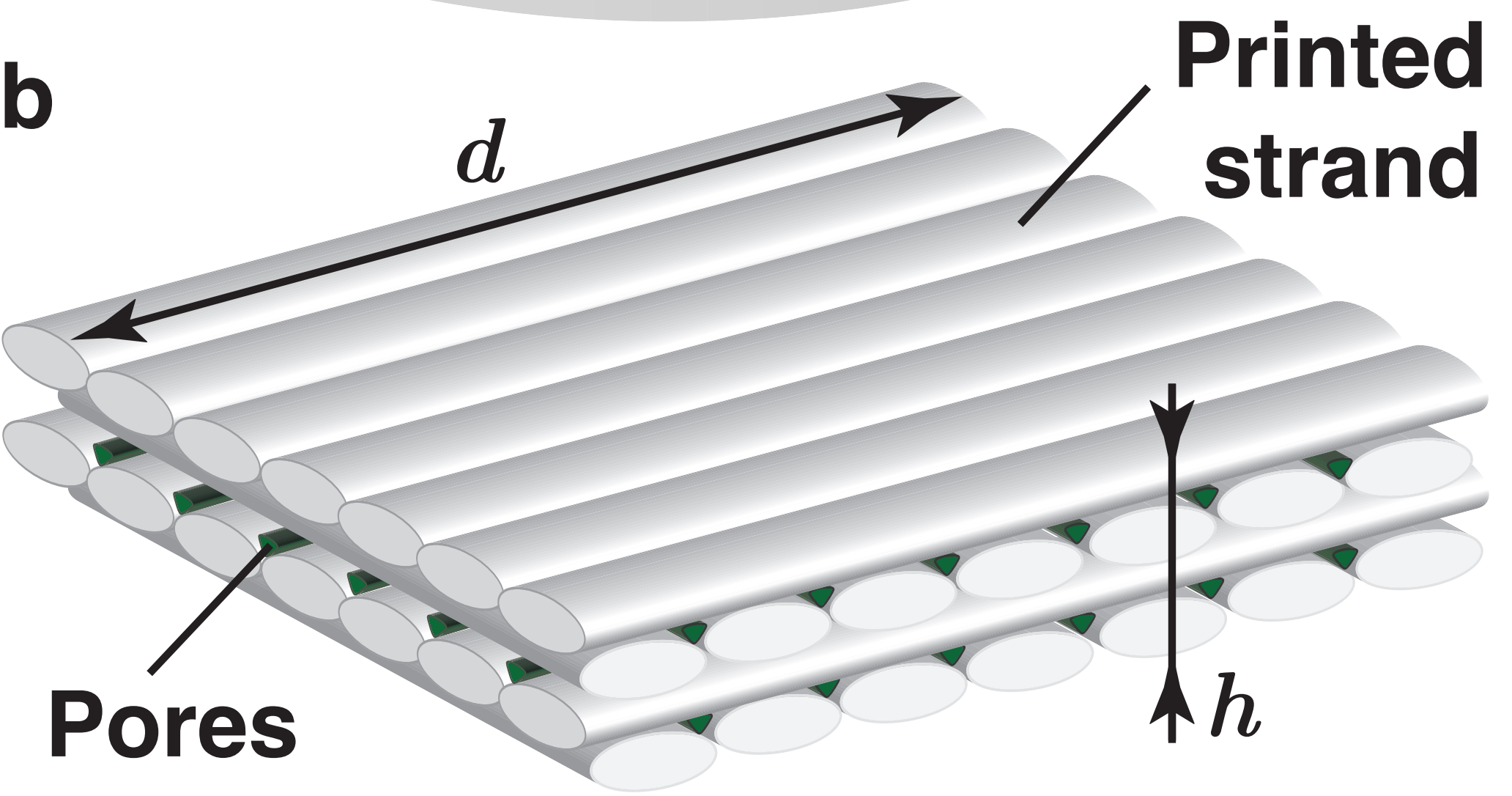




\section{Cell cover}

Sample chamber, $\boldsymbol{V}_{\mathbf{c}}$

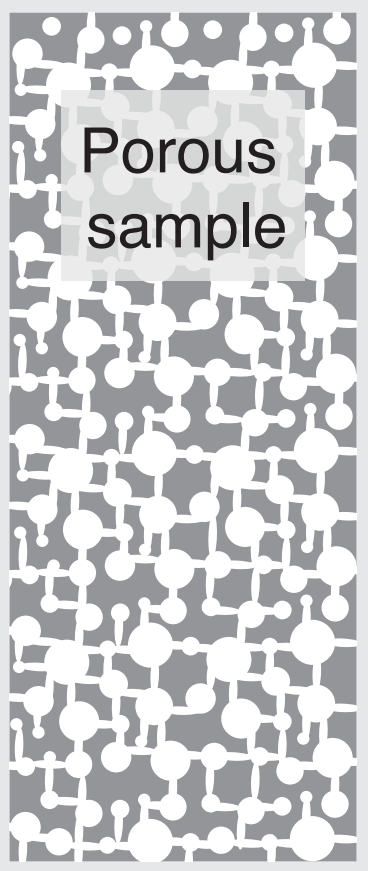

\section{Pressure} transducer

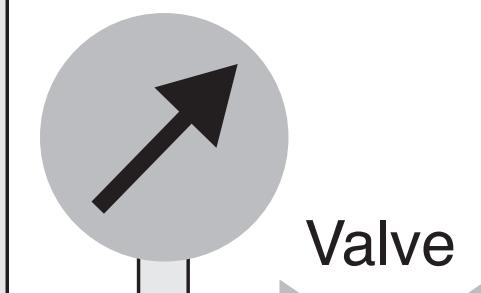

Gas

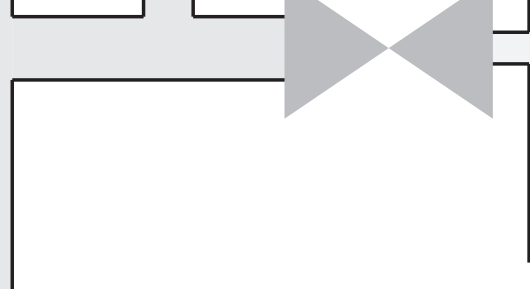

Vacuum

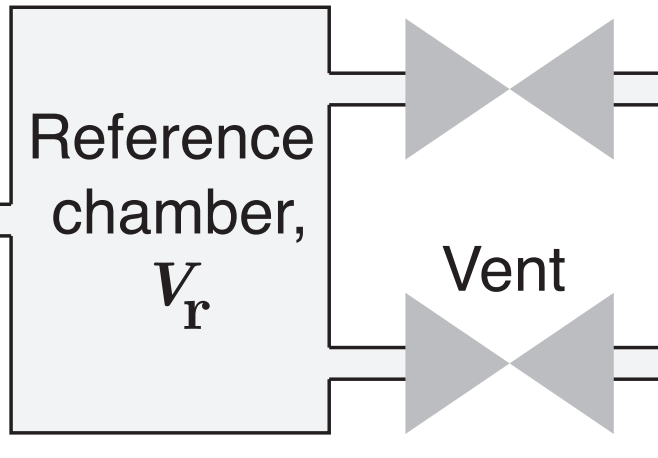


mercury intrusion
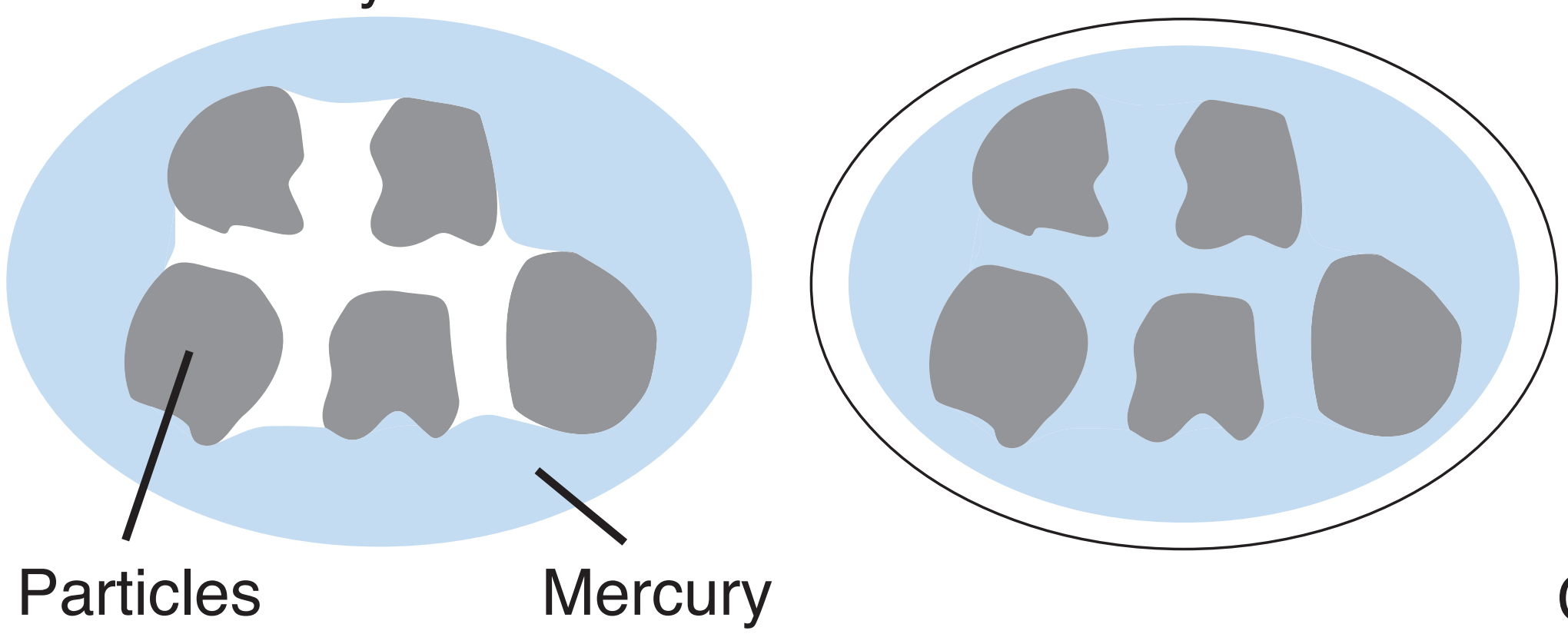
of the skeleton

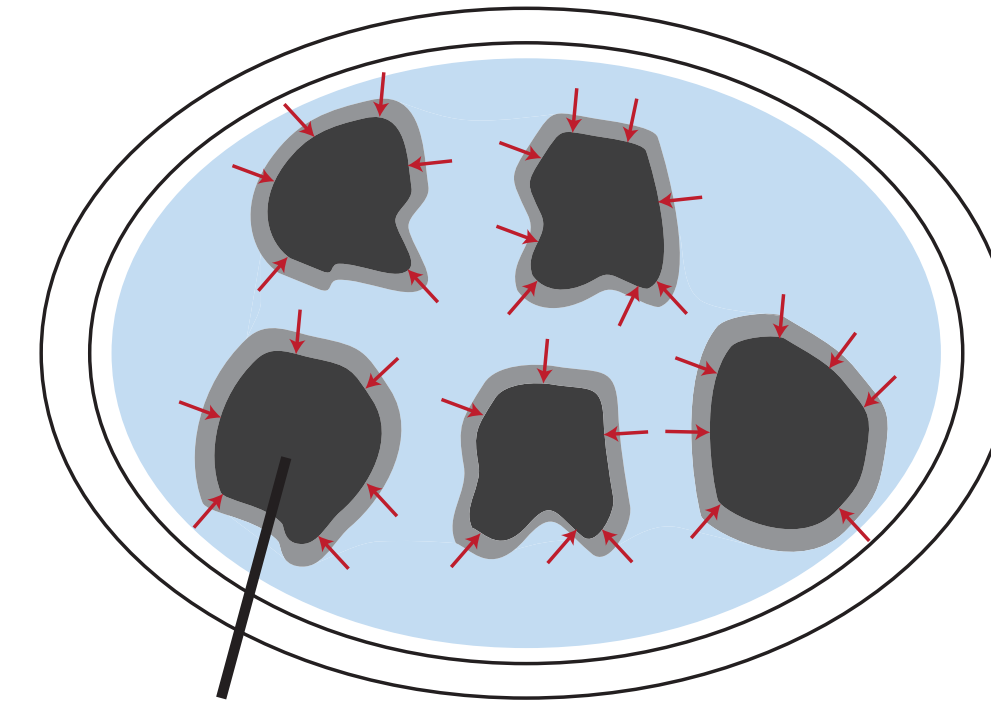

Compressed particles

\section{Pressure}


FigureMlagentic

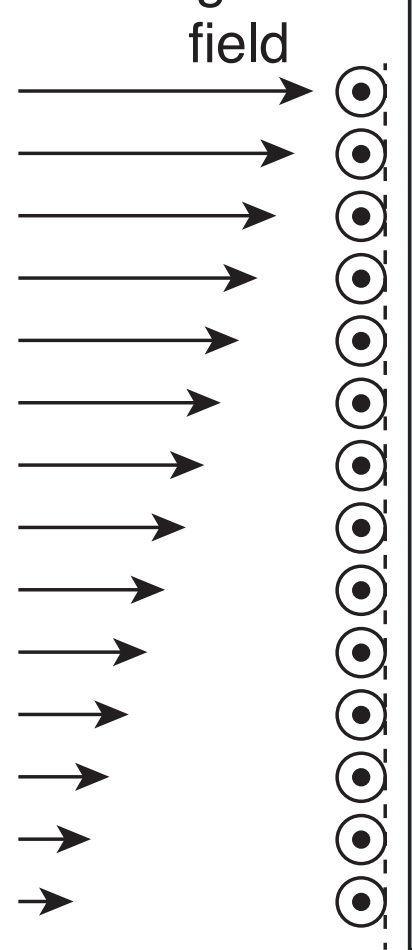

$\mathrm{N}_{2}$ gas

\section{Cryostat}

RF coil

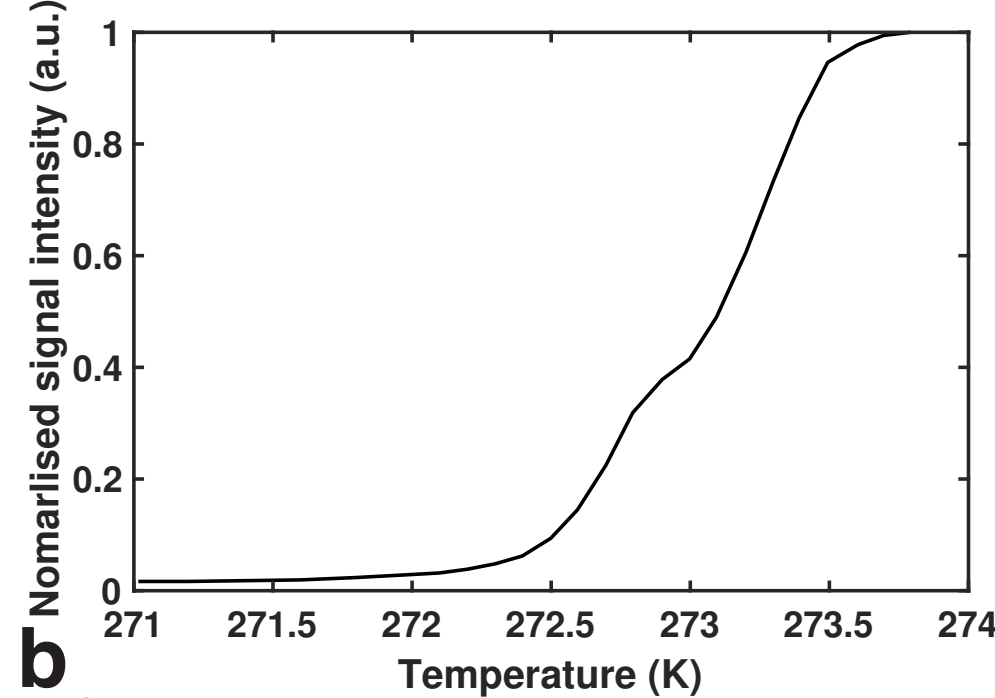

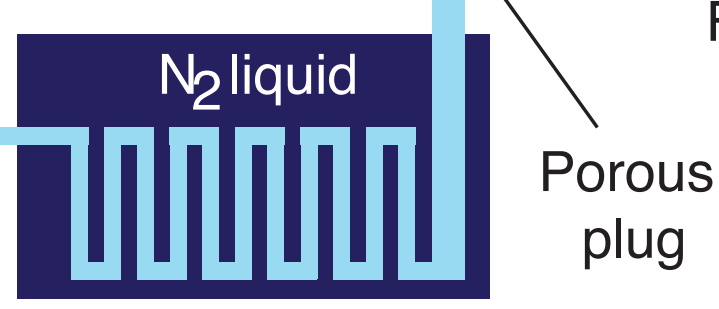

Faraday shield

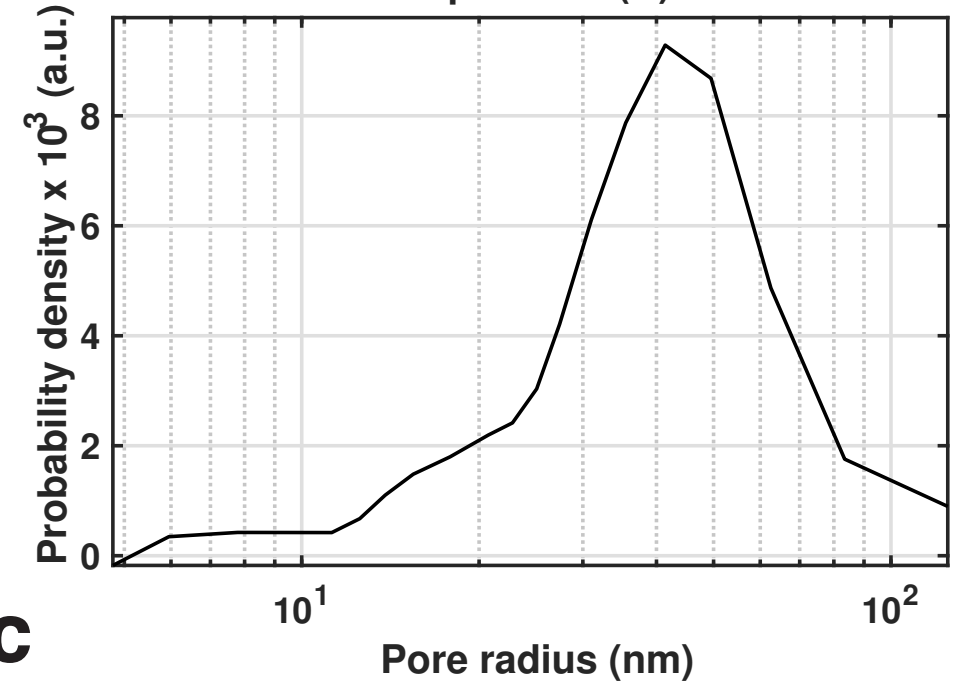




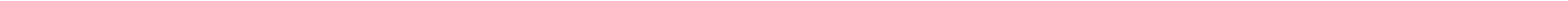




\section{Data acquistion with $\mathrm{X} \mu \mathrm{CT}$ system}

\section{Import and reconstruct} images
Analyse pore data
Filter and segment images 
Porous
X-ray sample

source 

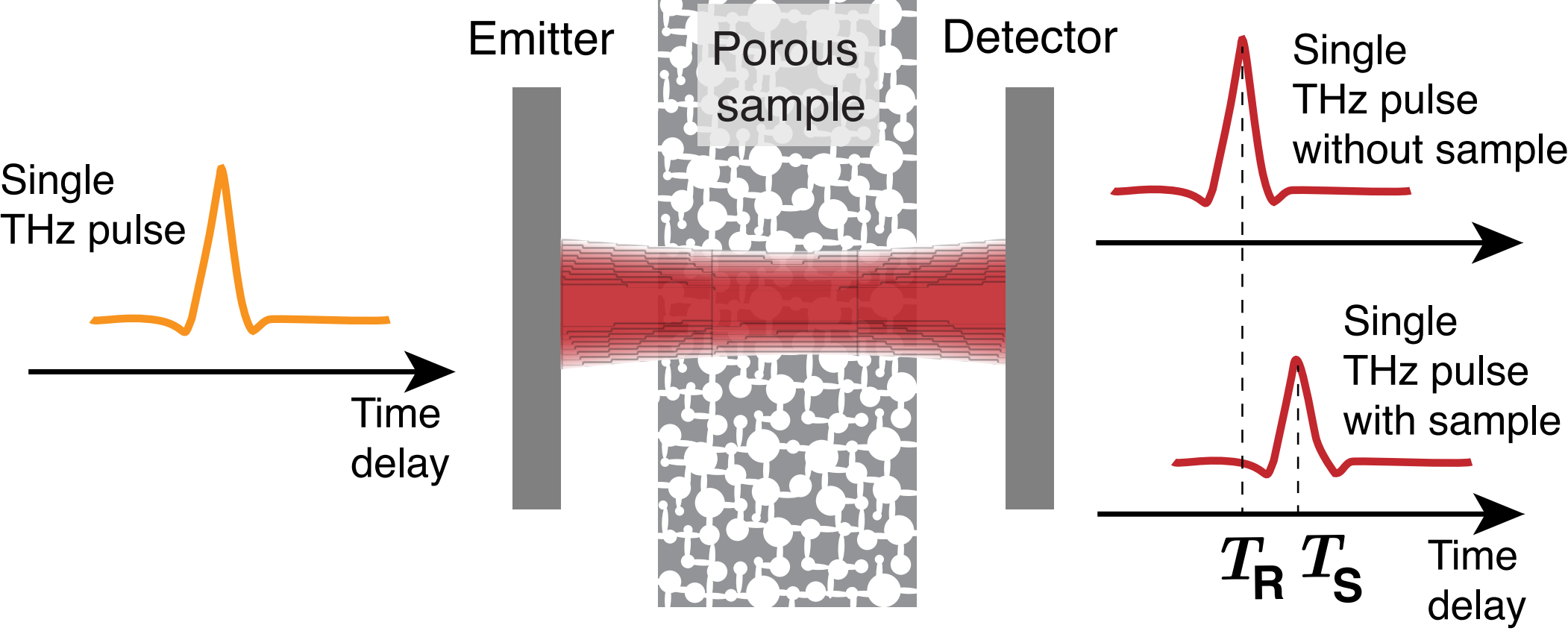
Figurp.16

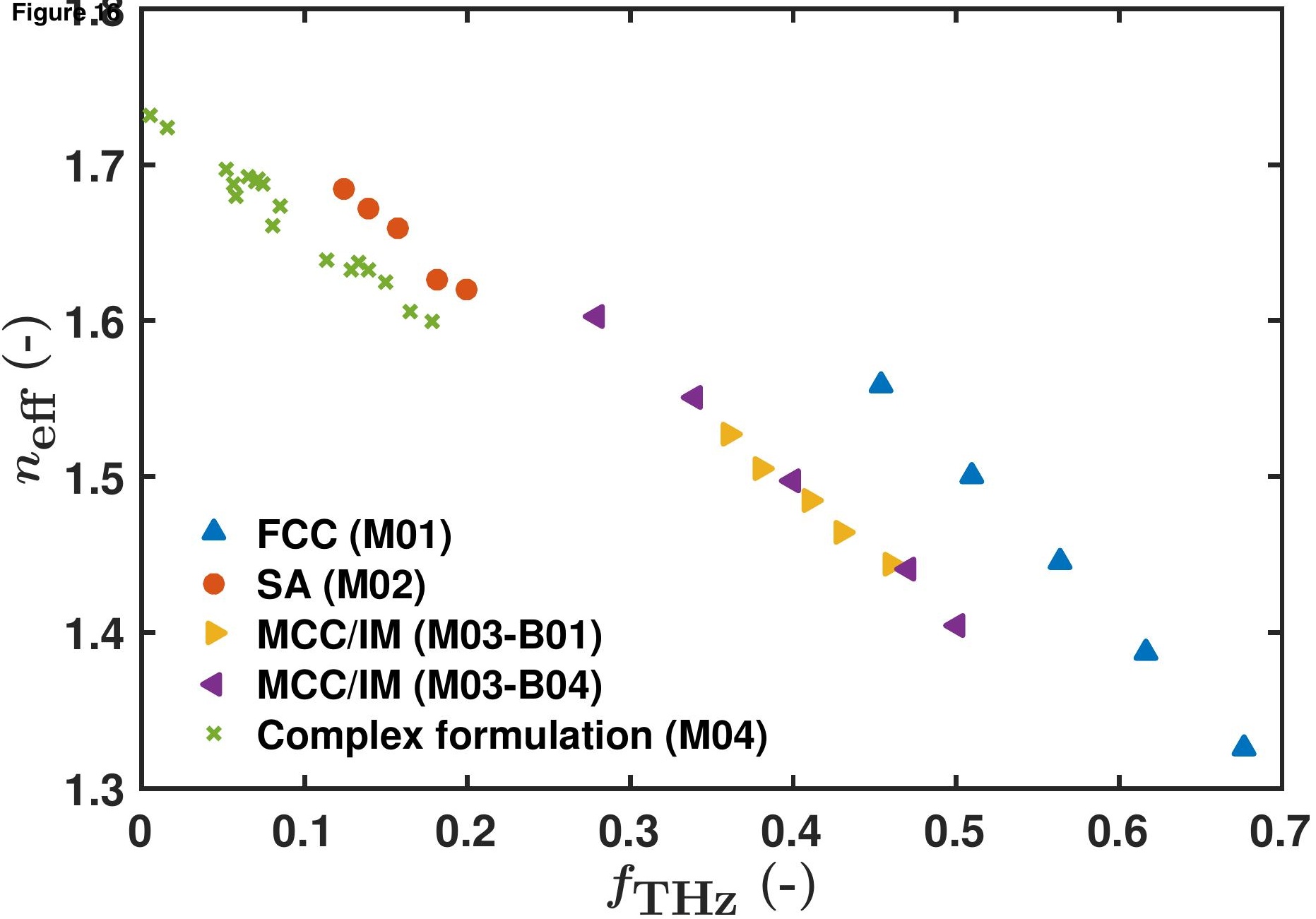


Figure 07.7

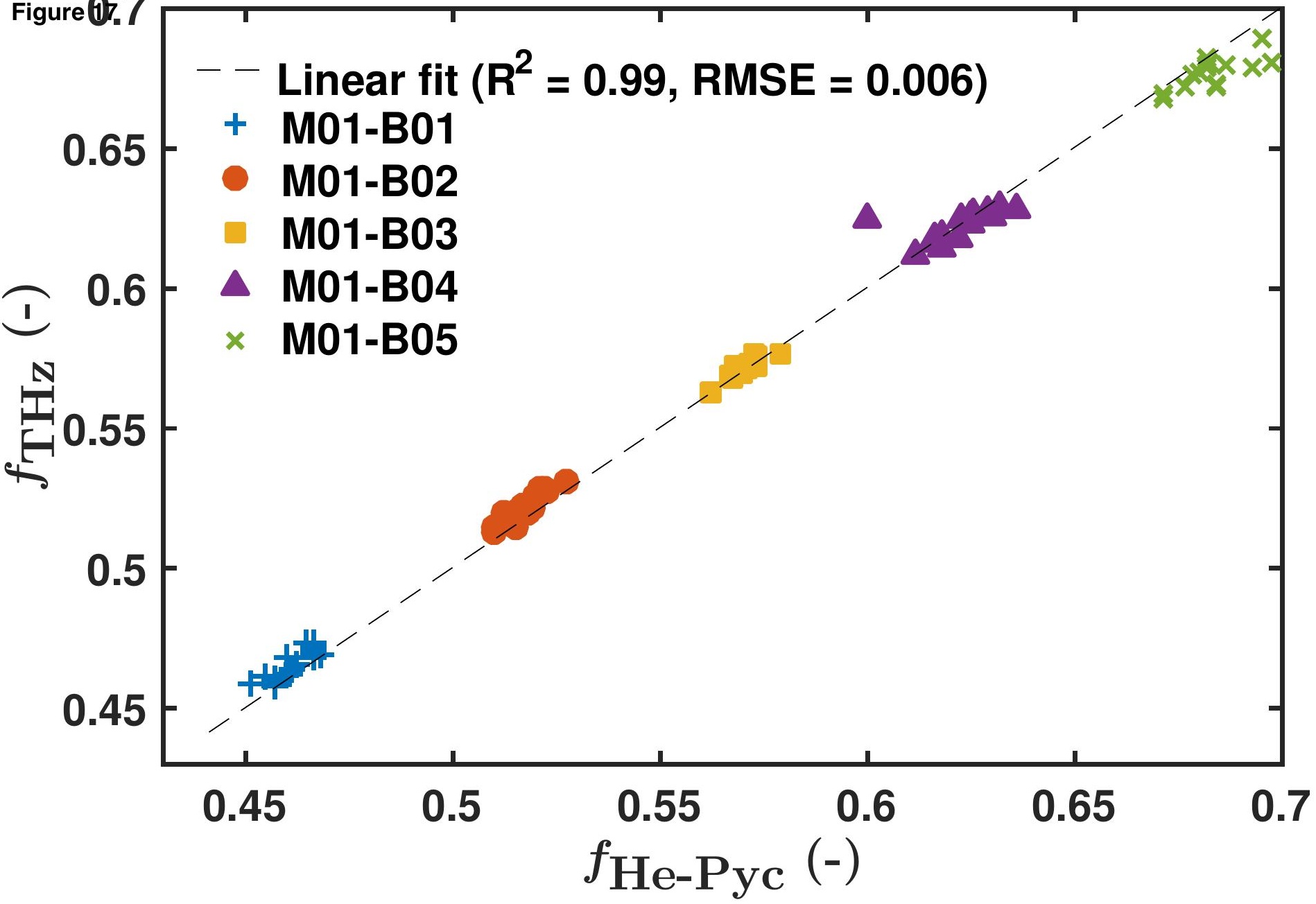




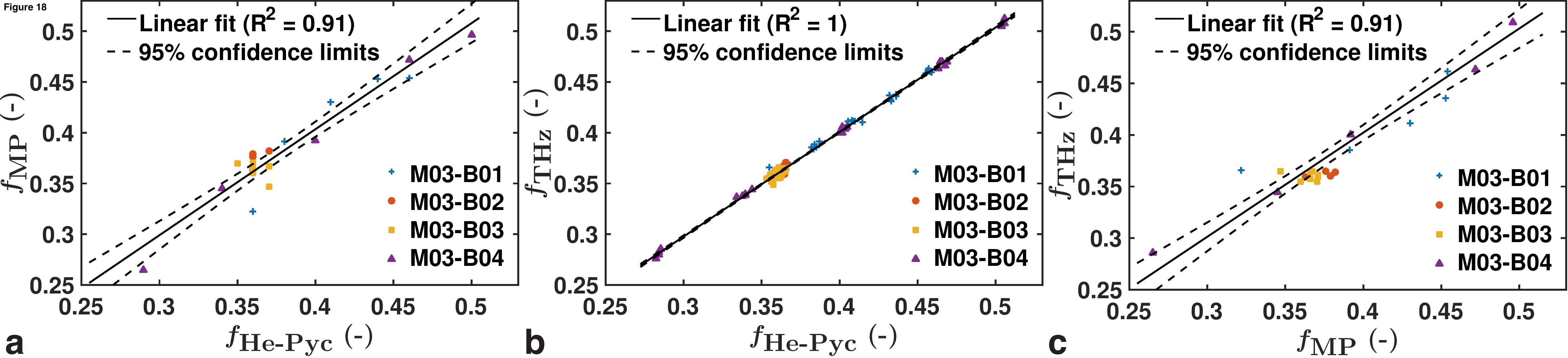

